\title{
BABY BOOMER LIVING: DESIGNING A MODERN CONTINUING CARE RETIREMENT COMMUNITY
}

\author{
A Professional Project \\ presented to \\ the Faculty of California Polytechnic State University, \\ San Luis Obispo
}

\author{
In Partial Fulfillment \\ of the Requirements for the Degree \\ Master of City and Regional Planning \\ by \\ Ryan Wassum
}

May 2013 
(C) 2013

Ryan Wassum

ALL RIGHTS RESERVED 


\title{
COMMITTEE MEMBERSHIP
}

TITLE:

AUTHOR:

DATE SUBMITTED:

COMMITTEE CHAIR:

COMMITTEE MEMBER:

Baby Boomer Living: Designing a Modern Continuing Care Retirement Community

\author{
Ryan Michael Wassum
}

May 2013

Umut Toker, Associate Professor, PhD

City \& Regional Planning Department

Paul Wack, Professor Emeritus, PhD

City \& Regional Planning Department

COMMITTEE MEMBER: Kathy Machado, PhD (KCM client) 


\begin{abstract}
Baby Boomer Living: Designing a Modern Continuing Care Retirement Community

Ryan Wassum
\end{abstract}

With the largest U.S. generation in the midst of retirement, the Baby Boomer cohort is vastly changing the senior housing landscape. As the housing market gradually improves and the development of senior housing chases the increasing demand, Baby Boomers are a highly selective cohort with more buying and spending power than their predecessors, are healthier and more active, and are demanding an unconventional modification of alternative senior housing. The "traditional" senior community is outdated and no longer seen as a viable choice for retirement, and new and innovated models have surpassed the old-fashioned establishments.

Among the innovative senior community models, the Continuing Care Retirement Community $(\mathrm{CCRC})$ combines a variety of unique residential options and comprehensive services that meet the needs of new and active retirees and aging seniors. Focusing on the Baby Boomer cohort in conjunction with a modified CCRC model, this project examines the current demographic and housing landscape for Baby Boomers and seniors, as well as assesses trending planning techniques and design elements to formulate an ideal senior living prototype for the 234 acre Sinclair Ranch in Chinese Camp, California.

In culmination of research, academic literature review, survey analysis, and case study review, key trending planning and design elements have emerged to develop a state-ofthe-art CCRC intended to meet market demands and desires of a growing and highly selective senior cohort. Thus, this project concludes with a design Draft Plan for the Sinclair Ranch that captures both the characteristics of an innovative CCRC and the emergent desires stemming from the shifting senior landscape. With key design recommendations and proposed community features, the draft plan is intended to outline and guide the vision of the proposed development for the Sinclair Ranch CCRC.

Keywords: Baby Boomer Living, Baby Boomer Community, Senior Community, Retirement Community, Continuing Care Retirement Community, CCRC, Senior Housing Landscape 


\section{ACKNOWLEDGMENTS}

I'd like to thank my entire committee team and all of those involved in helping me cultivate and finalize my professional project.

Primarily, I would like to thank Kathy Machado for giving me the opportunity of a lifetime to research and develop a senior community focusing on the shifting needs of Baby Boomers. Her confidence and ongoing positivity was a pleasure to work with. In addition, I'm grateful for a solid and supportive committee chair, Umut Toker, for his extended help and advice for the entire duration of this project. I'd also like to thank committee member Paul Wack for his involvement and unique humor along the way.

Lastly, I would like to sincerely thank those who participated in my surveying process as well as my peers and classmates for their encouragement and supportive feedback. 


\section{TABLE OF CONTENTS}

Page

LIST OF TABLES

vii

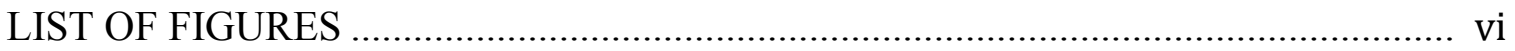

\section{CHAPTER}

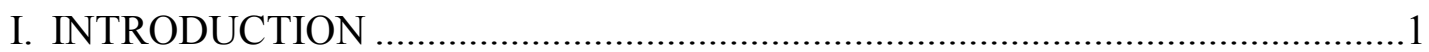

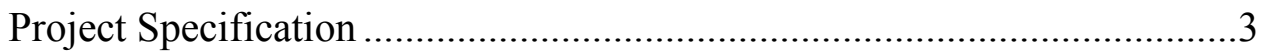

II. LITERATURE REVIEW .............................................................................

2.1. Senior Landscape ..................................................................... 5

2.2. Senior Housing Landscape ........................................................

2.3. Continuing Care Retirement Community .......................................10

2.4. Planning \& Design Trends for CCRCs ........................................12

2.4.1. Building Cohesively With the Built Environment.........................13

2.4.2. Landscape Design and Human Interaction .................................... 14

2.4.3. Placemaking and Wayfinding .........................................................16

2.4.4. Smart Growth and Sustainable Design ....................................... 18

2.4.5. Key Amenities and Services .....................................................20

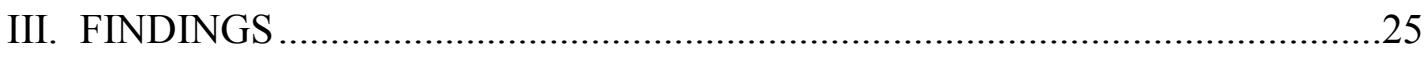

Summary of Key Findings and Design Trends ......................................34

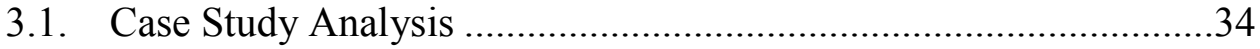

3.1.1. Case Study 1: RiverWoods at Exeter CCRC ..................................34

3.1.2. Case Study 2: Trilogy at Monarch Dunes .....................................40

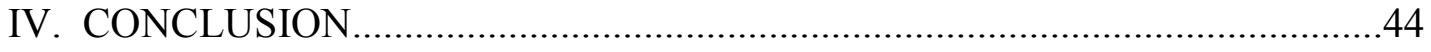

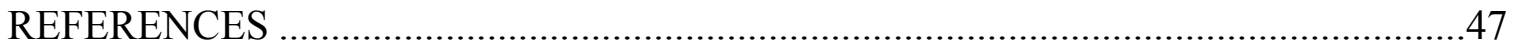

APPENDICES

A. Sinclair Ranch Community Draft Plan .....................................50

B. Survey Instrument ...........................................................69 


\section{LIST OF TABLES}

Table Page

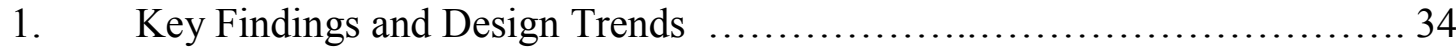




\section{LIST OF FIGURES}

Figure Page

1. Population 65 and Older by Size and Percent: 1900 to 2010 ............. 6

2. Percent 65 Years and Older and 85 Years and Older by County: $2010 \ldots \ldots$

3. Interest in Living in a Senior/ Retirement Community ................. 25

4. Preference for Moving into a Senior/ Retirement Community ........... 26

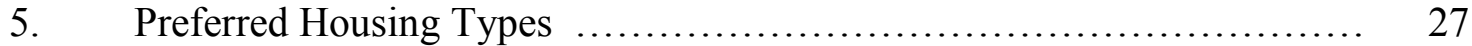

6. Preferred Activities and Services for a Senior/ Retirement Community ... 30

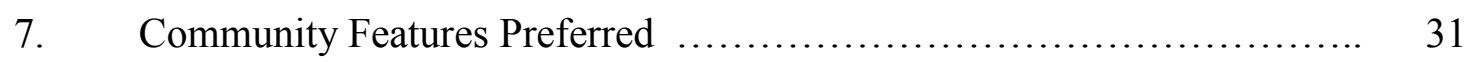

8. $\quad$ Preferred Method for Short Distance Travel ......................... 32

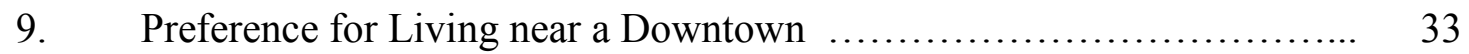

10. Aquatic Center ............................................... 35

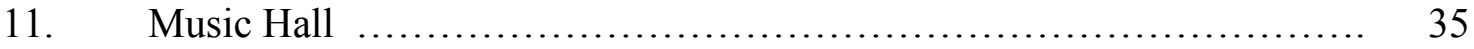

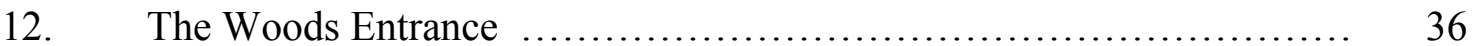

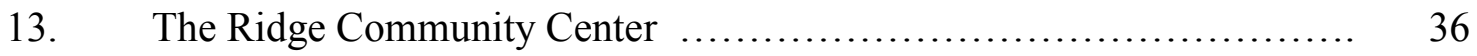

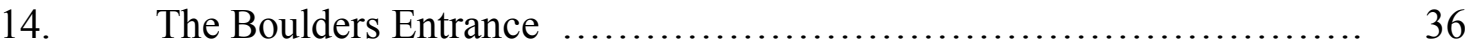

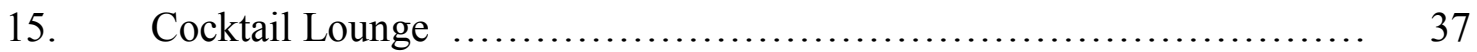

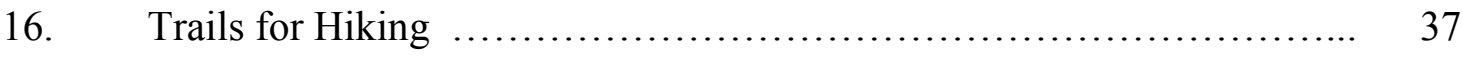

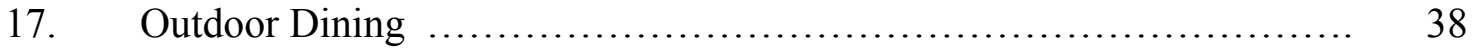

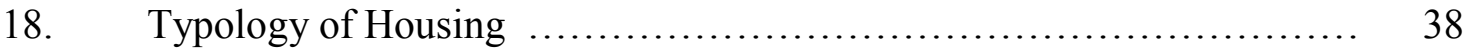

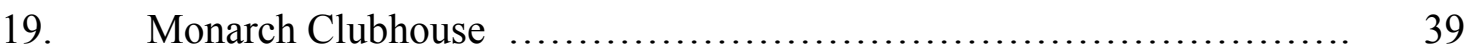

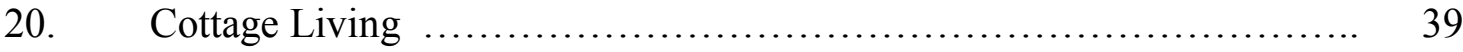

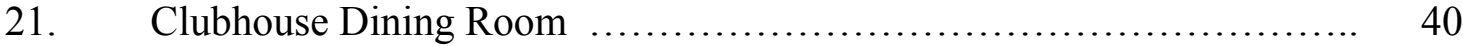

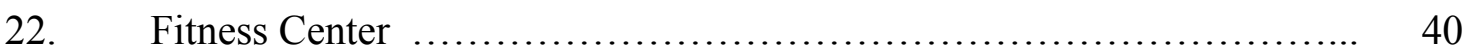

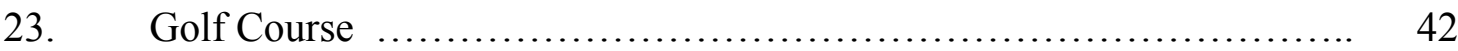

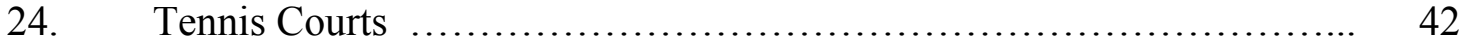




\section{CHAPTER 1.}

\section{Introduction}

As the largest generation in U.S. history, with over 82.8 million people born between 1946 and 1964, Baby Boomers are a key segment of the population that are organically and inorganically shaping the growing shift in housing and social needs (Lynn, Wang, 2008). According to John Mcllwain (2010), author of Housing in America, Boomers have redefined every age they have entered, and the older ones will do so again. They do not yet see themselves as aging; "60 is the new 50 " is their view. While aging in place, especially in suburbia and rural areas, may not be as feasible as it once was for new and progressive Baby Boomer, demographic and economic demands are representing key issues for seniors that the planning field must address. Issues such as accommodation downsizing, transportation, and increasing focalization on health and wellness will affect how and where Baby Boomers prefer to retire.

With Baby Boomers in the midst of retiring at a vast rate with no signs of slowing down, the need for senior housing is becoming increasingly significant and exceedingly competitive to meet market preferences. To meet specific needs and exceeding preferences of today and tomorrow's Baby Boomers and seniors, retirement communities can no longer solely be a place for aging and accommodation, but instead must be 
tailored to enhance activity and quality of life, meanwhile providing tiered levels of comfort, care, and service for the various aging stages of the elderly.

There is evidence suggesting Baby Boomers are seeking "maintenance-free living, easy lifestyles, and more leisure time" according to Lynn and Wang (2008). This is a shift from the former aging in place mentality and policies must be adjusted and prioritized to meet the new demand of educated and highly selective Baby Boomers. According to Kristin Hunt (2012), a senior housing analyst, potential residents today have a higher level of services, less likely to give up anything in their lifestyle except for the big house in exchange for downsizing. Abbott et al. (2009) claims daily life in many areas is being redefined by a need to downsize and create pedestrian-friendly environments that contribute to healthier people (p. 1). They ultimately want to enhance their quality of life, desiring pedestrian oriented and mixed-use communities that are aesthetically designed to promote walkability, social activity, and connectivity.

The older baby boomer cohort is healthier and more energetic than its parents, and the move into retirement and life care communities may be deferred for a decade or more unless these housing forms adapt to the desires of this new group of young seniors (Mcllwain, 2010). In fact, senior centers around the country are evolving to attract Baby Boomers, and a recent AARP article written by Salley Abrahm (2012) describes how facilities are "preparing for the deluge of fitness-focused boomers". Abrahm's (2012) also affirms “today's senior centers, and other community models for the over-50 crowd, are hoping to become a one-stop health shop, social, recreational and life-long learning resource centers that meet the needs of the 'young-old and the 'old-old'." In modernizing and enhancing facilities, as well as modifying programs and activities, active Baby 
Boomers can be enticed to a community rather than deterred, a key tactic in generating a competitive edge in an aggressive market.

\section{Project Specification}

The Sinclair Ranch is an underutilized piece of property directly adjacent to the current regeneration and preservation efforts of Chinese Camp, California, a dilapidated yet historic gold mining village on Route 120 to Yosemite National Park. Under the direction of Kathy Machado, a key stakeholder and part owner of the Sinclair Ranch, the family has envisioned a senior community to be developed on their 234-acre property for over the past 10 years. With slow momentum owed in part to unstable economic conditions and funding and investment obstacles, the hope of a developing a state of the art and multifaceted senior community is moving forward once again.

This professional project will investigate current senior communities and market conditions, and provide planning and design recommendations that will shape a viable, efficient, and vibrant Continuing Care Retirement Community (CCRC) to meet the growing needs of Baby Boomers, the 82.8 million people born between 1946 and 1964 . To explore these needs however, it is important to note that there has been a shift in lifestyle and retirement demands by the Baby Boomer generation, desiring more compact and pedestrian oriented communities. These specific communities allow for accommodation downsizing and reduced maintenance, meanwhile providing independent living and a sense of community complete with daily opportunities for leisure and activity. Thus, with shifting demands altering the retirement community landscape, the project will be driven by the following primary questions: 
- What are trending lifestyle demands for retiring Baby Boomers and seniors?

- What type of planning principles and design techniques in CCRC's can help meet these demands?

These questions in conjunction will help guide the formulation of a draft plan to develop the Sinclair Ranch CCRC.

This project will contain two elements: an assessment and overview of current conditions in the senior landscape and housing market, as well as a set of recommendations for future use (the Sinclair Ranch Draft Plan). The Draft Plan will include a section that will outline items that should be considered for the final plan, but were not further explored or included as part of this professional project due to lack of time or resource constraints. Moreover, it will then be the responsibility of the client to ensure the final product is applicable to all local, state, and federal laws. The Sinclair Ranch CCRC will include a master site plan followed by implementation recommendations. The Draft Plan may contain key goals and objectives, as well as primary and secondary recommendations to achieve a desirable CCRC in the competitive marketplace. It is important to note that providing additional offerings and activities for a senior community is burdened by higher production costs, however it is equally important that the plan meets the needs of retiring Baby Boomers, and thus is realistic and implementable. 


\section{CHAPTER 2.}

\section{Literature Review}

\subsection{Senior Landscape}

The older population is an essential and growing segment of the United States population. In this present year of 2013, it has been projected that the senior population, age 65+, will increase from 16 million in 2008 to over 40 million; thus, making the senior population the only major cohort to gain share in the overall U.S. population (Lynn, Wang, 2008). Between 2000 and 2010, the population 65 years and over increased at a faster rate (15.1 percent) than the total U.S population at 9.7 percent (US Census, 2010). The region with the most rapid growth in the population 65 years and over was the Western United States at 23.5 percent, increasing from 6.9 million in 2000 to 8.5 million in 2010. Likewise the region with the fastest growth in the population 85 years and over was also the West at 42.8 percent, increasing from 806,000 in 2000 to 1.2 million in 2010 (US Census, 2010). In the state of California alone, those aged 65 years and over accounted for 4.2 million in 2010. By the year 2030, the U.S. Census Bureau projects that the senior population (age 65+) will account for approximately 20 percent of the U.S. population (Lynn, Wang, 2008). 


\section{Population 65 Years and Older by Size and Percent of Total Population:}

\section{0 to 2010}

(For more information on confidentiality protection, nonsampling error, and definitions, see www.census.gov /prod/cen2010/doc/sfl.pdf)

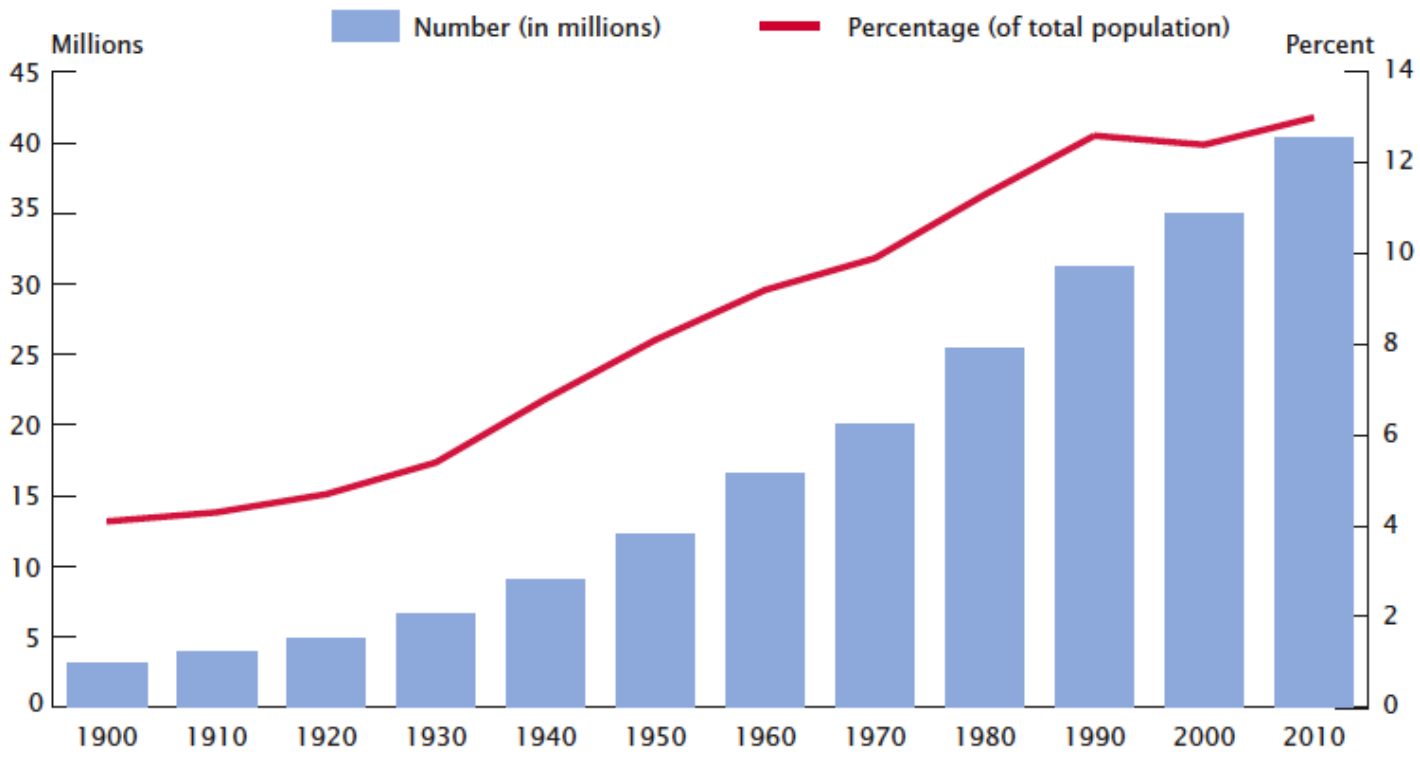

Sources: U.S. Census Bureau, decennial census of population, 1900 to 2000; 2010 Census Summary File 1.

Figure 1.

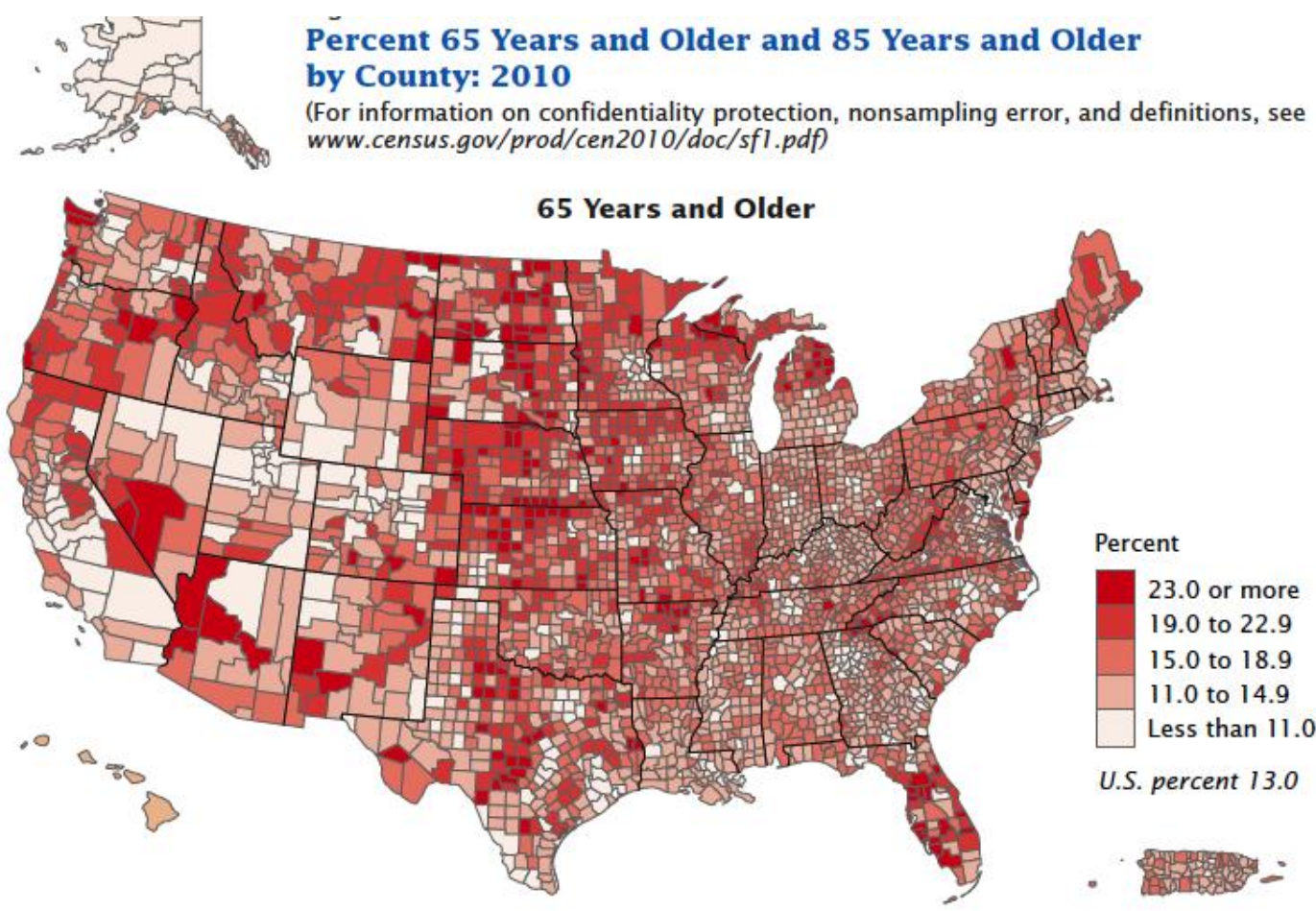

Figure 2. 
Approximately 1.3 million people 65 years and over were in skilled-nursing facilities in 2010 (US Census, 2010). Amongst these large and vastly growing numbers, Lynn and Wang (2008) define three distinct groups that comprise the senior population as follows:

1. GI Generation: This generation is comprised of those aged $84+$ and are World War II era seniors. They are characterized as fiscally conscious and conservative, and require a considerable range of medical support and personalized care.

2. Silent Generation: The Silent Generation, ages 67-87, were born between 1925 and 1945. This cohort of over 50 million Americans experienced the Great Depression in the 1930s and were also raised before the vast growth of the 1950s. The majority of this group is now retired.

3. Baby Boomers: Ages 48-66, Baby Boomers were born between 1946 and 1964. They are the largest generation in U.S. history and represented over 30 percent of the population in 2007. In 2011, the first wave of Baby Boomers turned 65, significantly modifying the senior population both quantitatively and qualitatively. With an estimated annual spending power of $\$ 2$ trillion, Baby Boomers are seeking maintenance-free living, easier lifestyles with more leisure time, as well as prefer multiple options and customization of their lifestyle. As this subgroup of the senior population is in the midst of retirement, their options and preferences play a momentous role in reshaping and improving the development and offerings of conventional senior housing and retirement communities. 


\subsection{Senior Housing Landscape}

Senior housing supply, as well as retirement community options, will continue to play a critical role in the planning field as outdated regulations are revised and new and essential pedestrian and senior-oriented planning policies shape future development. According Hunt (2012), new senior housing developments are not keeping up with Baby Boomer demand since the economic downturn and resulting financing constraints; thus, "virtually no new supply is coming on the market, and that will continue in the near term," according to managing partner at Capital Seniors Housing in D.C., Scott Stewart (Hunt, 2012).

With underscoring forecasts and a vastly growing senior population, it is important that housing supply complies with the demand for appropriate and specialized senior housing. In fact, in 2010, the senior housing market transitioned from a niche market into a major specialized market (Lynn, Wang, 2008). With a major market presence and escalating competition among retirement and senior community options, it is imperative that a community is holistically planned as well as specifically tailored to meet the market needs of Baby Boomers as they retire and advance within the aging process. Similar to the distinct groups that characterize the senior population, senior housing options are also broken down by level of services, amenities, and accommodation settings. Lynn and Wang (2008) describe the five segment types as follows:

1. Active Adult Communities and Senior Apartments: These 55-plus adult communities normally consist of condos, co-ops, or single-family homes with little to no services offered. They do however offer an assortment of amenities such as clubhouses and lounges that appeal to active adult homeowners. 
2. Independent Living Facilities (ILFs): Also known as congregate care facilities, ILFs offer a multi-family design to seniors that are less active and may have difficulty with daily housekeeping. They are similar to senior apartments, however offer additional services such as meals, housekeeping, organized activities and transportation.

3. Assisted Living Facilities (ALFs): ALFs combine multi-family properties with personalized support services for seniors. Normally, ALFs cater to those who need daily activity assistance but do not require nursing home care. To retain the characteristics of residential apartments, units and common areas are designed to accommodate a higher level of support.

4. Skilled Nursing Facilities (SNFs): Hospital-like in nature, SNFs typically provide the highest level of care and assistance, further making it the most expensive of all senior housing options. Since many SNFs offer acute and medical care, they are highly regulated and usually require state licenses.

\section{Continuing Care Retirement Communities (CCRC): A CCRC combines} attractive residential living with high levels of service, including comfort, health, wellness, security and additional needs for aging seniors (Lynn, Wang, 2008). Otherwise known as a one-stop shop of comprehensive and tiered care, CCRC's are the smallest segment within the senior housing market due to the heavy cost to build and complex local regulatory approval processes (Lynn, Wang, 2008). Heavily catering to the upper-middle class and affluent, it is estimated that over 745,000 older adults take residence in 1900+ CCRC's (Zarem, 2010), creating a multibillion-dollar industry that is not meeting the pace and demand of today's retiring population (Greene, 2010). 
When reviewing different senior housing models, it is important for any community to utilize its resources for physical activity and wellbeing through pedestrian trails and linkages, and it is equally important to provide connectivity and access to the local community or town in order to maximize quality of life. According to Design for Aging Review (2010), breaking down campus boundaries and providing easy access to neighborhood services, amenities, and public transportation allows older adults to integrate with existing communities, further deinstitutionalizing senior living environments. In conjunction, this allows providers to allocate fewer resources on space and programming since they can rely on nearby or connected senior-friendly nonproviders. It is important to reiterate that Baby Boomers $60+$ are much more active than past generations and it is crucial that planning policies stress rather than deny appropriate infrastructure that capitalizes and enhances physical and mental wellbeing for seniors (Sbranti, 2006).

To establish centrality and boundary within the wide range of senior living options, this project will focus primarily on Continuing Care Residential Communities. The client, Kathy Machado, has stipulated CCRCs align with her goals and objectives in pursuing the planning and development of Sinclair Ranch.

\subsection{Continuing Care Residential Community (CCRC)}

A CCRC is a specific type of senior community offering a variety of services, however it is distinct in that it provides a progression of services from independent living to full-time nursing care, a one-stop shop focusing on wellness activities and amenities (Barnett, 2010). Specifically, the American Association of Homes and Services for the aging (AAHSA) defines a CCRC as, 
A habitat that offers a full range of housing, residential services, and health care to serve its older residents as their needs change over time. This continuum consists of housing where residents live independently and receive certain residential services, such as meals, activities, house keeping, and maintenance; support services for disabled residents who require assistance with activities of dialing living; and health care service for those who become temporarily ill who require long-term care (Abbott et al., 2009, p. 19).

Jane Zarem (2010) of the CCRC Task Force, states an overall objective of any CCRC is to "create an environment and choices that enable older adults to experience fully actualized, creative and satisfying aging" (p. 11). The CCRC is also meant to provide an alternative option to the impersonal and old institutional model of senior or retirement communities, striving to achieve a balance between independent living for healthy seniors and service-oriented care that allows elderly to age in place within a personalized community.

Continuing Care Retirement Communities are not a new phenomenon and have been around for more than 100 years (Spears, 1992). During the 1960s, a big expansion was sparked by demographic and socioeconomic changes of the late twentieth century, and has continually gained momentum with increasing life expectancy for seniors and growth in both number and proportion of elderly in the population. In fact, "an individual who reaches older adulthood can reasonably expect to live two or more decades. Retirement is no longer an individual's last few declining years but rather the beginning of a significant portion of an individual's life" (Barnett, 2010, p. 5). With significant demographic and social changes shaping the assisted living market, CCRC leaders banded together and identified three overriding needs: 1) some form of congregate housing that would combine security with privacy; 2) some communal social supports and activities to replace or supplement the missing family; and 3) assured LTC services to help fill the gap left by Medicare and other U.S. health insurance (Spears, 1992). Even 
though CCRC leaders identified overarching needs, CCRCs are still considered complex entities because they are in part a long-term care insurance company, restaurant, apartment complex, social service agency, health spa, real estate firm, HMO, primary care clinician, home care agency, and nursing home (Spears, 1992).

In the year 2010, there were approximately 1,900 CCRCs in the United States and growing (Zarem, 2010, p. 5). According to the AAHSA, it is estimated that over 745,000 older adults live in a CCRC within the United States (Abbott et al, 2009). Though the majority of CCRCs are highly multifaceted and match the progression of demographic and socioeconomic changes, they continue to be driven by the competitive marketplace and the cultural and lifestyle services they select for their members. Today's CCRCs are adding more social and recreational spaces that are comparable to those being offered at a country club, and are updating their facilities with state of the art technology because that is what the market demands (Hunt, 2012). In fulfilling market demands, CCRCs and other senior housing projects also remain among the most practical land use options. From a community perspective, they create new construction and service jobs, do not add to the crowding of area schools for children, give sizable payments-in-lieu-of-taxes for municipal purposes, and provide attractive campuses that also serve as good neighbors" (Abbott et al., 2009, p. 99).

\subsection{Planning \& Design Trends For CCRCs}

With the Baby Boomer cohort shifting the senior housing landscape, planning and design trends have been adjusting to help meet the intensive demands and needs of this progressive cohort. From traditional design concepts to non-traditional, new elements are synchronizing with former conventional models and are bringing innovative planning 
techniques to meet future needs. It is evident that traditional communities with sterile aesthetics and lack of open and natural space are becoming increasingly unpopular and discarded. In fact, quite the opposite is happening with the resurgence of nature as a focal element for the development of senior communities.

\subsubsection{Building Cohesively With The Natural Environment}

One of the most prominent and fulfilling planning techniques for senior communities has, and will continue to be, the assimilation and cohesion with the natural environment. According to Rachel Kaplan's well-known research in the 1980's, "Nature matters to people. Big trees and small trees, glistening water, chirping birds, budding bushes, colorful flowers - these are the important ingredients in a good life" (Abbott et al., 2009, p. 57). Still valid and increasingly gaining momentum in the planning world, nature is a vital ally in building functional and sustainable communities. It was Frederick Law Olmstead, who discussed over 100 years ago that space, light and pastoral views had recuperative powers for all through healthy recreation in nature that was accessible (Abbott et al., 2009, p. 57). Olmstead expressed the power of healing through engagement and interaction with nature; however, it was Rachel and Stephen Kaplan who built upon Olmstead's theories. The Kaplans claimed that nature can "engage involuntary attention, provide mental restoration, reduce stress, and allow the body to be recharged to a healthy state" through the identification of four components:

1) Being Away: Environments that contribute to a sense of escape from ordinary distraction and that allow one to get away from the details that require deep concentration or mental escape (environments such as nature preserves, gardens or outdoor recreation areas).

2) Extent: Environments that enable one to feel that he or she is in a whole other world. 
3) Fascination: Triggered by the attributes of places that capture the involuntary attention.

4) Compatibility: A match between an environment and one's purposes or inclinations, such that one's directed attention is not needed and is allowed to rest. Allows for restorative benefits to people through activities such as walking or hiking, gardening, and watching wildlife. (Abbott et al., 2009, p. 61)

After a lifetime of hardships and experiences, it is essential for seniors to connect with the calming and positive characteristics that nature provides; otherwise, "the inability to be in contact with nature all contribute to chronic, persistent stress," according to environmental psychologist Roger S. Ulrich (Abbott et al., 2009, p. 61). With nature views providing therapeutic influences and benefits, Ulrich asserts that this knowledge should be taken into account in deciding where to build a hospital or medical facility, as well as which environmental design elements will optimize the experience with nature and create more healthful spaces (Abbott et al., 2009, p. 65). Furthermore, Perkins (2004) claims that lifestyle is determined largely be the design of a community and its components, and that nature is a key amenity in contributing feelings of relaxation (p. 97).

\subsubsection{Landscape Design And Human Interaction}

Like the positive outcomes of immersing and experiencing nature, landscapes, and thus landscaping, play a vital role in shaping outdoor human environments. In the outdoors, it is critical for landscapes to incorporate pedestrian-friendly design, and needs to be designated for the enjoyment of people and not motorized vehicles (Abbott et al., 2009, p. 189). The outdoor environment also provides a pleasant setting for activities such as walking and hiking (Perkins, 2004, p. 98). It is essential senior-friendly outdoor landscapes include the best practices of barrier-free access, sensory design, and 
therapeutic gardens, and are dependent on basic conditions such as types of soil, shade, climate and topography, location and outdoor function (Abbott et al., 2009, p. 190). Given the local climate and topography, it is important to utilize and plant trees that will thrive in the natural environment or are native to the existing terrain. Abbott et al. (2009) states that "trees are the thread woven throughout a neighborhood, making them a tapestry of life and of visual interest" (p. 191), and also purify the air and provide shade where elders can relax safely and reconnect with others and nature.

Landscapes provide experiences with nature that heighten "sights, sounds, smells, textures, movement, and life force," further allowing one to feel comfort and relief as a human (Abbott et al., 2009, p. 190). Out of the many benefits nature provides, it is important to highlight landscaping impacts and how people physically and aesthetically perceive their surroundings. In a retirement community survey, $99 \%$ indicated that "living in pleasantly landscaped grounds" was essential or important (Abbott et al., 2009, p. 69). Perkins (2004) claims that buyers are drawn to communities because they are controlled environments and have a sense of arrival (p. 98). With such high favorability and importance on containing beautified landscaped grounds, this desire will continue to play a vital role in retirees and seniors connecting and choosing a to a future community.

Although it has been surveyed that aesthetically pleasing grounds are important, landscaping must also be functional and provide stimuli for seniors. According to Thrive, a not-for-profit gardening organization based in Reading, England, outdoor landscapes and gardens should be barrier-free, simple, and devoid of curves and intricate patterns (Abbott et. al, 2009, p. 191). Thrive suggests that borders, raised edgings, planters along paths, and paths with changes in material such as gravel or bark help guide and orient people as well as provide stimuli. Thrive also recommends the use of materials 
and natural elements for creating landmarks and orientation, which can be optimized by utilizing selective colors and bold materials for plants and associated furniture (Abbott et al., 2009, p. 191). Likewise, Abbott et al. (2009) explains that people strongly appreciate the scents of flowers and plants, and that people sometimes retire to places "for the smells" evoked by pleasant, interesting, and life-affirming scents (p. 192). The collaboration of smart and selective planting with the use of natural and harmonizing materials for outdoor landscapes can greatly impact how seniors are mentally and physically stimulated by their surroundings.

\subsubsection{Placemaking and Wayfinding}

Another central stimulus for older adult populations relates directly to the creation and development of placemaking and wayfinding. Abbott et al. (2009) describes placemaking as the process of designing the quality of life that makes a person feel welcome, whereas wayfinding provides people with the ability to navigate locations in a secure and comfortable matter. In addressing placemaking, it is important to remember cultural amenities and vernacular architecture stimulate ones senses and provide a feeling

of belonging in a community (Abbott et al., 2009, p. 187). It is also essential that outdoor environments are being experienced from a "human-scale" perspective. Accurate scale and subsequent placement of buildings within a community inform the design of pedestrian rights-of-way, as well as semi-public spaces such as front porches, building foyers, and front yards. To encourage socialization, senior-friendly accommodations should be set relatively close to sidewalks, which further optimizes how pedestrians can safely interact with one another and move safely through the built environment. (Abbott et al., 2009) 
Wayfinding can be accomplished by creating networks of safe, paved pedestrian and bicycle pathways that allow people to socially and physically maintain connections with the world around them. Designing senior-friendly outdoor environments that enhance connections and networks for physical activity cannot be overemphasized. Studies have shown that residents in walkable neighborhoods engaged in more than 70 minutes per week of moderate to high physical activity than those in a less-walkable neighborhood. (Abbott et al., 2009, p. 186). Walking and exercise are extremely important elements for a senior community and these activities can be enhanced through pedestrian circulation design. Harrigan et al. (1998), stresses that when designing critical circulation patterns, one must envision the residents moving around the community, meandering from place to place on a daily basis (p. 209). Residents interact differently with visual and noise sanctuaries, as well as fields of view and subsequent areas that make it possible for residents to see and be seen (p. 209). Allowing for the natural flow of movement, pedestrian circulation should provide easy and direct access to site facilities, as well as support social interaction (Carstens, 1993, p. 38). For example, Carstens (1993) encourages the general layout of pedestrian circulation systems to be developed as a feeder or collector system, with walkways leading from accommodations to cluster walkways and then major access routes. This allows for greater socialization opportunities as residents meander the walkways or pathways.

By making walkways and sidewalks easily accessible and more welcoming, it encourages people to safely utilize sidewalks more often and help curb their dependency on cars. The construction of sidewalks and pathways should be senior-friendly, utilizing nonslip materials for surfaces such as broom-finished concrete or colored asphalt, and should be a minimum of 5-feet wide in residential areas and 10-feet wide in commercial 
areas. Areas between the sidewalk and the street curb should be designated for appropriate signage, landscaping, and other furnishings and amenities. In accommodating street trees, benches for resting, street light posts, and other safety requirements, a minimum width of 6-feet is recommended. To maximize walkabilty and pedestrian-orientation, it is important that senior communities cater to the pedestrian experience and right-of-ways, and secondarily to the passage of automobiles that have traditionally taken precedence. (Abbott et al., 2009)

\subsubsection{Smart Growth and Sustainable Design}

Although not as widely advanced in the traditional senior housing circuit, smart growth design can be utilized to greatly enhance and complement newly planned senior communities. For over the past decade, design professionals, community groups, and developers have been working together to counteract patterns of unsustainable, sprawling, and auto-oriented development across the Unites States (Abbott et al., 2009, p.

175). Abbott et al. (2009) defines the following 10 planning principles as the focalization of smart growth (p. 175):

1. Direct development toward existing communities

2. Preservation of open space and farmland

3. Mixed uses

4. Distinctive and attractive places

5. Compact building design

6. Range of housing choices

7. Variety of transportation choices

8. Walkable neighborhoods

9. Community and stakeholder collaboration in development decisions

10. Predictable and cost-effective development decisions

Even though all principles might not be applicable to senior developments, many of them are significant issues especially for that of the Baby Boomer cohort. It is important to offer a wide range of housing choices, as well as mixing land uses to produce great 
streets, and public and pedestrian-oriented places that allow gathering and social experiences for a community. (Abbott et al., 2009)

Within the umbrella of smart growth principles, distinctive and attractive senior communities need to be designed to respect local and surrounding natural features and architectural traditions. Elements that define a community or help reinforce its identity can make people feel as though they belong and are welcome. Abbott et al. (2009) identifies that distinctive and attractive communities convey a unique and special ambiance that appeal to retirees in their golden years (p. 176). Aesthetic architectural design and landscaping convey a community commitment to place, and thus public awareness and participation in creating and sustaining a place where people care about the community and one another, contributing to a renewed sense of self. This further promotes a sense of control over their environment and of belonging, which are essential and important factors for seniors to feel comfortable and safe. (Abbott et al., 2009)

Sustainable and green design is also another fundamental element when planning a distinctive and attractive senior community. The U.S. General Services Administration identifies sustainability as efforts to "reduce consumption of non-renewable resources, minimize waste, and create healthy, productive environments" (Abbott et al., 2009, p. 184). Like smart growth principles, sustainable or green building principles have multiple positive benefits for a community as well as the surrounding environment. According to the U.S. Department of the Interior's National Park Service, sustainable design practices "reduce negative impacts on the environment and the health and comfort of building occupants, thereby improving building performance" (Abbott et al., 2009, p. 184). This is especially important for Baby Boomers that are both environmentally and health-conscience because much of their future housing and destination choices will be 
new construction. Furthermore, the U.S. Green Building Council asserts that a sustainable approach to design should create buildings and interiors that achieve the following (Abbott et al., 2009, p. 185):

1. Are healthier for people and enhance productivity

2. Can be built at market rate and cost much less to operate

3. Use less fossil fuels, thus conserving energy, generating less global pollution, and saving on operational costs by requiring less maintenance

4. Use less water

5. Manage waste at the highest productive level

6. Reduce impacts on both developed and undeveloped land

7. Minimize the usage of materials and use materials with the lowest environmental impacts

\subsubsection{Key Amenities and Services}

When designing a retirement community for Baby Boomers, it is important to incorporate applicable services and amenities into the planning and design phase. Baby Boomers are more selective than their older cohorts and base their reasons for choosing a retirement community around pleasing services and amenities. In 2006 and 2007, New Life Management and Development, Inc. held focus group sessions with over 400 older adults to find out what services and amenities were important to them in a new retirement community, and an overwhelming majority said "everything"; among the highest were quality health care, an indoor swimming pool, a state-of-the-art fitness center with personal trainers, hiking and walking trails, elegant dining options, a computer room, a library, group travel options, a pub, and housekeeping (Abbott et al., 2009, p. 112). Moreover, the National Directory of Lifestyle Communities compiled a profile of 353 communities that ranked the following amenities as follows (Perkins, 2004, p. 99):

- Clubhouse $88.7 \%$

- Outdoor swimming pool 87.0

- Fitness Center 69.8

- Arts/Crafts Room 62.6 
- Walking Trails $\quad 62.6$

- Tennis Courts 55.3

- $\quad$ Rec. Vehicle Storage 50.0

- Shuffleboard 48.8

- Ballroom with stage 45.3

- Computer center 40.9

- Golf course 39.7

- Bocce court 38.2

- Restaurant 34.6

- Community gardens 29.8

- Indoor swimming pool 22.7

The clubhouse, which signifies the community center of the modern CCRC, is where residents of a community gather primarily to dine, socialize, and exercise among many other activities and services. Being the focal point of the community, these full-service facilities may have 50,000 square feet of space or more to meet the service and activity demand of Baby Boomers. (Abbott et al., 2009, p. 102).

In analyzing progressive and recently completed senior communities, it is important to view trending publications and awards. In the 2011 Design for Aging Review, a biannual competition that showcases facilities that improve quality of life for the aging while exhibiting innovation in their design and execution, a list was compiled to rank common themes in participating senior communities. The prioritized themes are as follows:

- Aging-in-place, including universal design features;

- Responding to the site and local conditions, including climate, culture, and vernacular style;

- Green/sustainable design features;

- Connection to nature, including profuse daylighting;

- Connection to the greater community, including access to existing services/amenities;

- Promoting sense of community between residents, including clusters of residences and shared commons;

- Housing alternatives, e.g. cohousing and Green Houses®;

- Intergenerational developments;

- Home-like/non-institutional environments; 
- Offering daily choice through extensive amenities (e.g. multiple dining venues);

- Sharing amenities and hosting programs for the greater community;

- Technology and physical environments that support staff;

- Providing a hospitality experience;

- Holistic wellness;

- Providing a welcoming, distinctive entrance;

- New image/feel to improve market appeal, including the entry experience;

- A focus on affordability;

- Collaboration/teaming during design development and construction;

- Partnering with senior-friendly non-providers; and

- Flexibility/adaptability for the future.

Designing for the elderly is no simple feat and there are an abundance of general issues that infiltrate the design and planning of a senior community. Diane Carstens (1993), in her book Site Planning and Design for the Elderly, discusses general concepts for design that react to age-related changes that can affect the older person's perception and interpretation of the environment. According to Carstens (1993, p. 15), the following principles should be exploited:

1. Adopt a "prosthetic approach" to design: a prosthetic environment allows the optimal functioning of the individual by offering support when needed, but allows for independence, challenge, and learning. (i.e. topography and length of walking routes, exposure to weather, elements to encourage participation by less able residents, and recreational options)

2. Provide variety and choice: a variety of outdoor areas and activities should be available to residents. (i.e. formal and informal spaces, places for social interaction, privacy, and intimacy, as well as choices in scale of spaces that exude clarity and ambiguity)

3. Promote a sense of autonomy, independence, and usefulness: allows a resident to perform tasks for themselves. (i.e. easy access to facilities, comfort of ease and use, options for control of privacy, and opportunities for participation)

4. Allow personalization and control over the environment: residents must be able to personalize, change, and control the environment to suit their own needs, abilities and personalities. (i.e. moveable site furniture, space for gardens and associated amenities, and patios and/or balconies) 
5. Provide adaptability of design (constant and accommodating models): design must be able to accommodate the changing interests, preferences, and abilities of aging residents within the project.

6. Provide access to community services, facilities, and information: easy access to neighborhood resources, transportation, and information about services and events should be available. (i.e. convenient public transportation, safe and convenient walking routes to community facilities, on-site facilities for large and small events involving the community at large, and scheduled trips to the local community)

In conjunction with Abbott et al., Carstens' principles are a reflection of the design related suggestions that have been compiled throughout this section. Furthermore, her recommendations solidify how to provide personalization and autonomy that Baby Boomers seek in a senior development.

While it is evident that trends and general statistics point at the undoubted growth of Baby Boomers and their housing demands, there are still unknowns and unforeseeable socioeconomic factors that may affect or influence the availability and design of assisted living options. According to Golant and Hyde, (2008), some of the primary "unknowns" include:

- The size and growth of the future older market for assisted living

- Whether older consumers will prefer properties that physically stand alone over those that are part of more extensive long-term care complexes that offer many different types of care and services

- The strength of competing long-term care alternatives - the familiar homes and apartments of older persons, and perhaps even nursing homes

- How assisted living providers will change their business models to cope with tomorrow's uncertain consumer markets

- Whether mom-and-pop board-and-care facilities will survive

Not all types of assisted living residences will thrive in the new and progressive climate, however those that steadily increase their current practice to the critical mass or shift scope of operations to achieve greater economies of scale will increase their chances of success (Golant \& Hyde, 2008). With data and trends increasingly forecasting distinct 
demands brought on by the Baby Boomer cohort, it is critical that preparation and planning are cohesively optimized to create a successful and competitive senior community in the $21^{\text {st }}$ century. 


\section{CHAPTER 3.}

\section{Findings}

Based upon trending data and existing research, this section identifies key findings in designing a modern Continuing Care Retirement Community. In addition to literature review, a preference survey was developed and submitted to a group of Baby Boomer respondents to gather additional data and correlation support (see Appendix B for survey example). The survey findings, in conjunction with trending literature review, will help guide the overall design process of the proposed CCRC. Lastly, this section incorporates a case study analysis to highlight key design features and attributes from applicable and highly merited retirement and senior communities.

To collect data for the proposed Sinclair Ranch CCRC, a survey was developed to gather key feedback and preferences for activities, services, and features sought for a retirement and senior community.

Distributed only to respondents within the Baby Boomer cohort, born between 1946 and 1964, over 30 surveys were completed and analyzed. Based on a

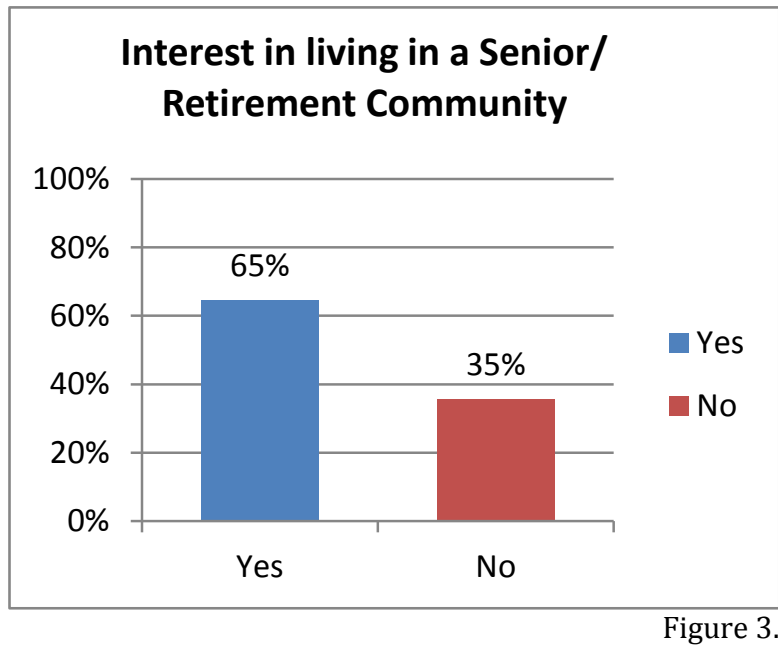
sample population of 31 Baby Boomers, $65 \%$ of respondents claimed retirement and senior communities as attractive options to 
live in as shown in Figure 3. With a favorable majority of those seeing retirement and senior communities as an attractive option to live in, the reasons for choosing a community vary. According to Figure 4, the top reasons for moving into a senior and retirement community are prioritized as follows: maintenance-free living, amenities, elderly care/ service, downsizing, and sense of place/ community. In fact, findings from literature review support the preference of survey respondents. Lynn and Wang (2008), identify that maintenance-free living and downsizing are high priorities for Baby Boomers so it is important to incorporate easy living and efficient housing units into the design of a CCRC.

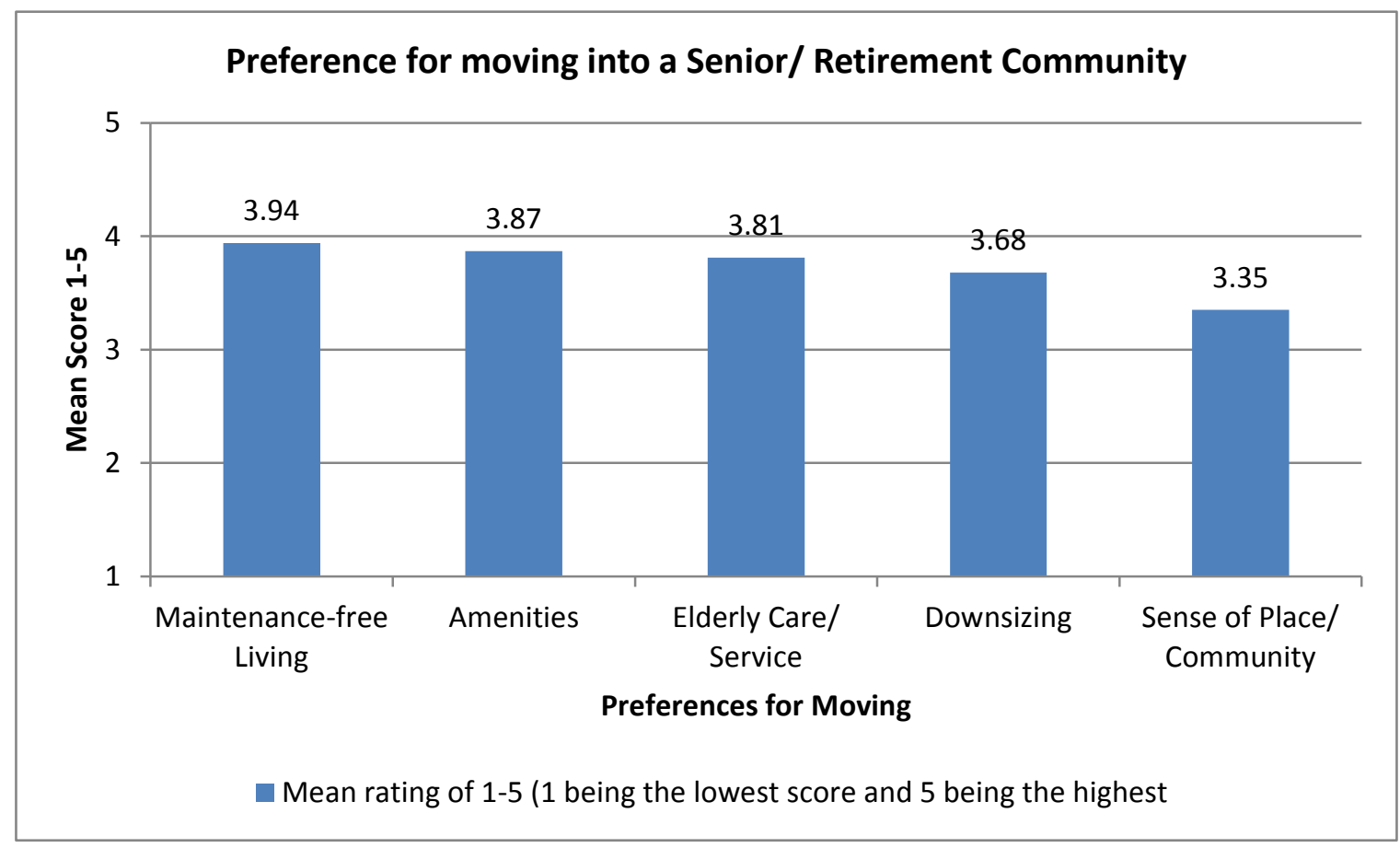

Figure 4.

When planning for a senior or retirement community, it is also important to offer the type of units and downsizing options that Baby Boomers and seniors seek as they consider communities. According to Figure 5, mixed use accommodations were ranked the highest with a $39 \%$ favorability, followed by equal favorability for both single-family 
housing and condominiums at $32 \%$. With a $7 \%$ favorability lead, mixed use housing types provide the combination of services, amenities, and housing that retirees are seeking. Mixed use developments are predominantly pedestrian oriented and can enhance social and physically activity with the personal convenience of services. However, it is noteworthy to mention that the sample population preferred single-family housing equally to condominium options, which seems counterintuitive when a prime factor for moving into such a community is "downsizing," as indicated by senior housing analyst Kristin Hunt (2012). Single-family housing and maintenance-free living do not necessarily support each other either. Condominiums and apartments are better suited for maintenance-free living, so an important take away will be to provide a combination of desired housing types that provide comfort and flexibility.

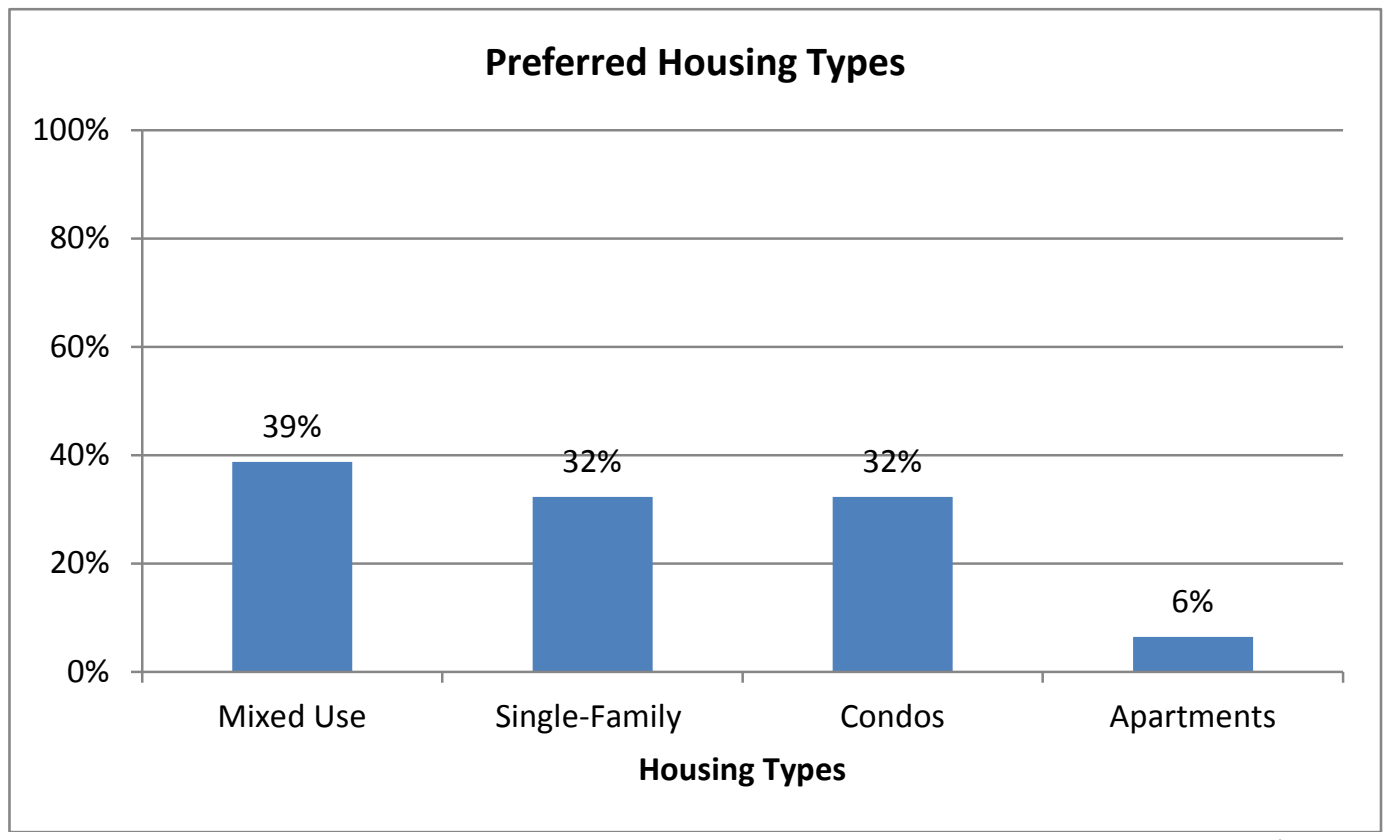

Figure 5.

As conveyed in Figure 4, amenities were valued as the second highest factor for moving into a retirement or senior community. In a recent AARP article, Sally Abrahms (2012) claims “today's senior centers, and other community models for the over-50 
crowd, are hoping to become a one-stop health shop, social, recreational and life-long learning resource centers that meet the needs of the 'young-old and the 'old-old'." With an increasing competitive market, it is vital that a community offers appropriate activities and services for their members. Indicated in Figure 6, the surveyed sample population ranked their top choices for activities and services. Out of a wide selection, walking trails received the highest mean score of 4.87 out of total score of 5 . Abbott et al. stresses outdoor environments that enhance connections and networks for physical activity cannot be overemphasized for social and health related reasons. It is imperative to support walking trails through a comprehensive pedestrian circulation plan when designing a community.

Complimentary to incorporating walking trails, fitness facilities were the second most preferred service among surveyors. Abrahms (2012) describes how facilities are "preparing for the deluge of fitness-focused boomers"; they are healthier than their predecessors and have an increasing focalization on health and wellness. State of the art fitness facilities are something Baby Boomers value extremely high, as well as other outdoor fitness-related activities. As shown in Figure 6, the survey also indicates that Baby Boomers like a variety of activities, including bocce ball, hiking, community gardening, swimming, and bicycling. On the other hand, they survey depicts kayaking, tennis, and horseback riding were the least preferred physical activities among surveyors. In analyzing the outcomes, the most unique activity preference was wine tasting, which ranked $4^{\text {th }}$ among all activities and services. Moreover, since surveyors ranked a variety of activities and services based on personal expectations, it is important to analyze the natural and existing physical landscape of a site, and thus incorporate appropriate activities and services that complement and balance the project site. 
Although it is comprehensible that physically related activities ranked highest amongst surveyors, it is critical to not neglect the need for a variety of daily services. In fact, dining options received the $3^{\text {rd }}$ highest mean score of 4.16 out of 5 , verifying that dining services are highly important when choosing a future retirement or senior community. Abbott et al. (2009) claims that "elegant dining options" are among the highest preferred services to be offered (p. 112). Depending on the size of the community, it is essential to offer a variety of indoor and outdoor dining facilities, including establishments to enjoy an alcoholic beverage or coffee or tea. In requesting surveyors to optionally provide additional services in the survey, the notion of a bar or lounge was highly preferred and mentioned by multiple surveyors. Complimentary to dining services, it would be beneficial to provide a bar or lounge within the main community center to offer residents an additional gathering space to socialize and enjoy. The community center is the epicenter of activity within the community, therefore they serve as an ideal focal point for dining, socializing, and exercising for residents (Abbott et al., 2009, p. 102). 


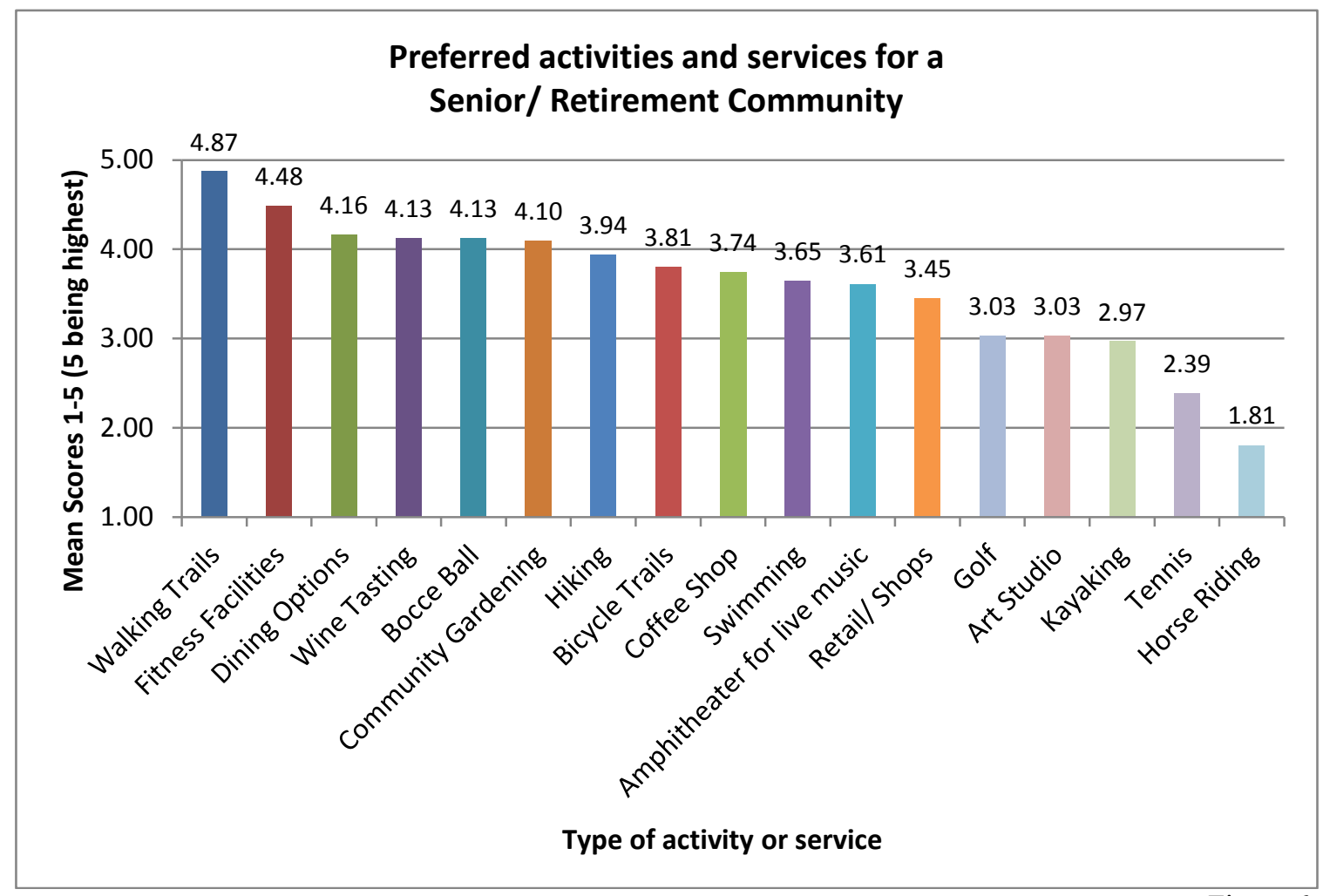

Figure 6.

In addition to activities and services, surveyors were asked to rank their preferred attributes and features a community should offer. As indicated by Figure 7, the top four preferred community features include gardens, a gated entry, landscaping, and parks/ open space. Gardens, landscaping, and parks/ open space are all components of humans interacting with nature, which has been proven to heighten "sights, sounds, smells, textures, movements, and life force"(Abbott et al., 2009, p. 190). The literature review section not only captures how important it is for communities to have aesthetically pleasant landscaped grounds by a 99\% favorability survey, but it is also one of the most significant factors in establishing a connection with visitors, which may ultimately lead to the selection of a community (Abbott et al., 2009). When designing a senior or retirement community, it is essential to incorporate abundant public spaces within the natural (and built) environment; nevertheless, the spaces must be functional and 
connected for humans to interact with and experience. To capitalize on connecting natural spaces and the built environment, smart growth principles, as well as sustainable and green design, should be utilized in the context of respecting local and surrounding natural features and architectural traditions. (Abbott et al., 2009)

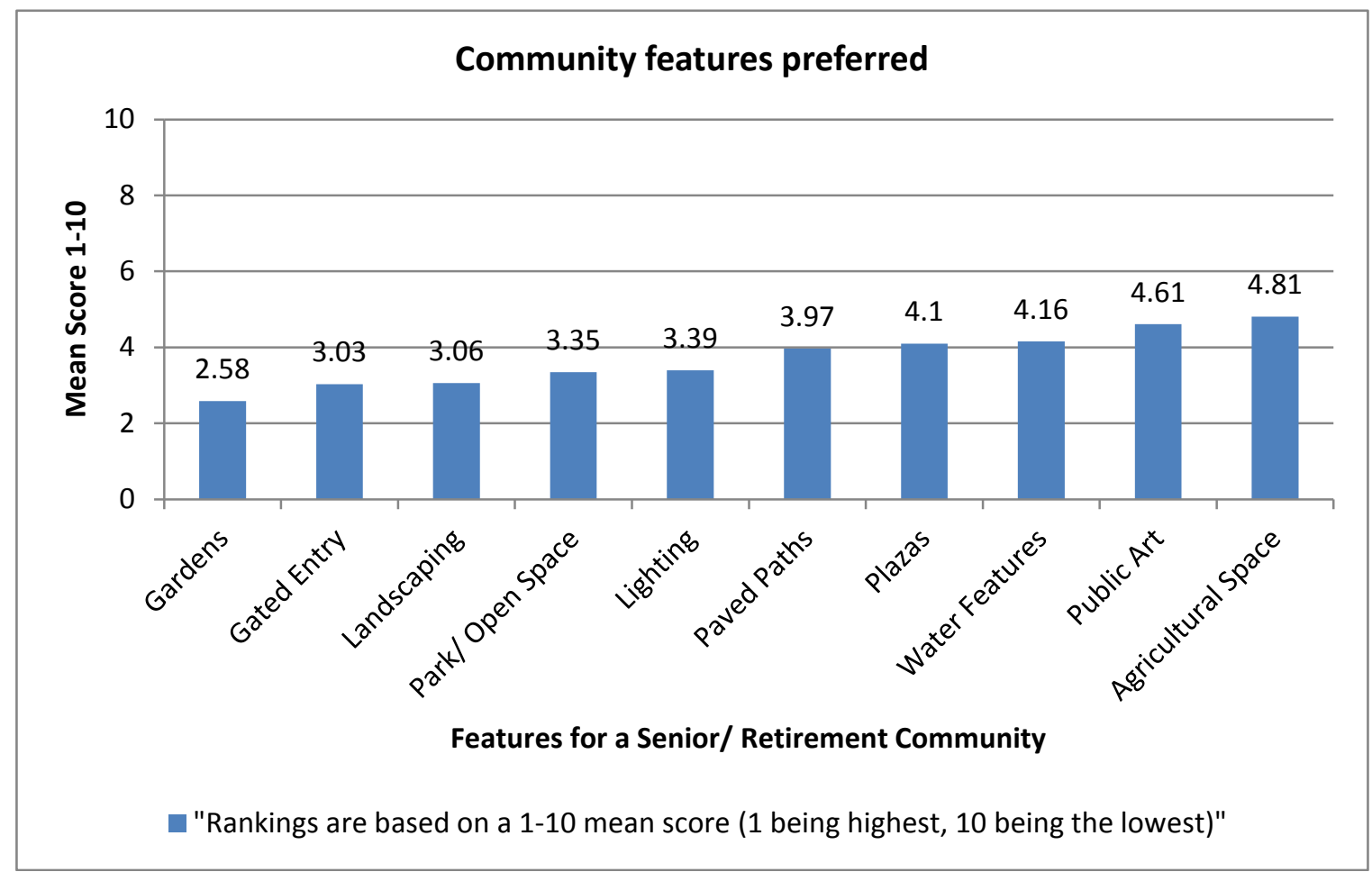

Figure 7.

When asked to identify preferred methods for traveling short distances, an overwhelming majority selected walking (as shown in Figure 8). As discussed prior, walking trails are a crucial activity component for Baby Boomers, so it is key to incorporate and maximize wayfinding when designing a community. In designing pedestrian circulation, wayfinding can be accomplished by developing networks of safe, paved pedestrian and bicycle pathways that further allow people to socially and physically maintain connections with the world around them. Bicycling was the second highest preferred method for short distance travel, so providing adequate pathways and 
bicycle facilities should be identified when designing a master community plan. While it is necessary to plan for automobile circulation within a senior or retirement community, it is highly beneficial to focalize on pedestrian-orientation and promote walkability and bicycling, and secondarily to the passage of automobiles. (Abbott et al., 2009)

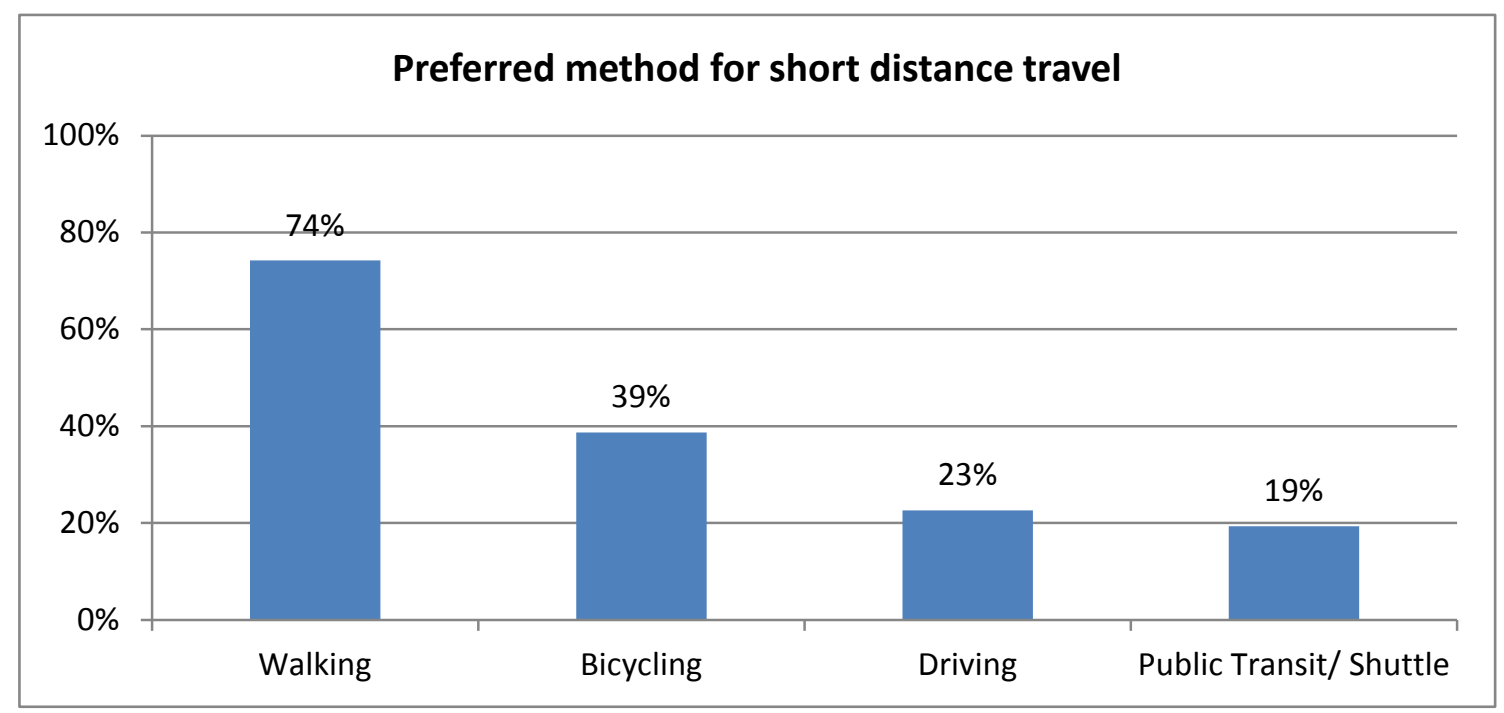

Figure 8 .

In an effort to reduce automobile use and enhance pedestrian-orientation, it is important for a senior or retirement community to be linked and connected to adjacent and surrounding communities. As indicated in Figure 9, the preference for living near a downtown is $81 \%$ favorable, compared to the $13 \%$ who claim living near a downtown is unimportant. The Sinclair Ranch CCRC will be located within walking distance to the village of Chinese Camp that is currently undergoing revitalization, so it is crucial to incorporate connectivity through walkways and pathways. According to Design for Aging Review (2010), breaking down campus boundaries and providing easy access to neighborhood services, amenities, and public transportation allows older adults to integrate with existing communities. This prevents seniors from living in isolation, and further deinstitutionalizes senior living environments and promotes community cohesion. 


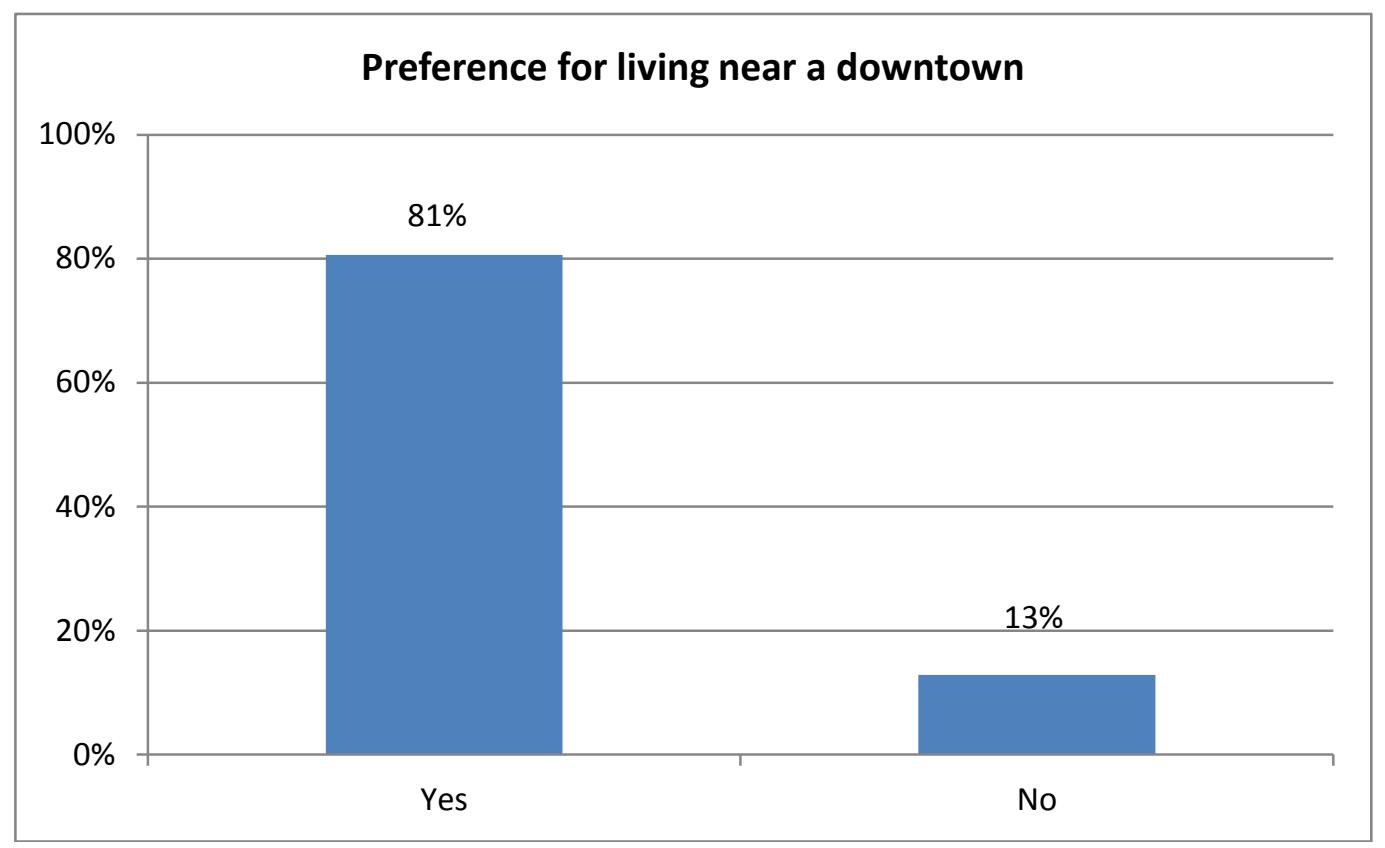

Figure 9 .

Given the multitude of key findings and design trends from both the literature review and survey data, it is important to review a summary table to reiterate current trends. Certain items were supported by information found in literature review, where as other data was collected by the completion of the Boomer Boomer survey. Table 1 identifies each key finding or design trend and depicts whether or not it originated from either literature view or the survey. 


\begin{tabular}{|l|c|c|}
\hline Table 1. & $\begin{array}{c}\text { Literature } \\
\text { Review }\end{array}$ & Survey \\
\hline $\begin{array}{l}\text { Senior and retirement communities, including CCRC's, are attractive } \\
\text { options to live in }\end{array}$ & $\sqrt{ }$ & $\sqrt{ }$ \\
\hline Maintenance-free living and downsizing are top priorities & $\sqrt{ }$ & $\sqrt{ }$ \\
\hline $\begin{array}{l}\text { Pedestrian-oriented communities that maximizes social spaces and } \\
\text { wayfinding throughout the natural and built environment are desirable }\end{array}$ & $\sqrt{ }$ \\
\hline $\begin{array}{l}\text { Mixed use developments with residential and service and/or } \\
\text { commercial facilities }\end{array}$ & $\sqrt{ }$ & $\sqrt{ }$ \\
\hline $\begin{array}{l}\text { Variety of housing options including mixed use, single-family, and } \\
\text { condominiums to serve different needs }\end{array}$ & $\sqrt{ }$ \\
\hline Single-family housing options for younger Baby Boomers and seniors & $\sqrt{ }$ \\
\hline $\begin{array}{l}\text { Onsite health facilities and care } \\
\text { Community center hub that offers a variety of amenities and services }\end{array}$ & $\sqrt{ }$ \\
\hline Top-notch fitness facilities for the fitness-focused cohort & $\sqrt{ }$ \\
\hline $\begin{array}{l}\text { Walking trails and pathways to enhance outdoor activity and } \\
\text { walkability; walking is also the preferred method for short distance } \\
\text { travel }\end{array}$ & $\sqrt{ }$ \\
\hline Elegant dining options with a variety of indoor/outdoor venues & $\sqrt{ }$ & $\sqrt{ }$ \\
\hline $\begin{array}{l}\text { Entertainment and cocktail lounges for socialization purposes; } \\
\text { preference for wine tasting activities }\end{array}$ & $\sqrt{ }$ & $\sqrt{ }$ \\
\hline $\begin{array}{l}\text { Landscaping, gardens, and open/park space are highly valued for } \\
\text { interacting with nature and aesthetic purposes }\end{array}$ & $\sqrt{ }$ & $\sqrt{ }$ \\
\hline Smart growth, sustainable, and green design & $\sqrt{ }$ \\
\hline Bicycling pathways for outdoor activity and short distance travel & $\sqrt{ }$ \\
\hline $\begin{array}{l}\text { Close connection and linkages to surrounding downtown or } \\
\text { community }\end{array}$ & & $\sqrt{ }$ \\
\hline
\end{tabular}

Table 1. Key Findings and Design Trends

\subsection{Case Study Analysis}

In conjunction with literature review and survey findings, a case analysis of existing CCRC's and senior communities is imperative in order to identify and examine trending characteristics in designing communities. The cast study analysis will be broken up into 3 sections, including amenities and services, community design, and marketing.

\subsubsection{Case Study 1: RiverWoods at Exeter CCRC}

The RiverWoods at Exeter Continuing Care Retirement Community is a premier and award winning senior community located in New England, offering a variety of first- 
rate accommodations and services in three unique neighborhoods. Since this institution is acknowledged and rated as a premier CCRC, it will serve as an essential case study to analyze and extract trending design elements that may help enhance the design plan for the proposed Sinclair Ranch CCRC.

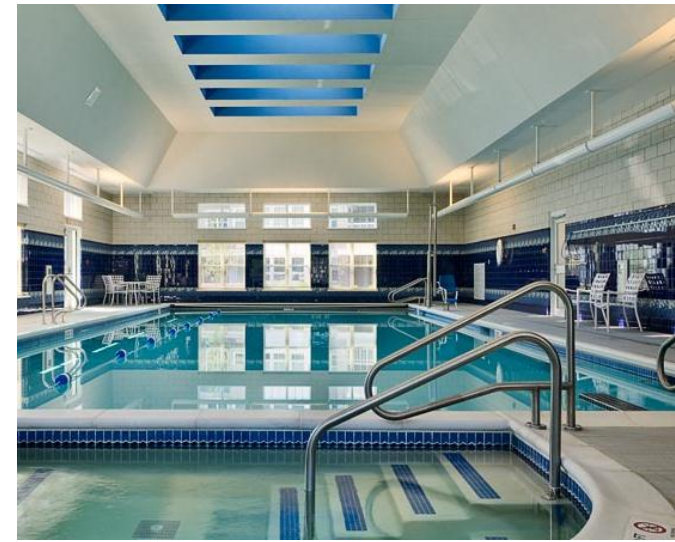

Figure 10. Aquatic center (riverwoodsrc.org)

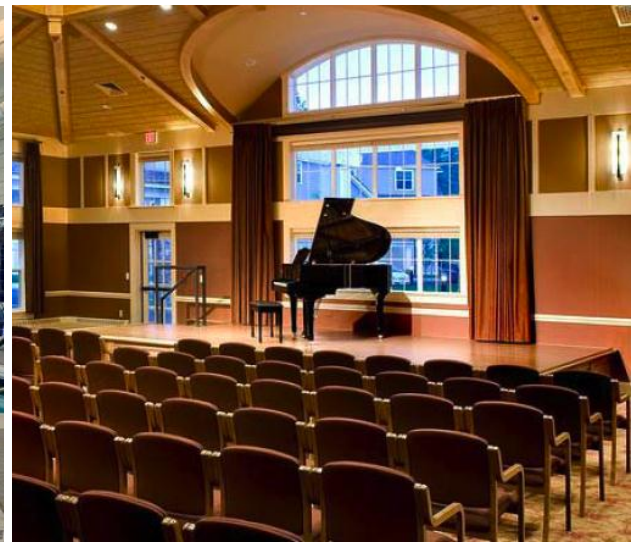

Figure 11. Music hall (riverwoodsrc.org)

\section{Amenities/Services}

The RiverWoods at Exeter CCRC offers a variety of living options depending on the type and level of service residents desire. The overall community offers assisted living, skilled nursing, and independent living among three different campuses called The Woods, The Ridge, and The Boulders. In contrast to conventional apartment style living, the addition of independent living duplex cottages and single family homes to The Ridge and The Boulders were developed to attract residents looking for alternatives to the lifestyle options offered at the original Woods complex. Incorporating cottages was essential in attracting younger, more active residents and Baby Boomers, which adds to the overall diversity and vitality of the RiverWoods community. In further assessing RiverWoods at Exeter, it is fundamental to review the distinct facts of the three different campuses. 


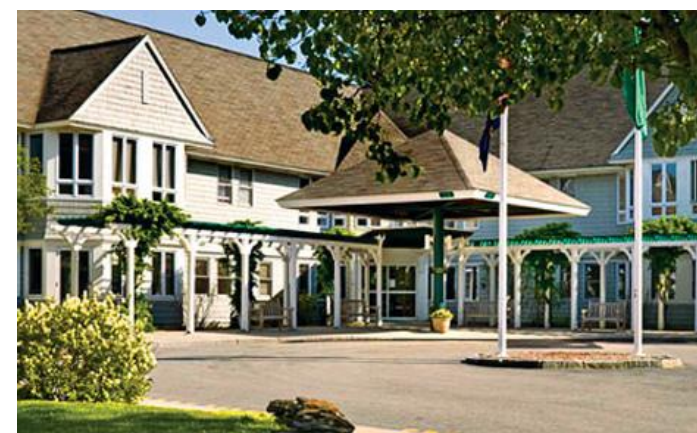

Figure 12. The Woods entrance (riverwoodsrc.org)

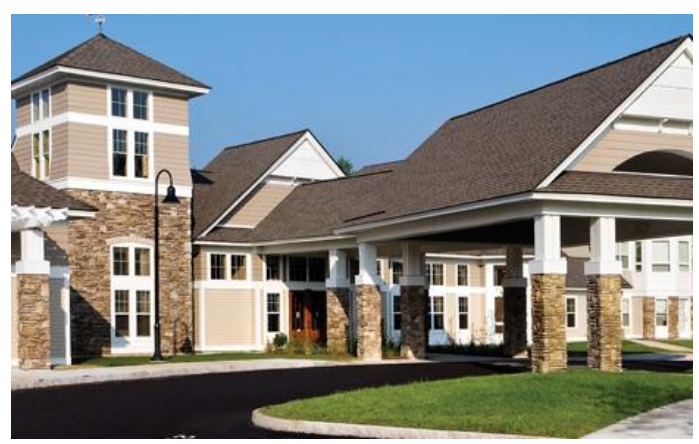

Figure 14. Boulders entrance (riverwoodsrc.org)

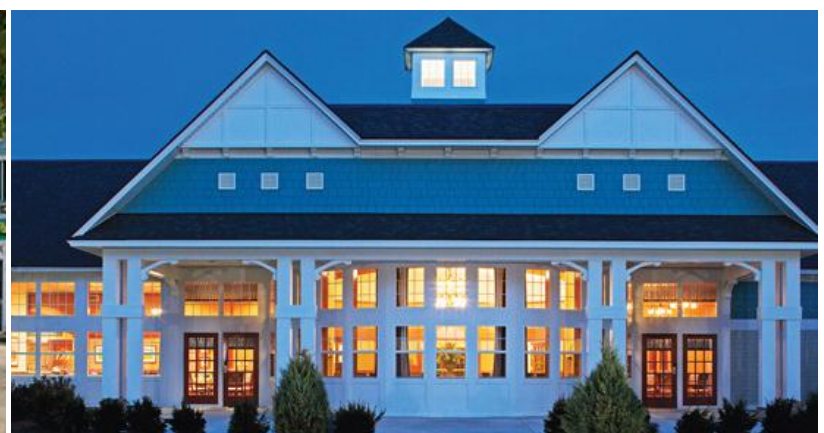

Figure 13. Ridge Community Center (riverwoodsrc.org)

\section{The Woods}

- The Woods is the original campus with 199 apartments

- Over 22 floor plans

- $3 / 4$ mile from The Ridge

- Special features include art studio, wood shop, dance studio and planting room

\section{The Ridge}

- $\quad 2^{\text {nd }}$ campus, with over 81 apartments and 11 cottages

- Over 8 floor plans

- Has gardens for flowers and growing vegetables

- Special features include a unique pottery studio

- Favorite gathering spot is the Living Room for cocktails

\section{The Boulders}

- The newest campus opened in 2010, with 72 apartments 24 cottages

- Designed using green principles

- $\quad 1 / 4$ mile from The Ridge

- Special features include Brick oven pizza and sports bar at the Bistro Café, ping-pong room, and Boulders Hall for large events

Although each campus is unique with different design elements and special features, each campus has the following duplicate facilities:

- Complete health care center, services and amenities

- Private Independent Living apartments

- Private Assisted Living apartments 
- Medicare-certified Skilled Nursing facility

- Wellness Clinic

- Three dining venues including indoor/ outdoor dining options

- State-of-the-art Pool and fitness center

- Resident managed library

- Country store

Fitness-related activities are a large component of the RiverWoods community. Each fitness center offers a full schedule of fitness classes with full time fitness professionals on staff. In addition to fitness centers, the community offers wooded trails for hiking and enjoying the outdoors. Nearby, community members can also take part in canoeing and kayaking the Exeter River in downtown Exeter.

Within the three campuses at RiverWoods at Exeter, facilities are well equipped to provide a multitude of different services and activities. To keep residents active and social, the community provides Art Galleries and Studios, Book Clubs, Bridge Club, Computer labs with Internet access, Concerts, Game \& Billiards areas, Libraries, Musical, Groups \& performances, Educational classes, a Resident-operated Campus Television Station, and a Resident-operated Country Store among many others.

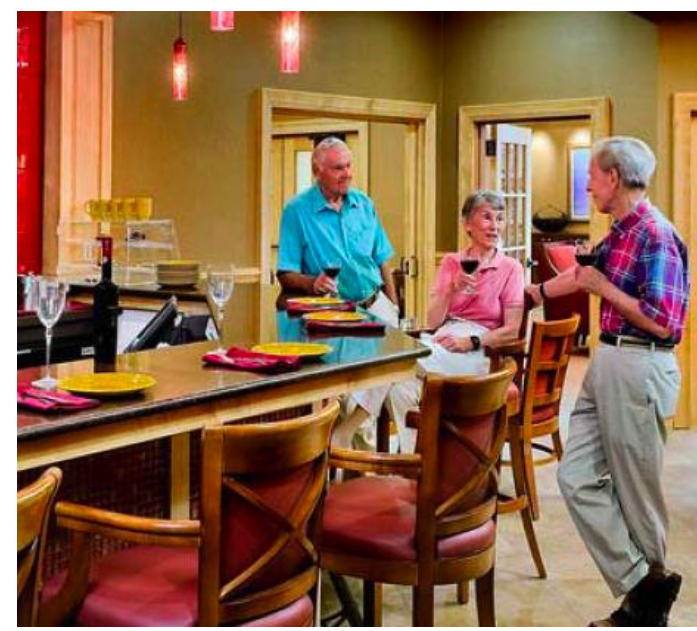

Figure 15. Cocktail lounge (riverwoodsrc.org)

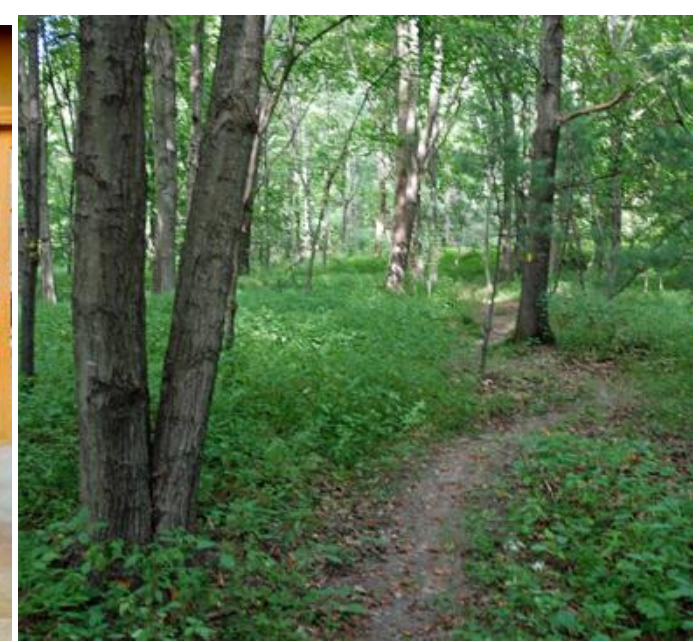

Figure 16. Trails for hiking (riverwoodsrc.org) 


\section{Community Design}

Intertwined with three distinct campuses, RiverWoods at Exeter is a community that highlights the unique New England culture. Although each neighborhood has its own unique character, architecture, and interior design, the majority of the buildings and facilities are Cape Cod inspired, resembling cottage-like buildings with wooden shingles and wooden materials, that are surrounded by lush landscaping, tree lined streets, and a forests. The overall design objective for RiverWoods is to maintain a cohesive community, while it must also appeal to changing demographics such as Baby Boomers. It is here where RiverWoods has an advantage over most other communities, offering three different aesthetic options ranging from traditional residential to more contemporary hospitality (RiverWoods, 2013). To preserve the community and maintain a unique sense of scale, facilities are no higher than three stories (or 35 feet in height) as stipulated by local zoning regulations.

Each campus focalizes around the community center, where the main social and cultural activities are located such as dining and fitness facilities. The campuses are not further than $3 / 4$ mile apart, which make them walkable and bicycle friendly so residents can reach different activities and social events. Due to the natural location of The Ridge and The Boulders, they are each uniquely inspired. The Ridge has the highest elevation within the community with some of the best view sheds, which is how this community received its name. On the other hand, The Boulders site inhabits natural boulders of all shapes and sizes, some as big as a single-story house. In conjunction with its name as The Boulders, a generous amount of stone was incorporated into the overall design of the site to enhance its unique location and geologic environment. 


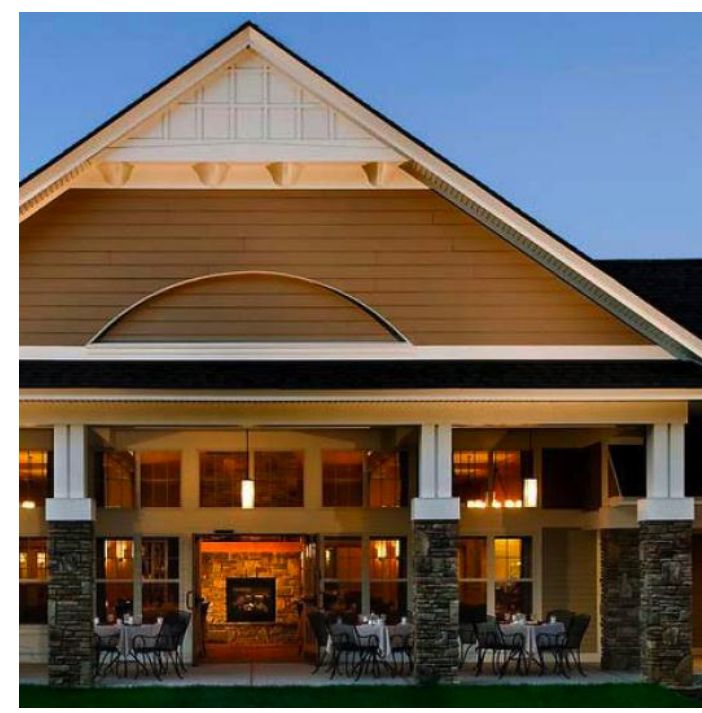

Figure 17. Outdoor dining (riverwoodsrc.org)

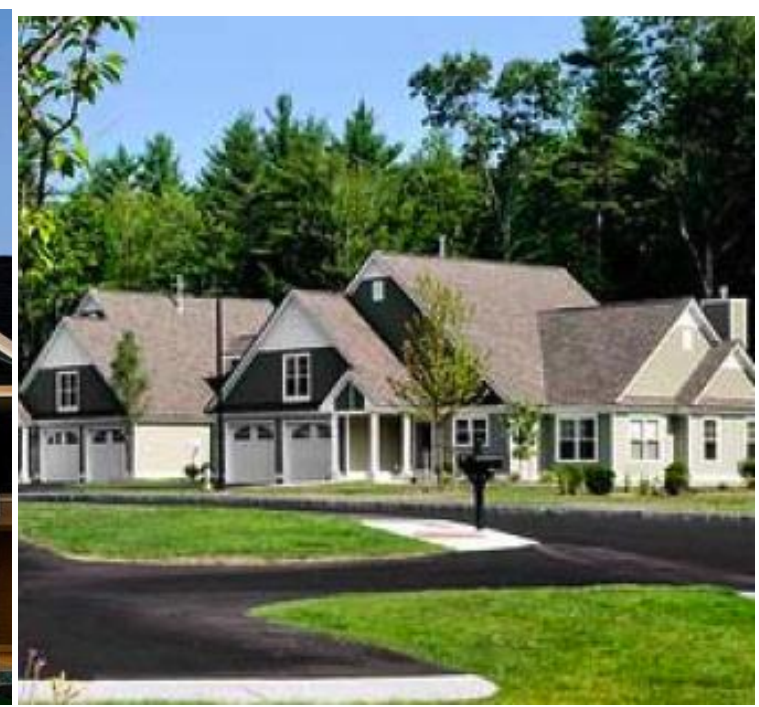

Figure 18. Typology of housing (riverwoodsrc.org)

\section{Marketing}

The RiverWoods at Exeter life care community can uniquely be identified as a classic New England style retreat. Located in historic Exeter, with a charming downtown and close proximity to the coast of New Hampshire, the area has a lot to offer active seniors and retirees over the age of 62. Developed as one community with three distinct neighborhoods, residents have the option to live active and independent lifestyles with a variety of tiered housing accommodations and services indicative of what a typical CCRC would offer. It is the RiverWoods at Exeter mission is to "provide a creative and secure continuing care community that enriches the freedom of senior living while easing the challenges of aging" (RiverWoods, 2013). Moreover, the community promotes itself as a place to "discover the freedom to enjoy your life as you wish," allowing residents to independently choose the right amount of comfort, care, and service in a classic New England setting (RiverWoods, 2013). 


\subsubsection{Case Study 2: Trilogy at Monarch Dunes}

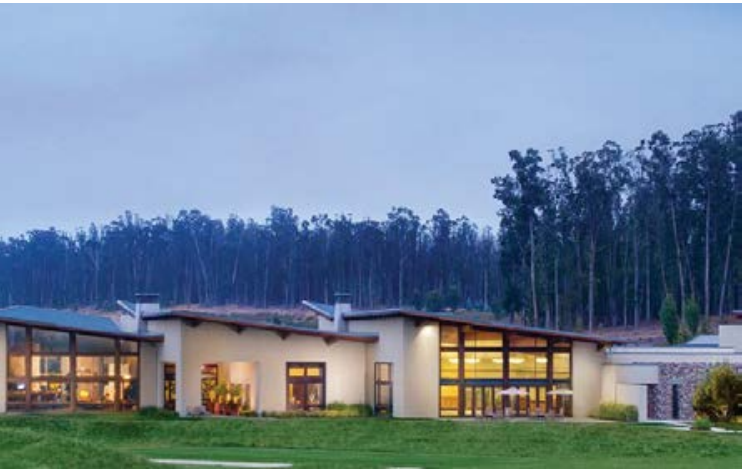

Figure 19. Monarch Clubhouse (trilogylife.com)

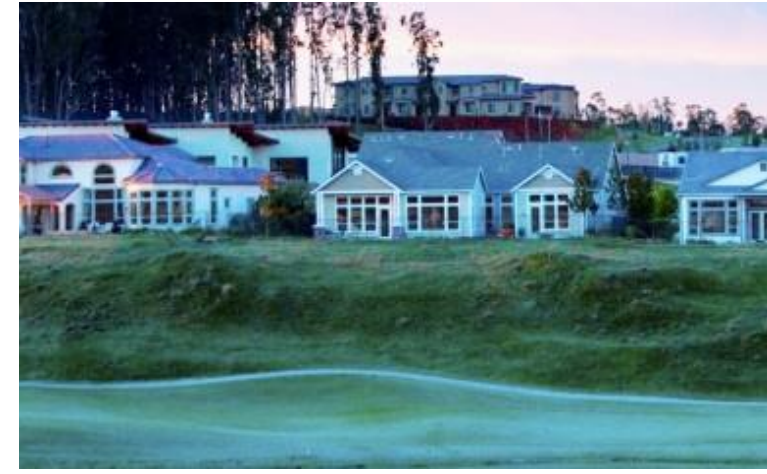

Figure 20. Cottage living (trilogylife.com)

Due to the valued preference for single-family residences in senior or retirement communities resulting from the survey, it is essential to analyze a community that offers a range of single-family options and amenities. Trilogy at Monarch Dunes is an active adult community located within the Central Coast of California in the community of Nipomo, which offers high quality single-family accommodations centered around a resort style clubhouse and village. Designed for a 55+ community, the senior residences range from 1,730 square feet $-3,690$ square feet. From smaller cottages to larger homes, as shown in Figure XX, Trilogy at Monarch Dunes offers residents the opportunity to downsize from their former home and live amongst a resort style community.

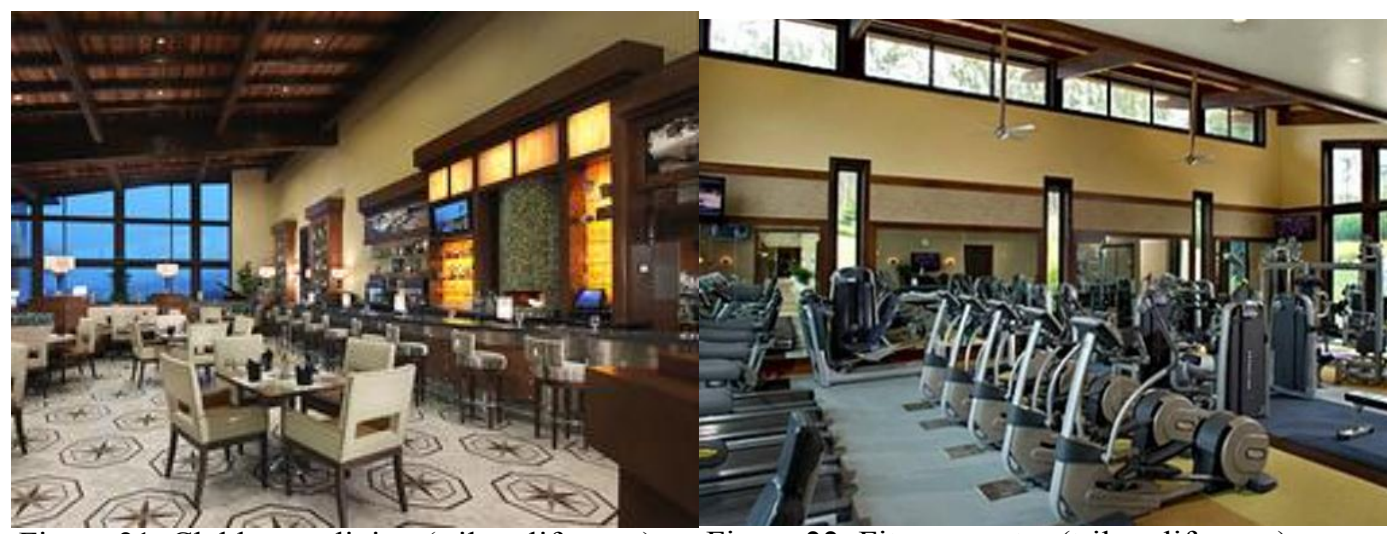

Figure 21. Clubhouse dining (trilogylife.com) Figure 22: Fitness center (trilogylife.com) 


\section{Amenities/Services}

Trilogy at Monarch Dunes offers a variety of amenities that resemble active and resort style amenities. Centralized within the Monarch Dunes community, the Monarch Club serves as the primary clubhouse for social and physical activity. As the only allinclusive resort on the Central Coast, The Monarch Club offers 5-star amenities such as dining and lounging at Adelina's Bistro and Bar, Sandalwood Spa, a wine shop and marketplace, and a state-of-the-art fitness center. The fitness center offers a variety of exercise classes and personal and private training. The marketplace is a combination of a farmer's market and old-time county store where residents can pick up fresh food to take home. There are also art studios, a wine library, and lounging and private dining rooms that may be utilized by residents to throw social gatherings or private parties. It is key to have social and physical activity located within the center of a community to maximize use and pedestrian orientation. The more inconvenient amenities are, the less likely residents will take advantage of and may deter visitors from choosing a community.

Within the vicinity of the Clubhouse, there are also other key resort style offerings. Outside the Clubhouse, there is a large outdoor swimming pool for swimming laps and aerobic classes, surrounded by poolside cabanas and chaise lounges. Including the poolside cabanas is a great use of outdoor space, further utilizing and complementing the pool area as a social space where friends and family can gather. In addition to the pool, the community offers a sculpture garden, championship tennis courts, and a 12-hole golf course that are highly attractive for active seniors. The golf course is intertwined throughout the community and residences, offering sweeping views of windswept dunes, eucalyptus trees, coastal vistas and amber-colored hillsides. Living on a golf course can 
promote walkability and outdoor exercise, while offering a beautiful landscape that residents can experience.

Along with existing services and amenities, organized groups are a large part of social activity within Monarch Dunes. Social activities include the Book Club, Cards and Bunco Club, Les Papillon Social Club, Supper Club, Scrapbook Club, and Trilogy Service Club. For more active and physical groups, Trilogy has groups for biking, bocce ball, hiking, tennis, and golf. Within an active cohort of seniors, it is important to offer a variety of social and physical activities that help stimulate and improve the health and wellbeing of residents.

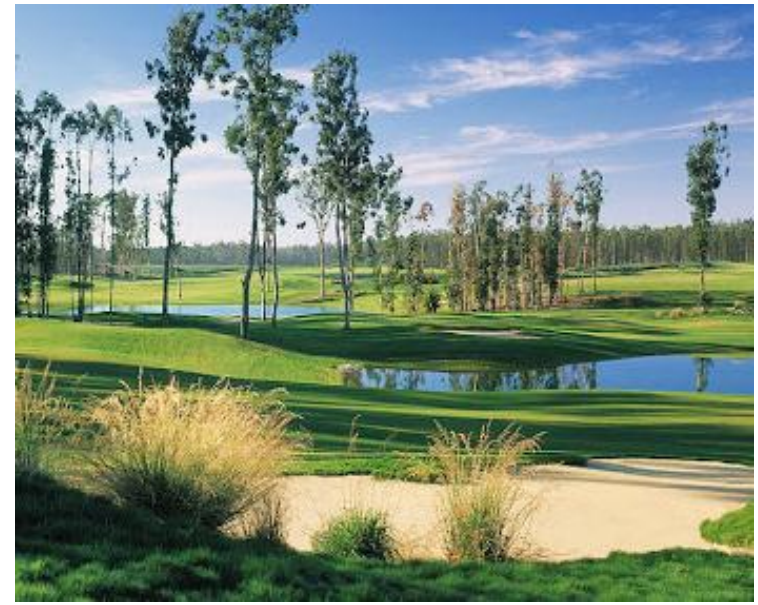

Figure 23. Golf course (trilogylife.com)

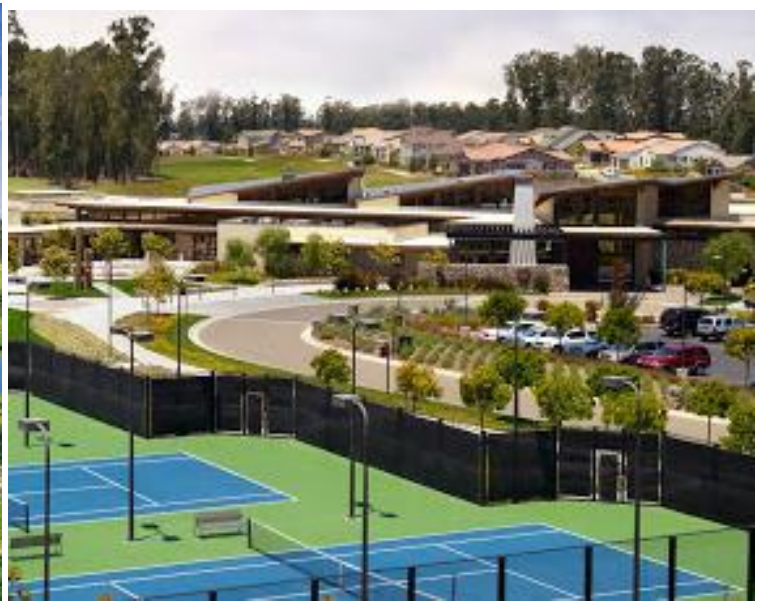

Figure 24. Tennis courts (trilogylife.com)

\section{Community Design}

Trinity at Monarch Dunes has a unique location in the midst of the Central Coast. With a mild climate year around, Monarch Dunes utilizes its location to incorporate an abundance of outdoor activities, including the 12-hole golf course and championship tennis courts. Likewise, the architecture and design for the community facilities is modern, yet blends in with the existing environment with its natural tones and use of stones and wooden materials. The Clubhouse, with its many amenities and rooms, is a focal point of the community that has both a contemporary and inviting setting. Large 
rooms, high ceilings, and ample windows give the Clubhouse an open and welcoming vibe for residents to feel relaxed and comfortable. Complementary however, the varieties of residences are both unique and subtle, encompassing a rustic or country cottage look with unobtrusive or bold colors. To resonate with seniors, it is important to offer modern conveniences and amenities, but not necessarily over exhaust a community with contemporary design and architecture. Moreover, Trilogy at Monarch Dunes balances being a modern resort and senior community for active adults, offering key amenities and services that Baby Boomers find desirable.

\section{Marketing}

In analyzing Monarch Dunes, it is important to identify the key characteristics that are being utilized for promotional consideration. When marketing Monarch Dunes, the community is highlighted as a place that "encourages wellness and makes you feel truly alive" (Trilogylife.com). Primarily identified as an active adult community and resort, health and wellness are valued elements that the community strives for. On their website, they promote outdoor activities, including hiking, mountain biking, golfing, kayaking, horseback riding, surfing, camping, and boating. With Baby Boomers being more active than their predecessors, it is key to target active adults with a plethora of outdoor activities. In addition, the community utilizes its location as being in the middle of wine country where one can "visit world-class wineries and quaint restaurants" (Trilogylife.com). As depicted in the former Baby Boomer survey, wine tasting is a preferred activity that scored highly amongst other activities. Monarch Dunes capitalized its marketing efforts by highlighting outdoor activities and showcasing the local wine region. 


\section{CHAPTER 4.}

\section{Conclusion}

With a growing elderly population heading into retirement, it is more important than ever to plan communities that meet the market needs and desires of those seeking retirement or senior living alternatives. It is evident that the current supply does not match up to the increasing demand, so it is critical that developers and cities work cohesively together to identify needs and help minimize housing shortages for a key segment of the U.S. population (Hunt, 2012). Urban and suburban sprawl has made senior and health care services more dispersed and difficult to access, and nearly impossible for the elderly to age in place in their current home or community as their parents once did. In conjunction, the plethora of senior housing alternatives has created an extremely competitive market, forcing communities to upgrade facilities, add premium services, and offer a higher quality of life compared to the former traditional senior community (Lynn, Wang, 2008).

Senior communities that want to remain competitive in the marketplace are already evolving to attract Baby Boomers. The Baby Boomer cohort is especially crucial to cater to as they are in the midst of retirement and have considerable wealth and buying power compared to their former predecessors. Although Baby Boomers are a wealthier cohort however, they are also much more selective and are seeking maintenance-free 
living and active and leisure lifestyles (Lynn, Wang, 2008). If not already acknowledged in the planning process, senior communities must be prepared for the large numbers of fitness-focused Baby Boomers that seek a multitude of indoor and outdoor recreational opportunities and services (Abrahm, 2012). Moreover, today's community models for Baby Boomers need to offer a well-balanced variety of social, recreational, and life-long learning opportunities that meet the expectations of younger and older seniors (Abrahm, 2012).

Offering a tiered-level of housing accommodations and health services, the Continuing Care Retirement Community (CCRC) was identified as the most applicable type of senior development for the Sinclair Ranch. A competitive CCRC combines attractive residential living with high levels of service, including comfort, health, wellness, security and additional needs for aging seniors (Lynn, Wang, 2008). It is estimated that over 745,000 older adults take residence in CCRCs, creating a multibillion-dollar industry that is only expected to grow and become a much larger and viable housing alternative for Baby Boomers (Zarem, 2010).

Through the culmination of literature review, data collection, and survey analysis, we identified key trending design techniques and services that will be focalized assets in the draft design plan for Sinclair Ranch. It is imperative to reiterate that potential residents are less likely to give up anything in their lifestyle except for the big house in exchange for downsizing (Hunt, 2012). Likewise, the Baby Boomer cohort are redefining the status quo by the latest desire to downsize and are even demanding pedestrianfriendly environments that contribute to healthier people (Abbott et al., 2009). Baby Boomers ultimately want to enhance their quality of life, desiring pedestrian-oriented and mixed use communities that are aesthetically designed to promote walkability and 
mobility, social activity, and connectivity. Furthermore, when planning a senior community it is essential to establish connections to adjacent communities to prevent seniors from living in isolation, and instead enhance and promote community cohesion and interactivity. 


\section{REFERENCES}

Abbott, P. S., Carman, N., Carman, J., \& Scarfo, B. (2009). Re-creating neighborhoods for successful again. Baltimore: Health Professions Press, Inc.

American Institute of Architects (2010). Design for aging review: AIA design for aging knowledge community.

Abrahms, S. (2012). Senior centers evolve to attract boomers. AARP Bulletin.

Barnett, M. D. (2010). Future expectations among older adults in independent living retirement communities. University of Houston. ProQuest Dissertations and Theses, 79.

Carstens, D. (1993). Site planning and design for the elderly: issues, guidelines, and alternatives. New York: Van Nostrand Reinhold.

Golant, S., Hyde, J. (2008). The assisted living residence: A vision for the future. Baltimore: The John Hopkins University Press.

Greene, K. (2010, Aug 07). Weekend Investor - the new basics - family value: Continuing-care retirement communities: weighing the risks. Wall street journal, pp. B.8. Retrieved from http://search.proquest.com/docview/740167969

Harrigan, J. E. (1998). Senior residences: Designing retirement communities for the future. New York: John Wiley \& Sons, Inc.

Hunt, K. (2012). The new senior housing market. Journal of property management, 77(3), 19-23.

Lynn, D., Wang, T. (2008). The U.S. senior housing opportunity: Investment strategies. Real Estate Issues, 33(2), 33-51.

McIlwain, J. (2010). Housing in america: the next decade. District of Columbia: Urban Land Institute. 
Perkins, B. (2004). Building type basics for senior living. Hoboken: John Wiley \& Sons, Inc.

The RiverWoods (n.d.). Retrieved from http://www.riverwoodsrc.org

Sbranti, J (2006, Oct 28). Active market: Senior communities cater to on-the-go boomers seeking low-maintenance retirement. McClatchy - Tribune Business News, pp. 11. Retrieved from http://search.proquest.com/docview/463205311

Spears, S. (1992). The continuing care residential community. New York: Springer Publishing Company.

Trilogy at Monarch Dunes. (n.d.). Retrieved from http://www.trilogylife.com/communities/california/monarchdunes

U.S. Census Bureau. (2010). Decennial census of population 1990-2010. Retrieved from http//:www.census.gov/prod/1/pop/p23-190/p23-190.pdf

Zarem, J. (2010). Today's continued care retirement communities (CCRC). CCRC task force. Retrieved from https://www.seniorshousing.org/ 


\section{APPENDICES}

A. Sinclair Ranch Community Draft Plan

B. Survey Instruments 


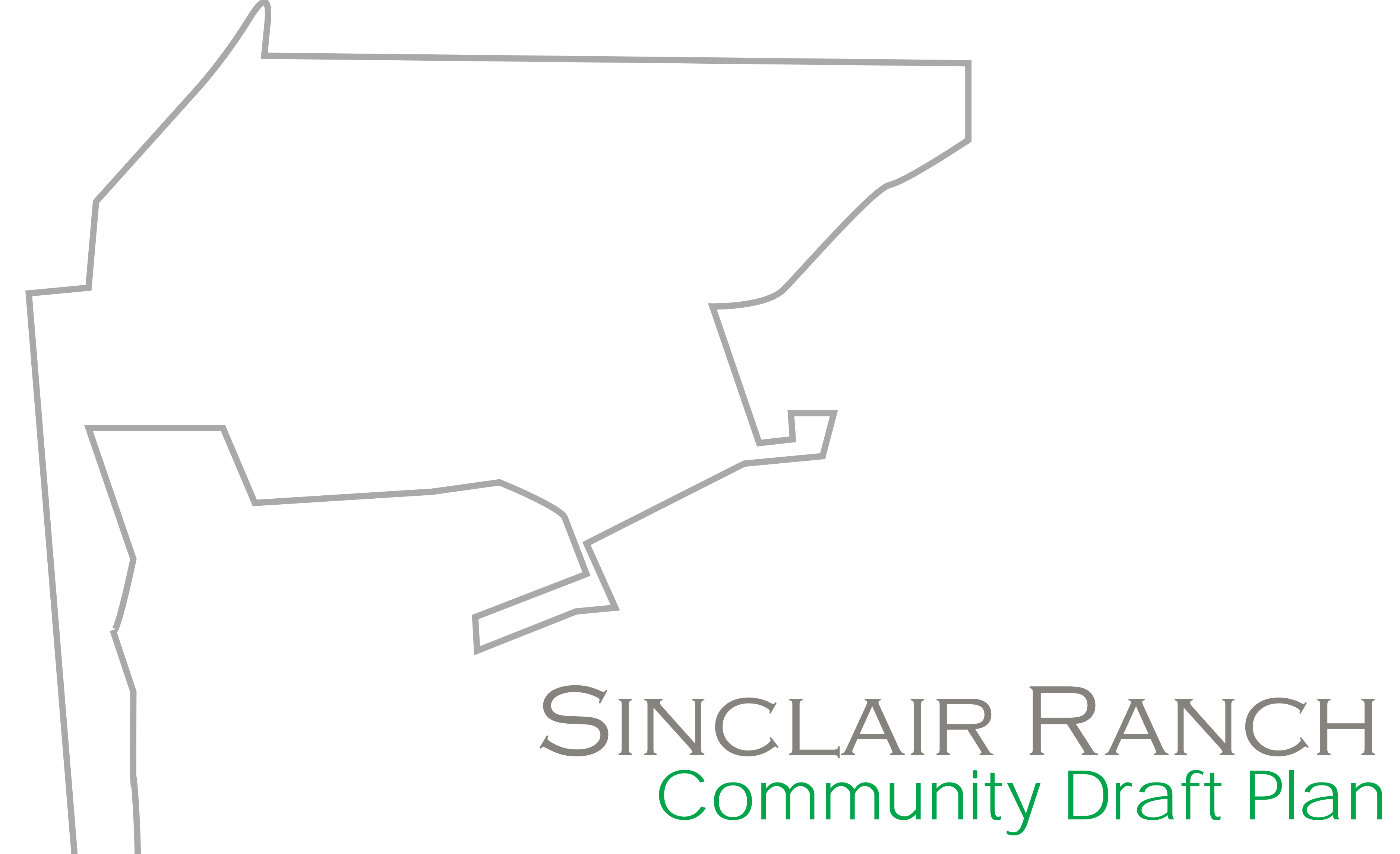

Drafted by Ryan Wassum

Master of City \& Regional Pla nnning 


\section{Table of Contents}

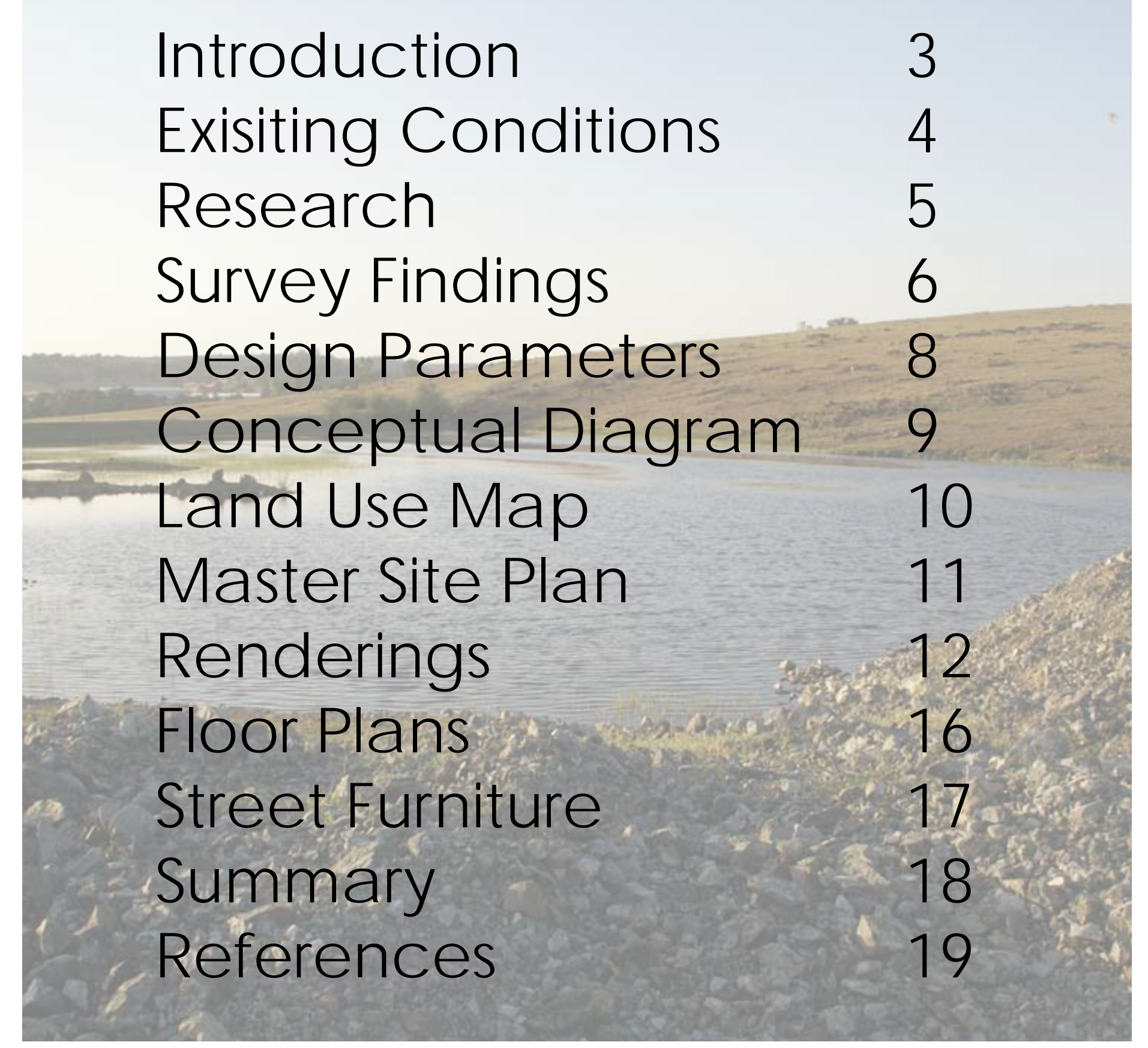




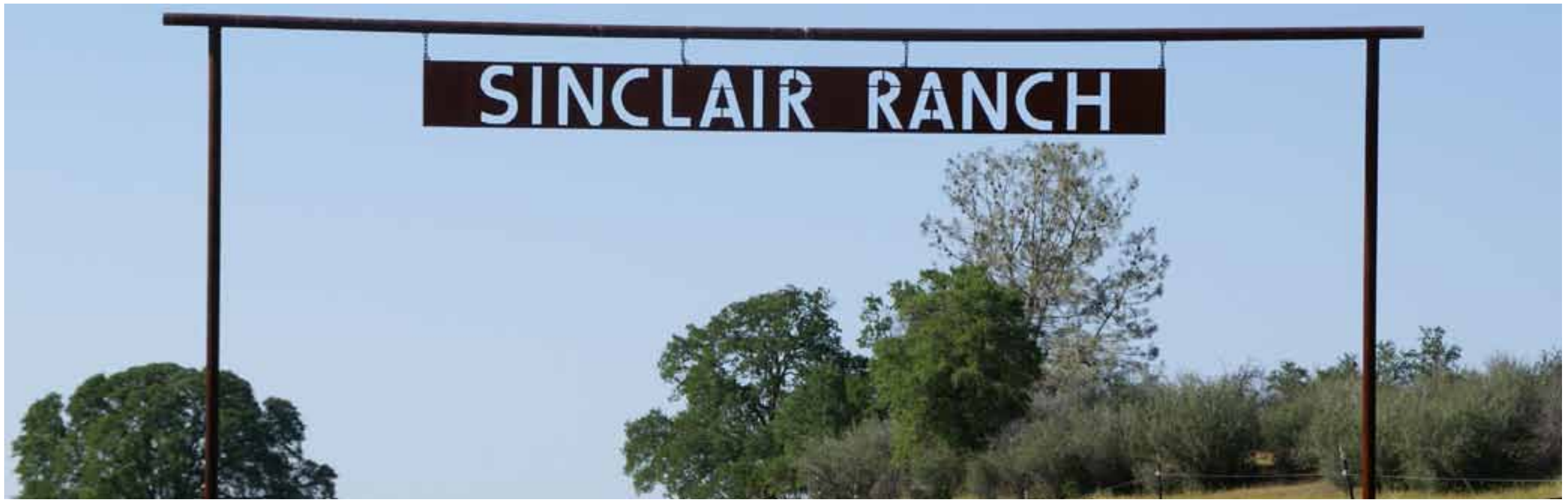

\section{Introduction}

With a growing elderly population hea ding into retirement, it is more important than ever to plan communities that meet the market needs and desires of those seeking retirement or senior living a ltema tives. Senior communities that want to rema in

competitive in the marketplace a re already evolving to attract Ba by Boomers. The Baby Boomer cohort is espec ia lly crucial to cater to as they are in the midst of retirement and have considerable wealth and buying power compared to their former predecessors. In addition, Baby Boomers a re also much more selective and are seeking maintenance-free living and active and leisure lifestyles (Lynn, Wang, 2008).

In exploring national trends and emerging markets for seniors, the proposed 234 acre Sincla ir Ranch Continuing Care Retirement Community (CCRC) in Chinese Camp.
Califomia, has been drafted to meet the needs of current and future Baby Boomers and aging seniors. Research has stressed that today's community models for Ba by Boomers and seniors need to offer a well-balanced variety of social, recreational, and life-long leaming opportunities that meet the expectations of younger and older seniors (Abrahm, 2012). Therefore, the Sincla ir Ranch CCRC has been carefully planned to balance the trending lifestyle demands of Baby Boomers and seniors and will ultimately offer a unique qua lity of life unlike tra ditional senior community models Please explore the "vision" of the Sinclair Ranch CCRC in the following pages. 


\section{Existing Conditions}

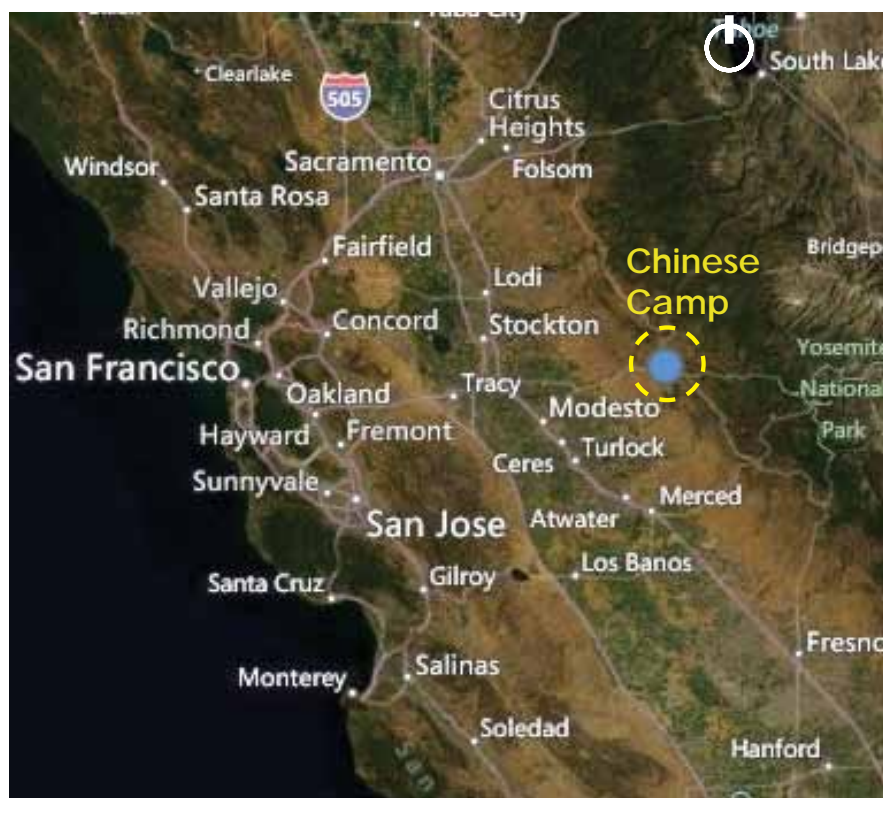

\section{Location}

Easy access to Highway 120 adjac ent to site

10 miles south of Sonora

60 miles west of Yosemite

100 miles southeast of Sacramento

130 miles east of San Francisco

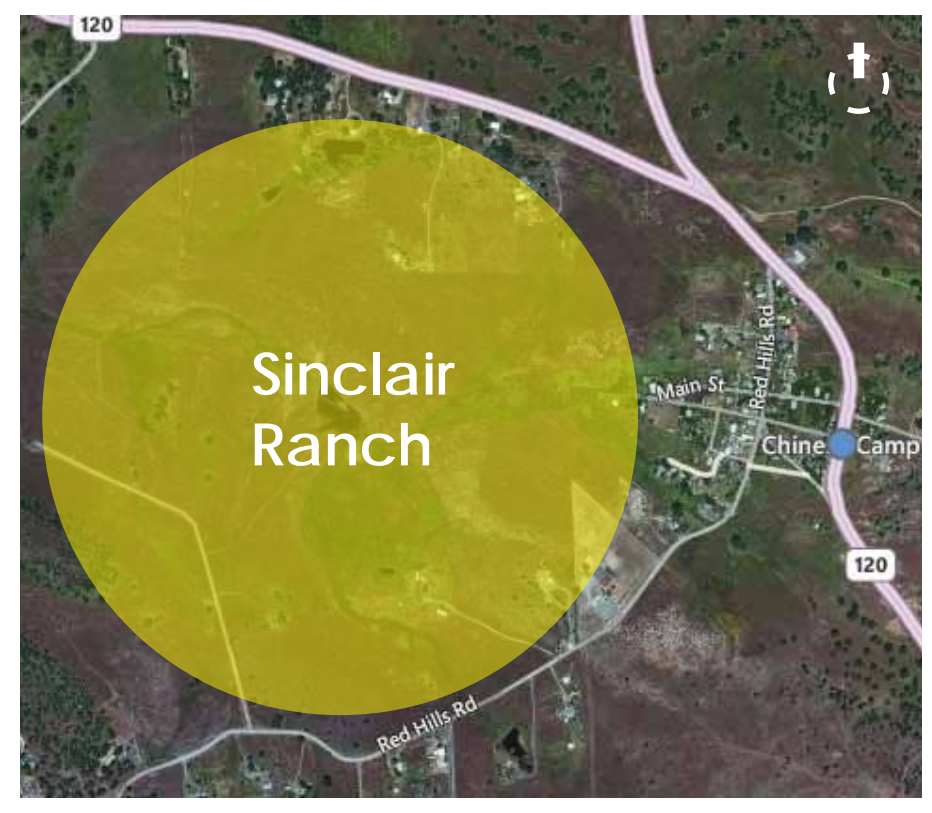

Size

234 acres of rolling hills adjacent to downtown Chinese Camp

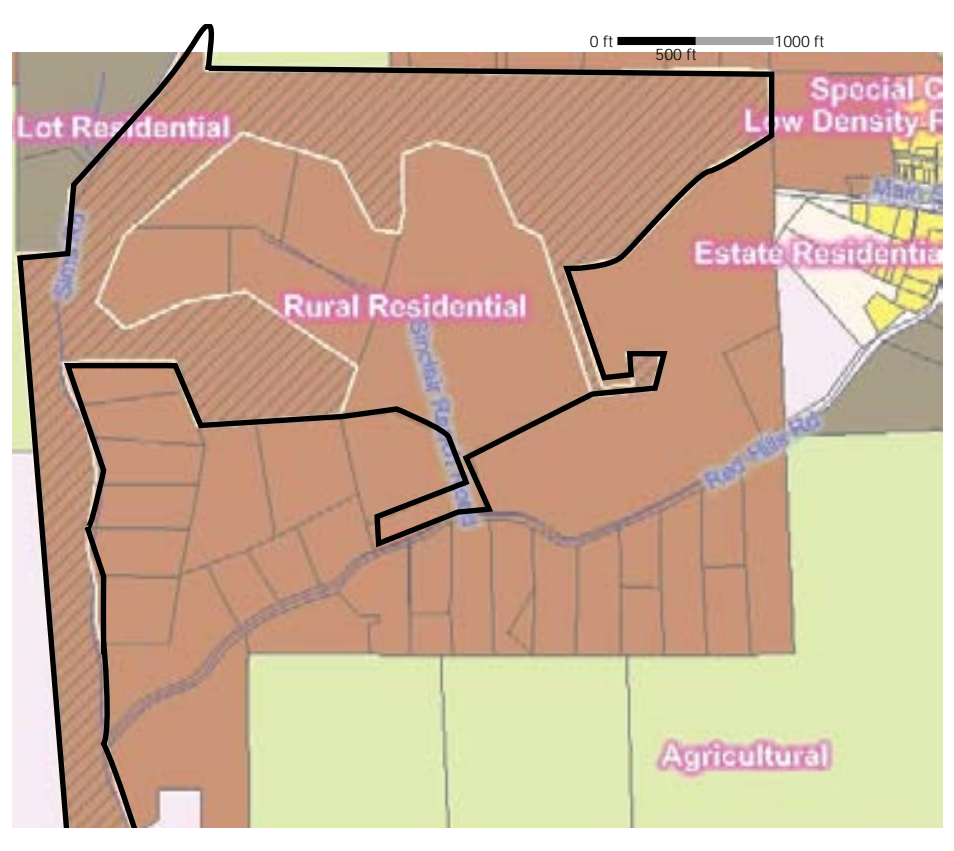

Zoning

\section{Rural Residential}

The Tuolumne County General Plan designates Sinclair Ranch as the only a rea of growth for the town of Chinese Camp. With a Conditional Use Permit and density bonus for build ing senior housing, each 10 acre parcel within the development can conta in 20 build ings a slong as $4 / 5$ of the ranch remains in open space and gardens. Ultimately, no more than $20 \%$ of the land can be dedicated to built structures. 


\section{Research}

With the Baby Boomer cohort shifting the senior housing landscape, planning and design trends have been adjusting to help meet the intensive demands and needs of this progressive cohort. From traditional design concepts to non-traditional, new elements a re synchronizing with former conventional models and a re bringing innovative planning techniques to meet future needs. It is evident that traditional communities with sterile aesthetics and lack of open and natural space are becoming increasingly unpopular and discarded. Moreover, through extenstive research and literature review, the following topics were highlighted in relation to developing a senior community:

\section{Building Cohesively With The Natural Environment}

One of the most prominent and fulfilling planning techniques for senior communities has, and will

continue to be, the assimilation and cohesion with the natural environment. Perkins (2004) claims that lifestyle is determined largely be the design of a community and its components, and that nature is a key a menity in contributing feelings of relaxation (p. 97).

\section{Smart Growth}

Abbot et al. (2009) defines the following 10 planning principlesas the focalization of smart growth (p. 175)

1. Direct development toward existing communities 2. Preservation of open space and farmland

3. Mixed uses

4. Distinc tive and attractive places

5. Compact building design

7. Range of housing choices

8. Walkable neighborhoods

9. Community and stakeholder collaboration in

development decisions

10. Predic table and cost-effective development decisions
Landsc ape Design And Human Interaction

Like the positive outc omes of immersing and experiencing nature, landscapes, and thus

landscaping, play a vital role in shaping outdoor

human environments. In the outdoors, it is critic a forlandscapes to incorporate pedestrian-friendly design, and needs to be designated for the

enjoyment of people and not motorized vehicles (Abbot et al., 2009, p. 189).

\section{Sustainable Design}

The U.S. Green Building Council a sserts that a susta inable approach to design should create buildings and interiors that achieve the following (Abbott et al., 2009, p. 185):

1. Are healthier for people and enhance produc tivity 2. Can be built at market rate and cost much less to

operate

3. Use less fossil fuels, thus conserving energy, generating ess global pollution, and saving on operational costs by equining less maintenance

5. Manage waste at the highest productive leve 6. Reduce impacts on both developed and undeveloped 7. Minimize the usage of materials and use materials with the lowest environmental impacts
Placemaking and Wayfinding

A central stimulus for older a dult populations relates directly to the creation and development of placemaking and wayfinding. Abbott et al. (2009) describes placemaking as the process of designing the quality of life that makes a person feel welcome, whereas wayfinding provides people with the ability to navigate locations in a secure and comfortable matter.

\section{Key Amenities and Services}

When designing a retirement community for Ba by Boomers, it is important to incorporate desired services and amenities into the planning and design phase. The National Directory of Lifestyle Communities compiled a profile of 353 communities that ranked the following amenities as follows (Perkins, 2004, p. 99):
Clubhouse

Outdoor swimming pool

Fitness Center

Walking Trails

Tennis Courts

Rec. Vehicle Storage

Shuffleboard
88.7\% Ballroom with stage

87.0 Computercen

$\begin{array}{ll}62.8 & \text { Golf course } \\ 62.6 & \text { Bocce court }\end{array}$

62.6 Restaurant

Community gardens

ndoor swimming pool 


\section{Survey Find ings}

To collect data for the development of the Sincla ir Ranch CCRC, a survey was

developed to gather key feedback and preferences for ac tivities, services,

and features sought for a retirement and senior community. Distributed only

to respondents within the Baby Boomer cohort, bom between 1946 and 1964

over 30 surveys were completed and a nalyzed.
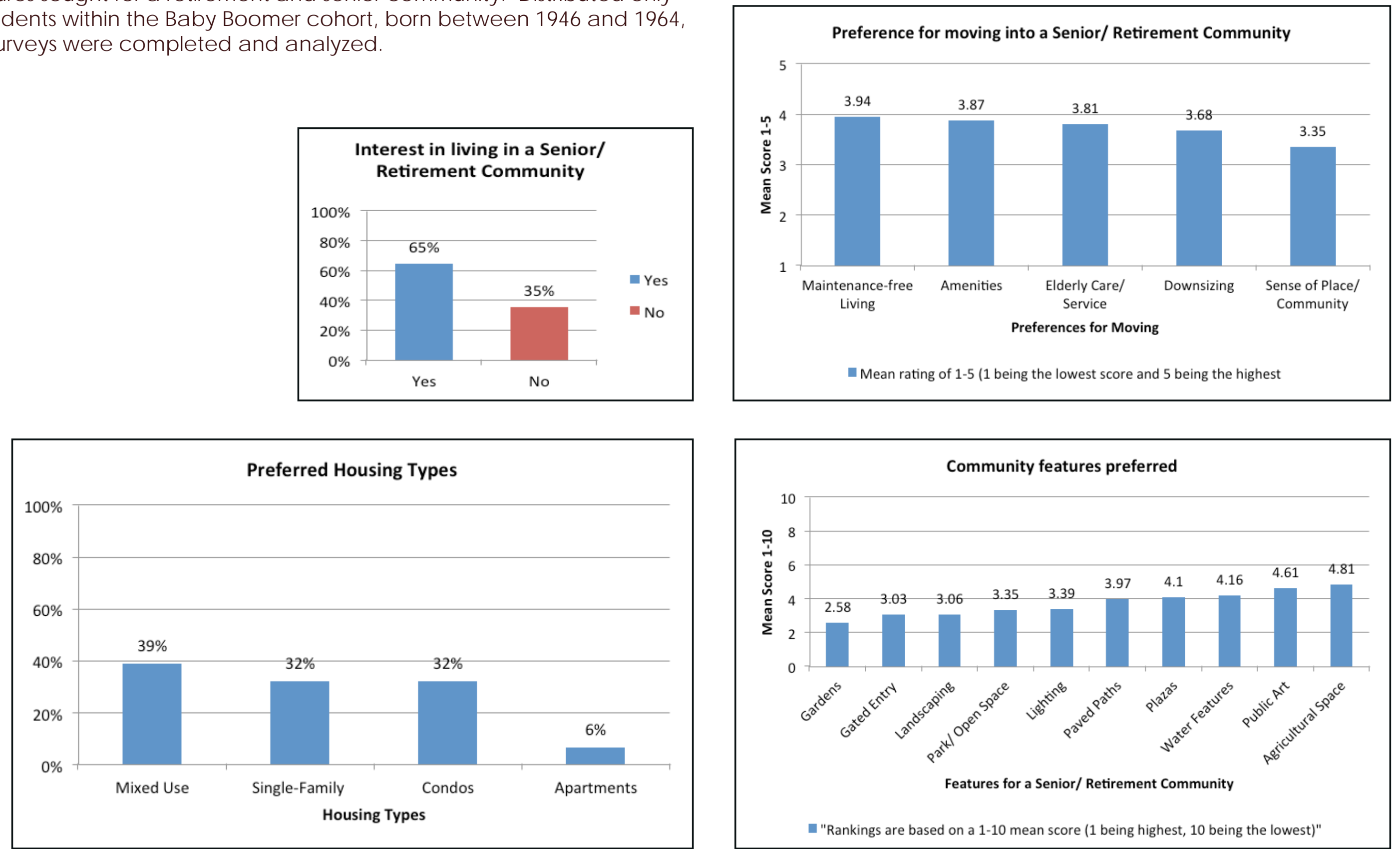


\section{Survey Findings}
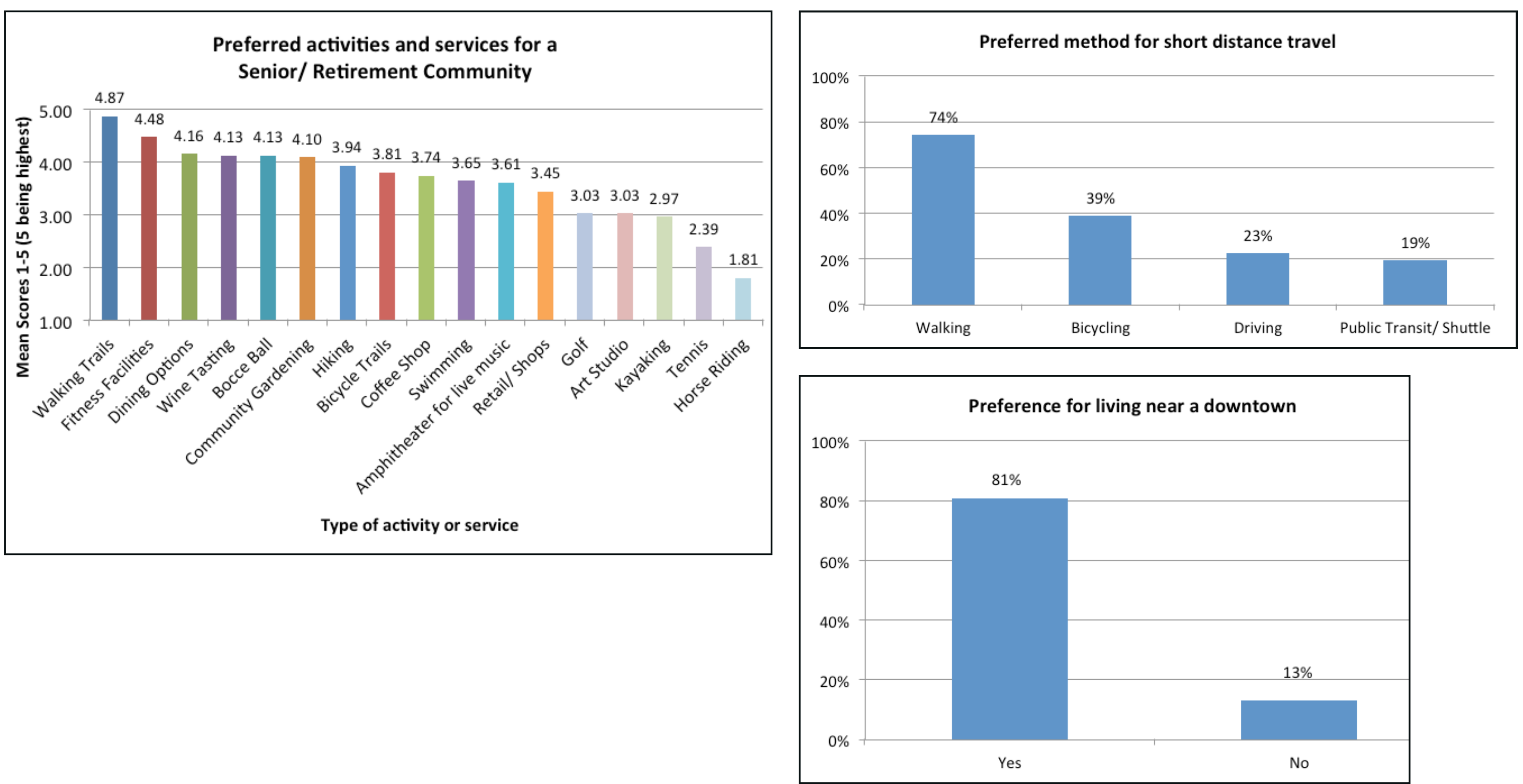


\section{Design Parameters}

In review of research and survey findings, the following list is a summary of key planning and design elements that guided the overall draft plan for the Sinclair Ranch CCRC:

1 Pedestrian-oriented community

2 Maintenance-free living and downsized accommodations

3 variety of housing options (including single family units)

4 Mixed use development

5 community center hub with a variety of amenities/ services

6 Top-notch fitness facilities

7 Walking trails and pathways to enhance connectivity and recreation

8 onsite health facilities and care 9 Variety of fine dining establishments, cocktail lounges, and wine
tasting

10 Ample open space for parks, gardens, recreation, and natural
landscaping

11 Bicycle pathways for recreation and short distance travel

12 sustainable and green design

13 Linkage to surounding community/ town 


\section{Conceptual Diagram}

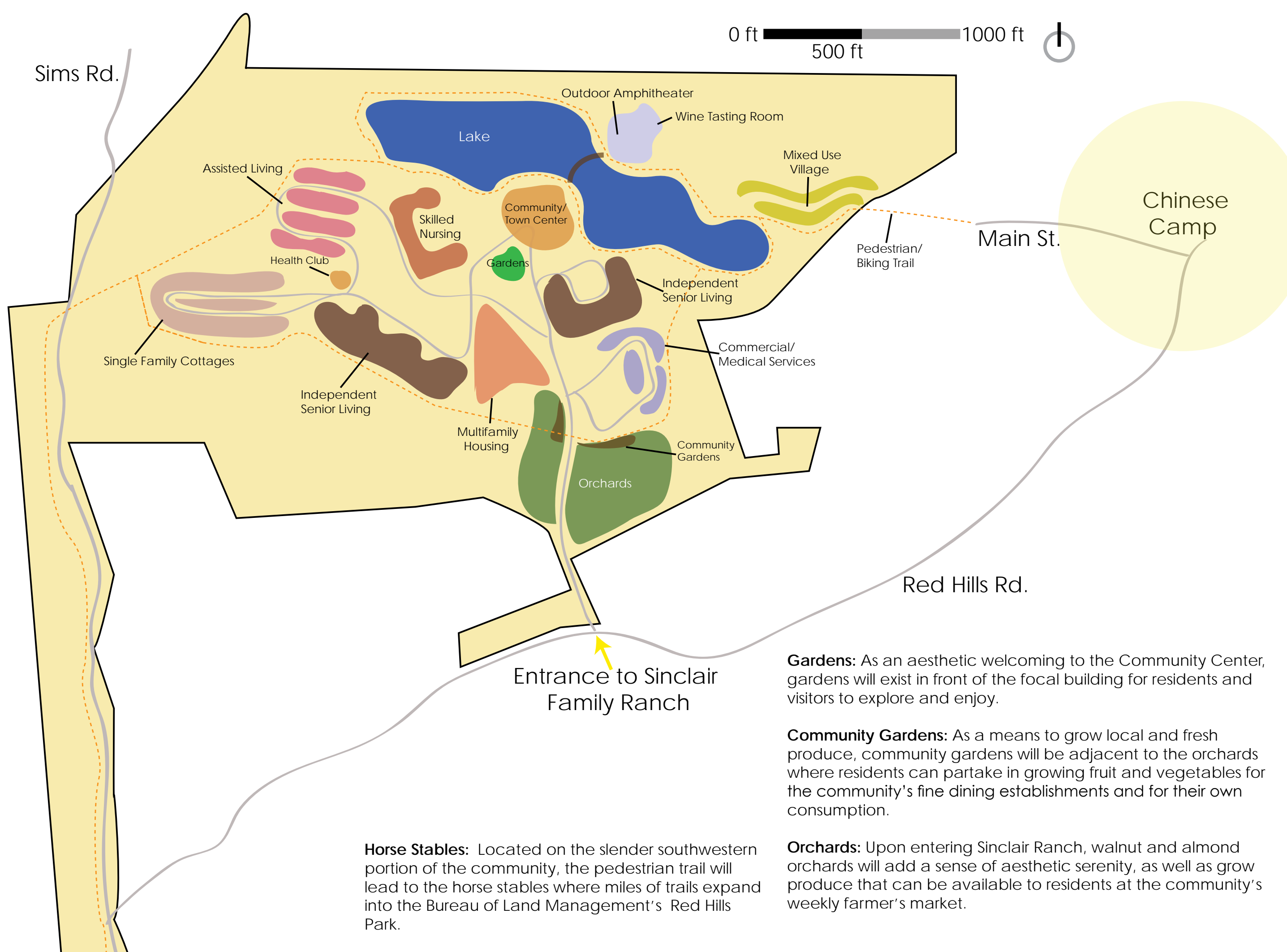

Community/ Town Center: Centrally located within the development and adjacent to the lake, the center will be the hub and focal point of social and physic al ac tivities for residents and guests.

Skilled Nursing: With prime nursing and health servic es for residents needing the most care, the Skilled Nursing facilities will be placed closest to the Community Center for easy accessibility.

Independent Senior Living: These individualized units within two story build ings will house hund reds of seniors that want to live independently, yet be close to the social and physic al activity of Assion Ling: Assised iv

Assisted Living: Assisted living residences will bridge the gap

between independent living and skilled nursing facilities. Coms , yet offer dally assistance where needed.

Single Family Cottages: Developed for the healthiest and most ac tive senior residents, these homes have the utmost privacy and active senior residents, these homes have the utmost privacy and
are located further away from the Community Center based on daily needs.

Multifamily Housing: To diversify the housing stock, a partment style units will be ava ilable to house local workers and fa milies.

Mixed Use Village: To compliment the ongoing effort to restore historic Chinese Camp as a tounist destination, the Mixed Use Village will expand Main St. into the Sinclair Ranch property towards the outdoor a mphitheater. The village will include shops, cafes, boutique hotels and bed \& breakfasts to accommodate guests and incoming tourists.

Commercial/ Medical Senvices: This center will offer a rea residents and community members key medic al services where one can see their local physician or specialist and visit the pharmacy all in one convenient location

Outdoor Amphitheater: Located just across the lake from the Community Center, the venue will be built into the hillside sloping down to the lake. At the top of the venue there will be a wine tasting Pedestrian/ Biking Trails: Placed strategic ally a round the accommodations, and focal points the trail will offer residents the chance to explore and recreate within the community. 


\section{Land Use Map}

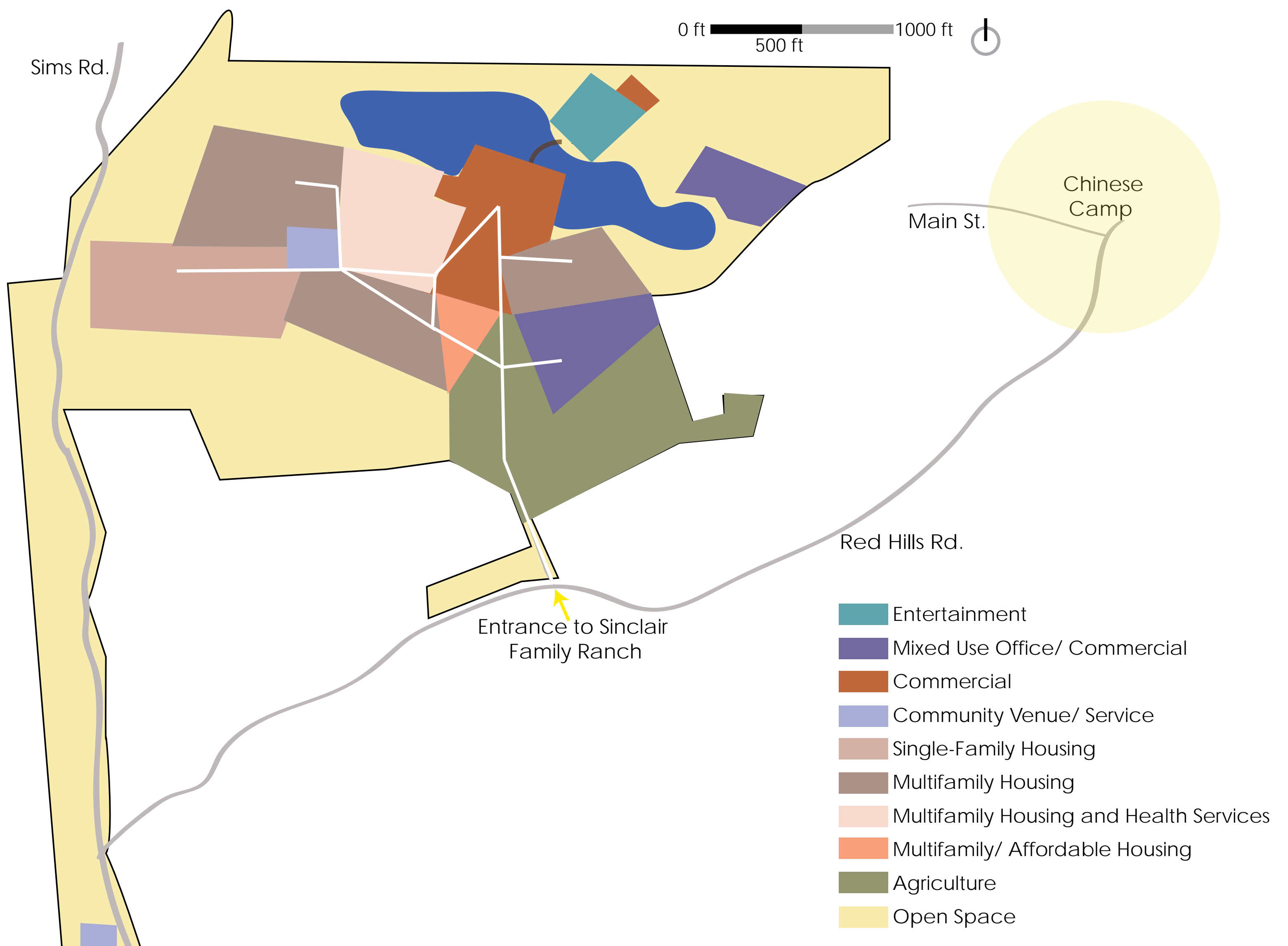




\section{Master Site Plan}

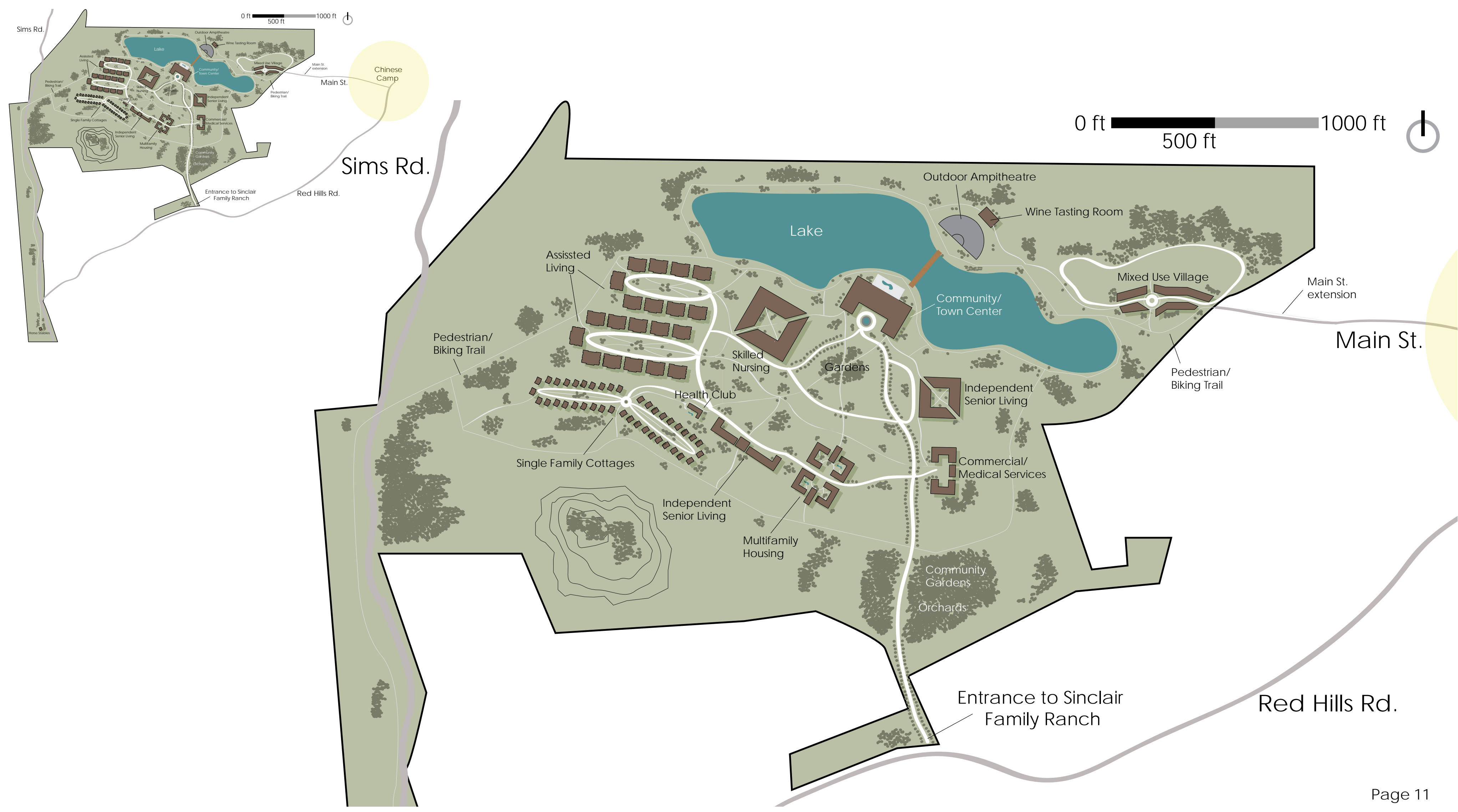




\section{Renderings}

\section{Sincla ir Ranch Draft Plan}

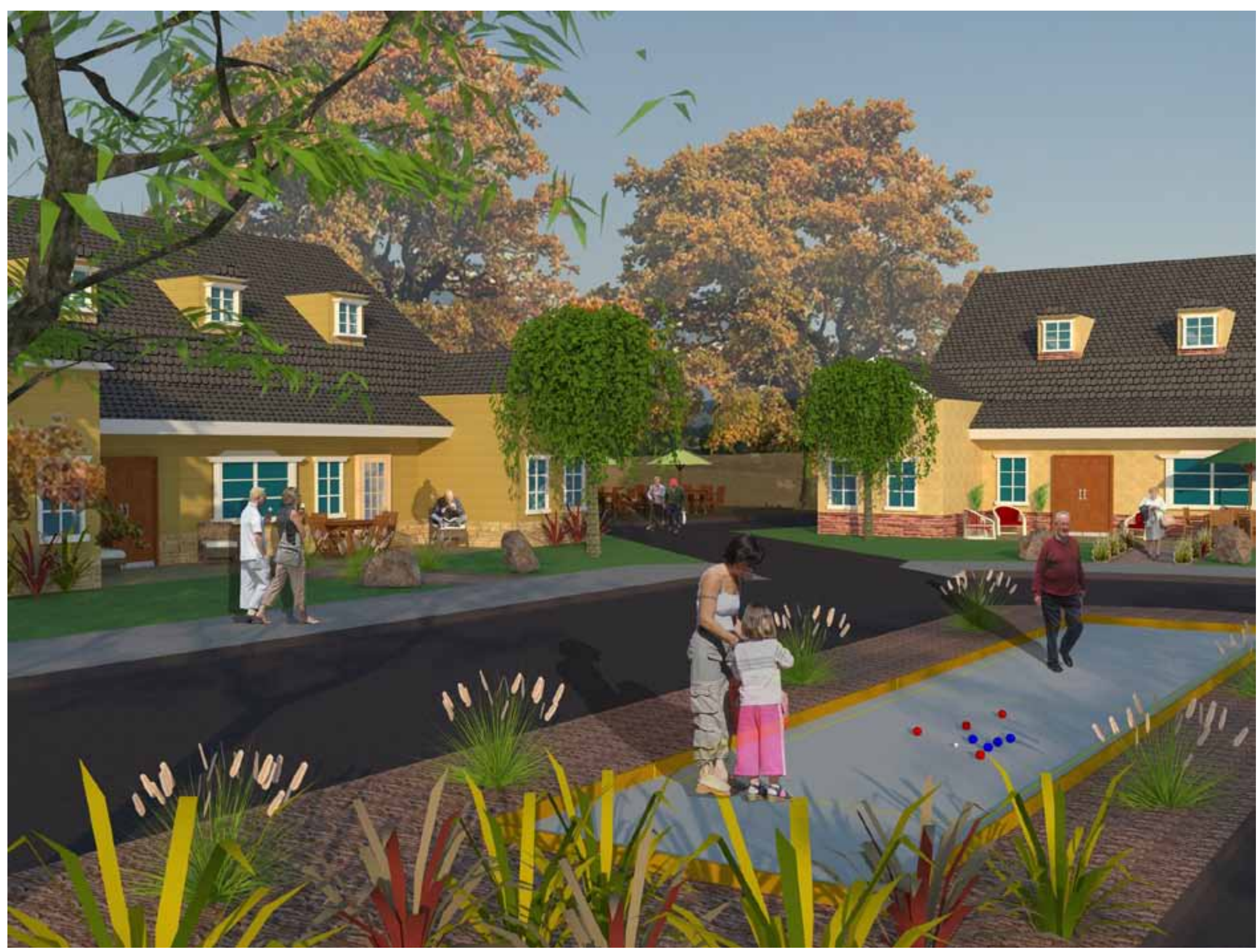

\section{Assisted Living Residences}

The Assisted Living Residences range from 5,000 s.f. communal homes where eld enly residences live together and receive the desired a mount of care and service. The residences are closely adjac ent to one a nother in order to allow socia lization and increase ac tivity with sha red elements such as bocce ball courts and outdoor sitting areas.

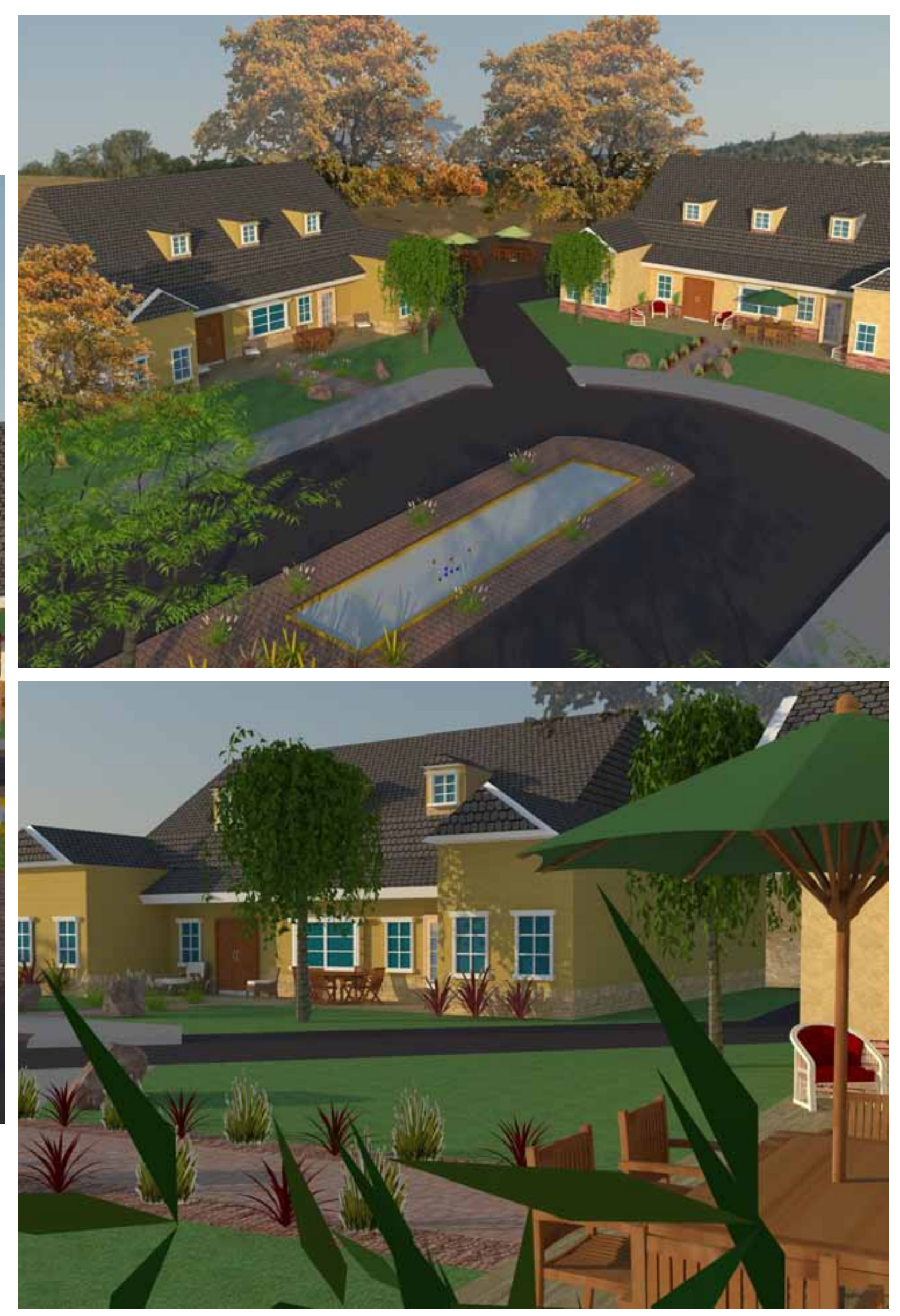




\section{Community Center}

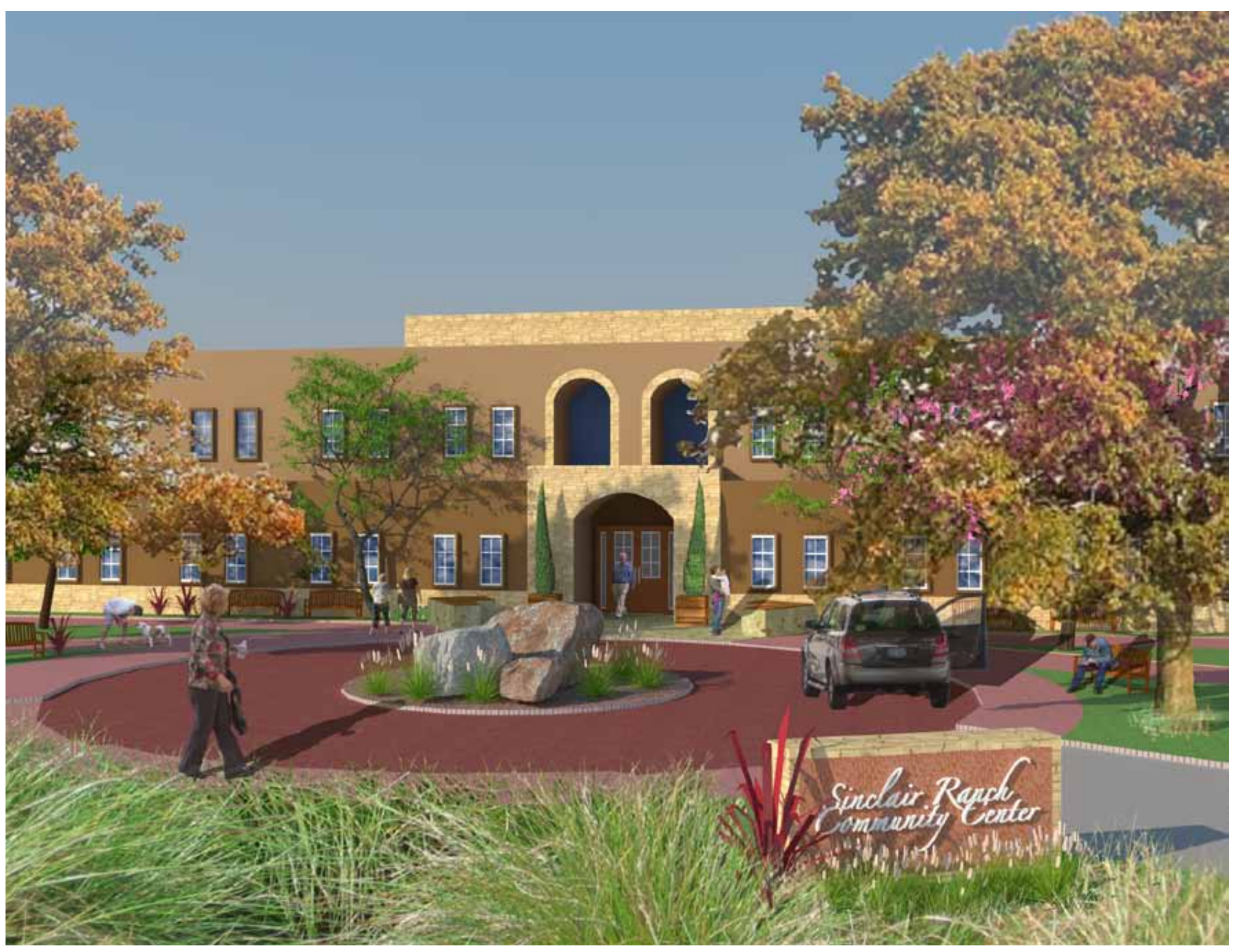

The main hub of social and physic al a c tivity, the 30,000 s.f. Community Center will house indoor and outdoor fine dining options, a coffee shop, hair and nail salon,

cocktail/ wine lounge, conference rooms and computer center, state-of-the-art fitness center, outdoor pool with cabanas, a market, and shops to accommodate a variety of needs.

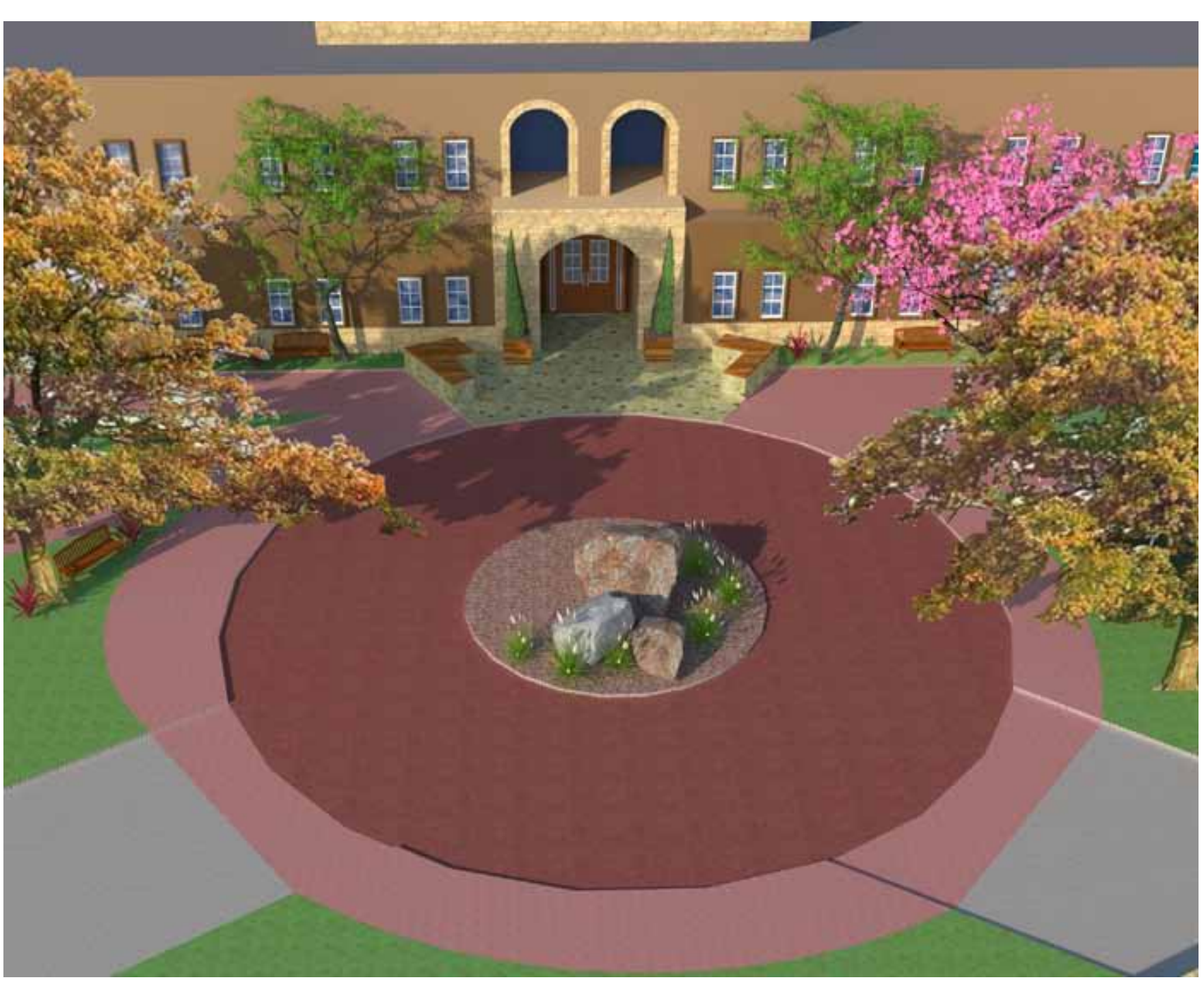




\section{Mixed Use Village}

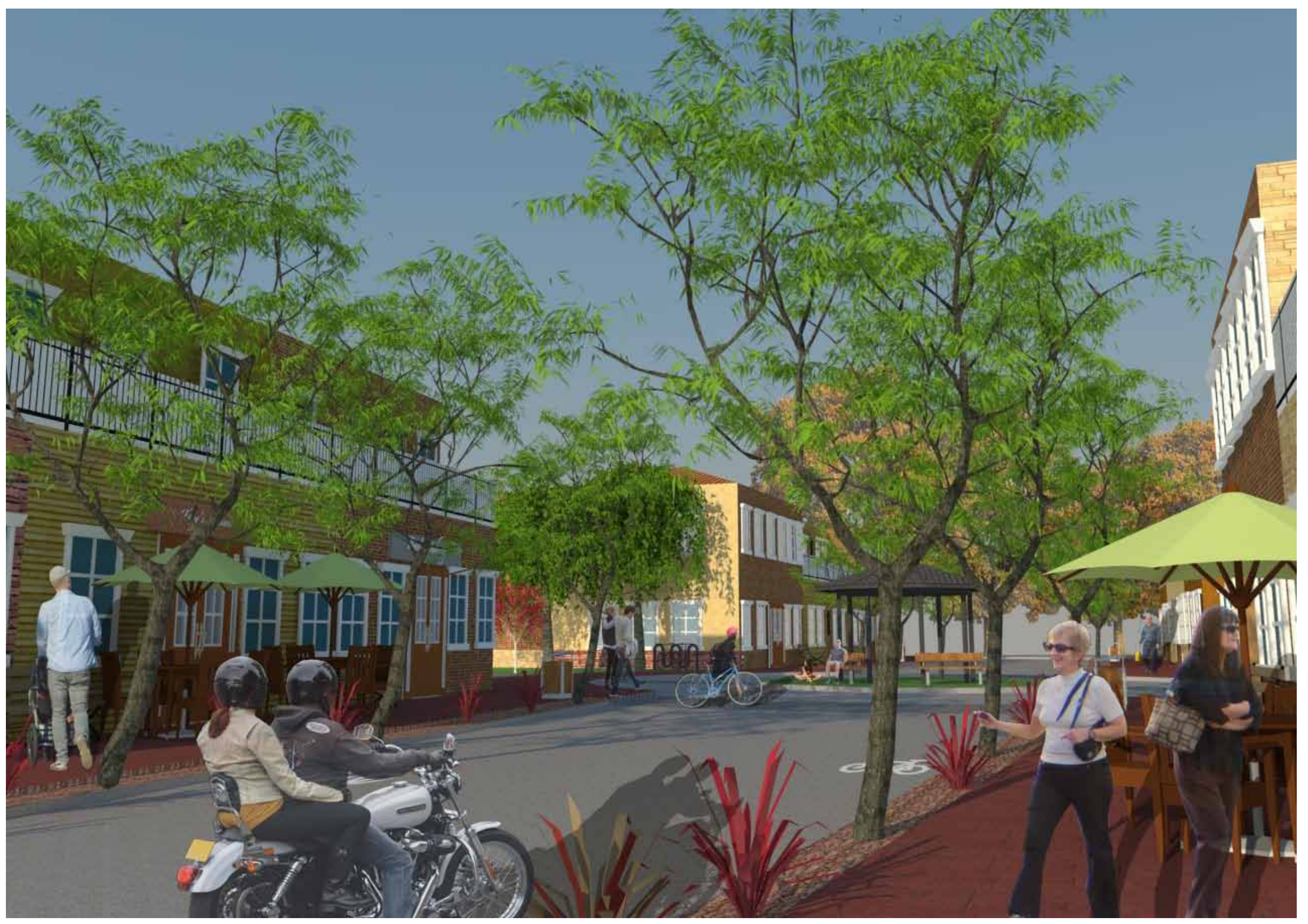

The Mixed Use Village, in addition to serving the Sincla ir Ranch community residents, will serve as a focal point for tounists and visitors with restaurants, bed \& breakfasts, shops, antiques, and community servic es. In addition, the Village will be a perfect destination for visitors to stroll through before or after attending a concert at the adjacent Sincla ir Ranch outd oor amphitheater and wine tasting venue.

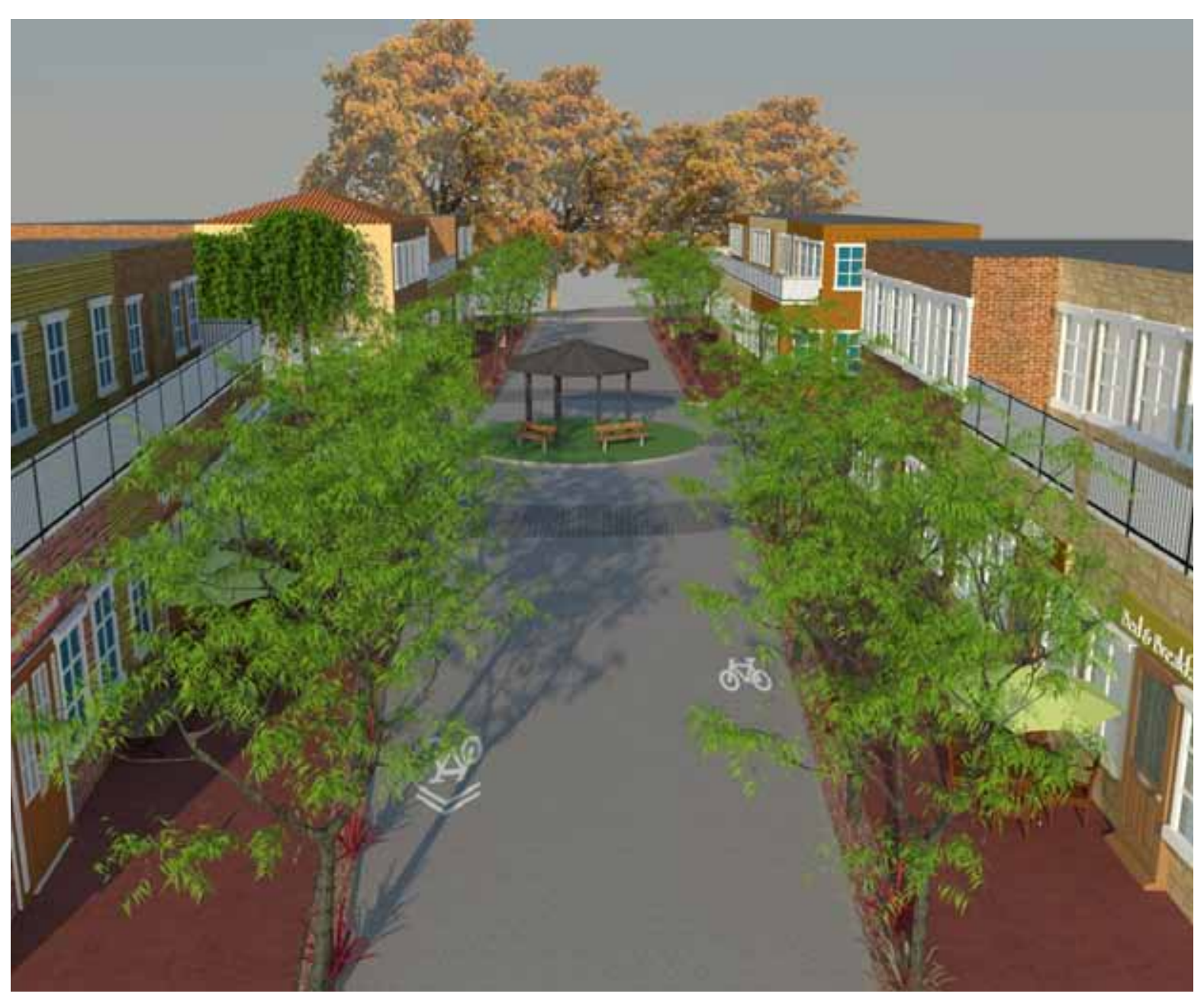




\section{Pedestrian/ Bicycle Trails}

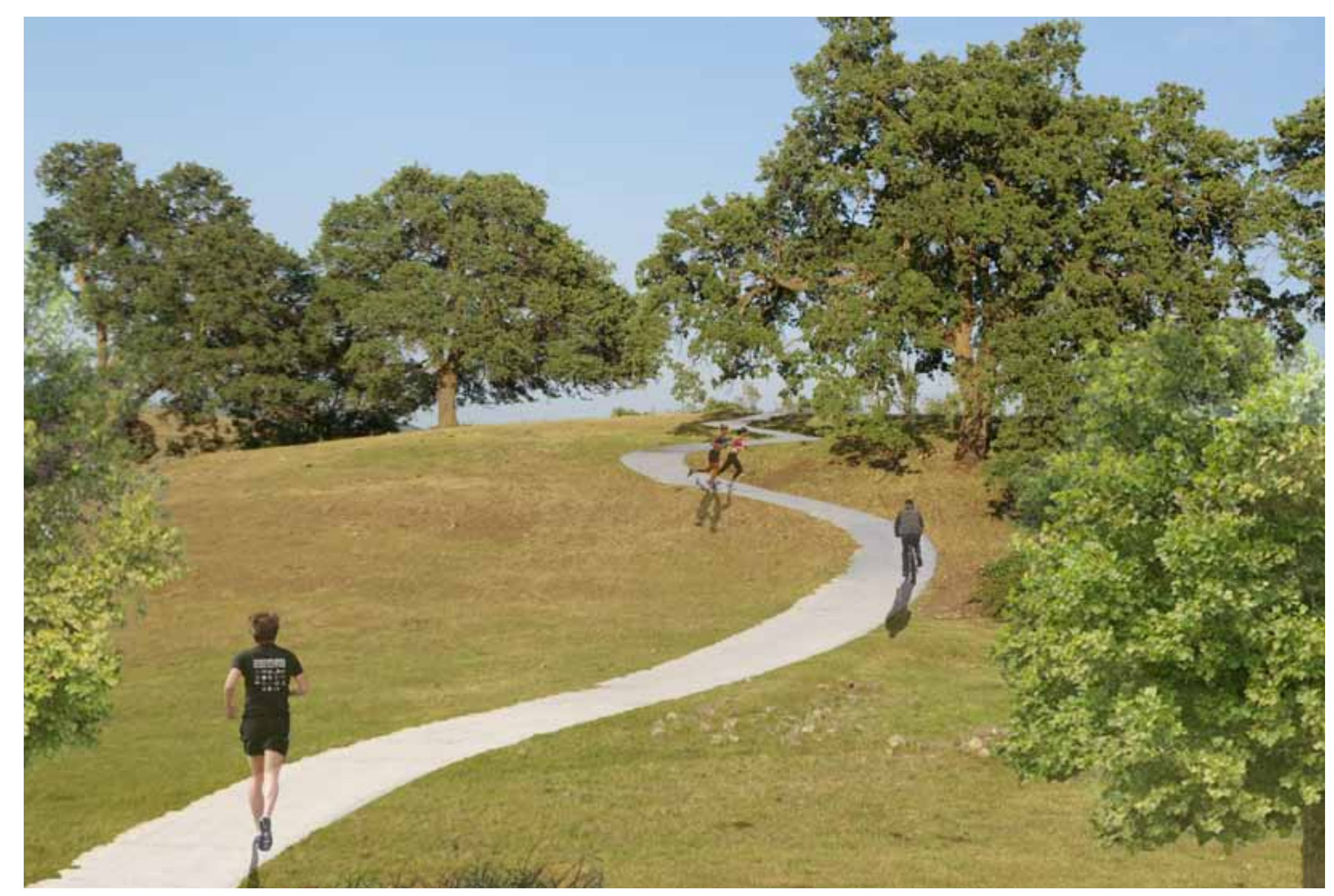

As a ma in pathway for connectivity a round the Sinclair Ranch community, the pedestrian and bicycle trails meander throughout the development and will give residents and visitors an opportunity to recreate and explore the beautiful rolling hills, the lake, and the abundance of old oak trees and native wild life.

\section{Community Gardens}

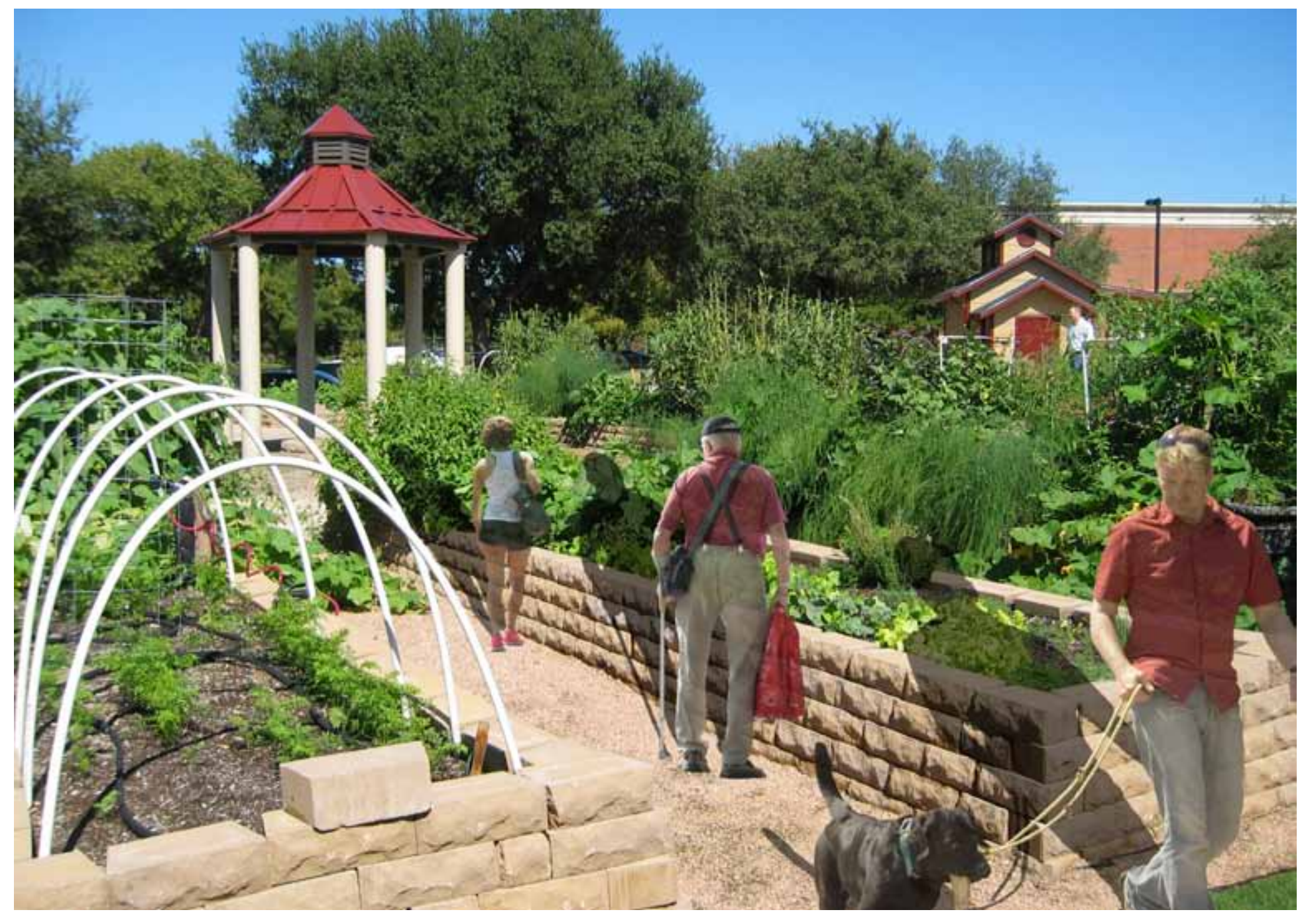

Community gardensare a great way to grow localized produce and engage the community. The fresh fruits and vegetables grown here can be utilized to prepare delic ious cuisine within one of the many Sinclair Ranch fine-dining establishments and can also be sold at the nearby Mixed Use Village Farmer's Market. 


\section{Sample Floor Plans}

The following sample floor plans are examples from preexisting plans and other communities that serve as an exemplary model for Sinclair Ranch.
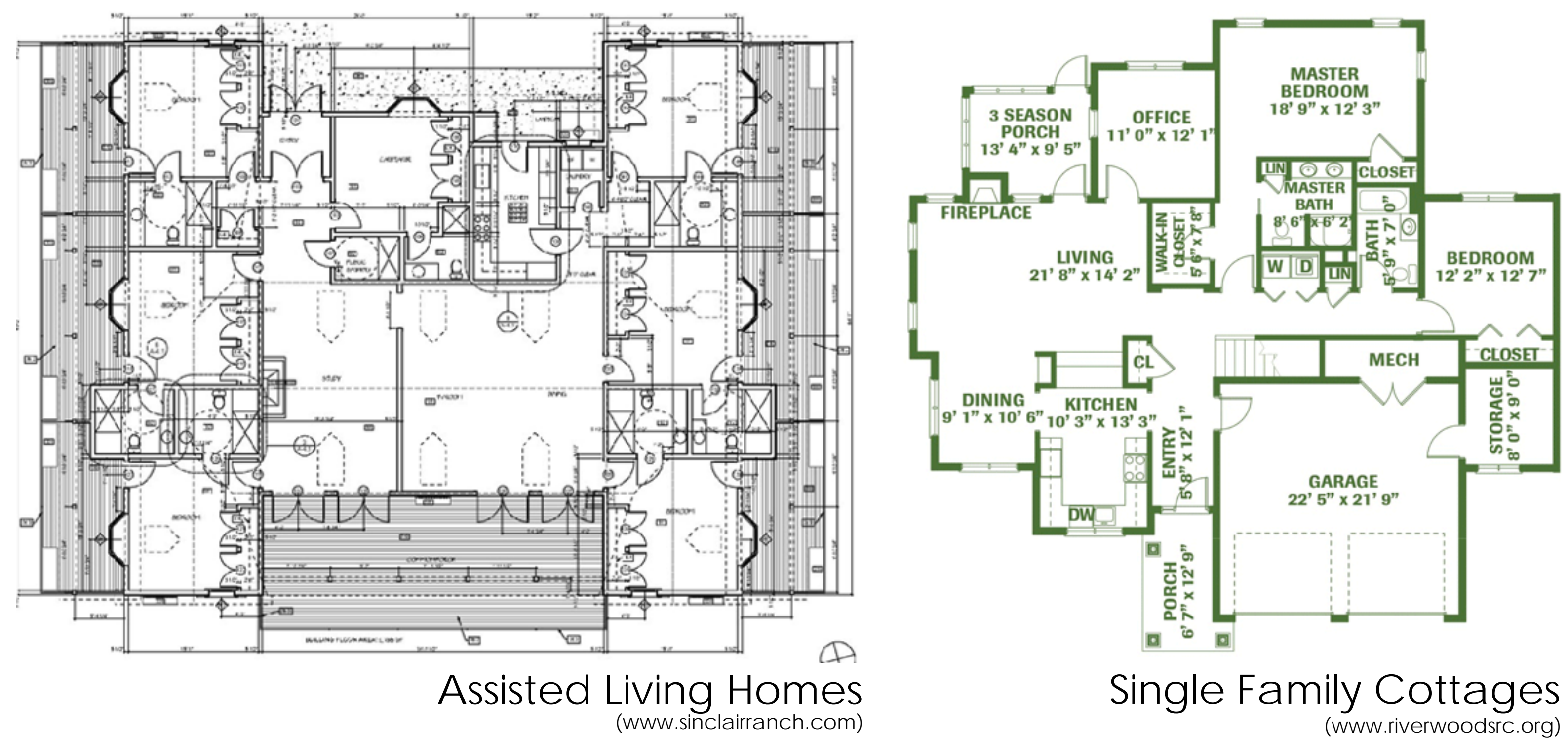

(www.riverwoodsrc.org) 


\section{Sample Street Fumiture}

Community benches Trash Cans

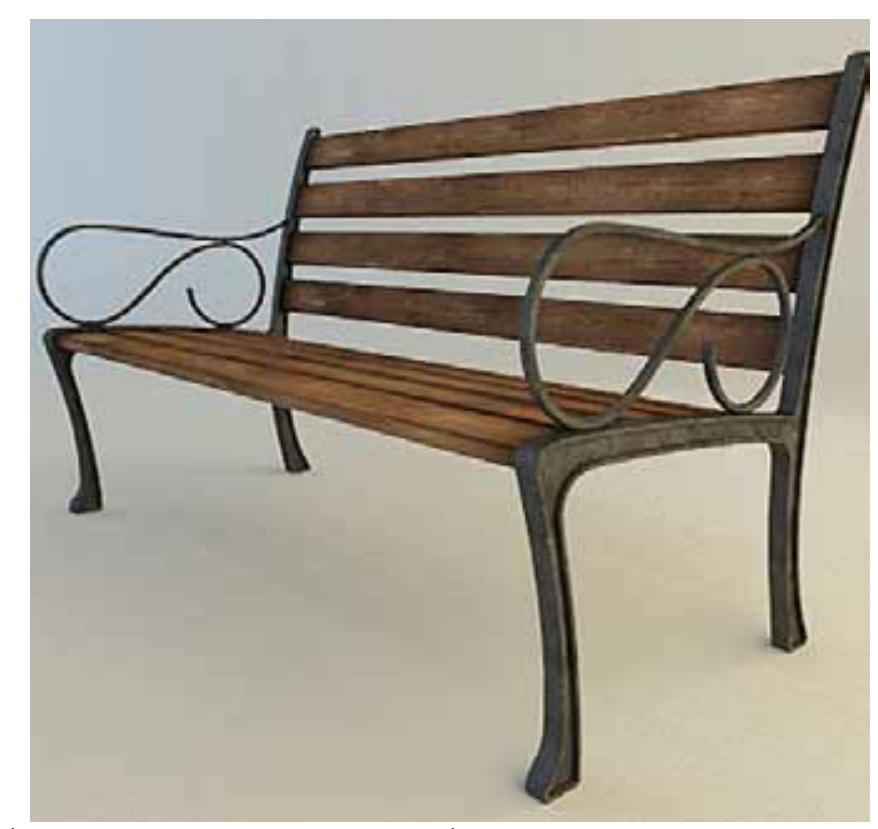

(www.turbosquid.com)

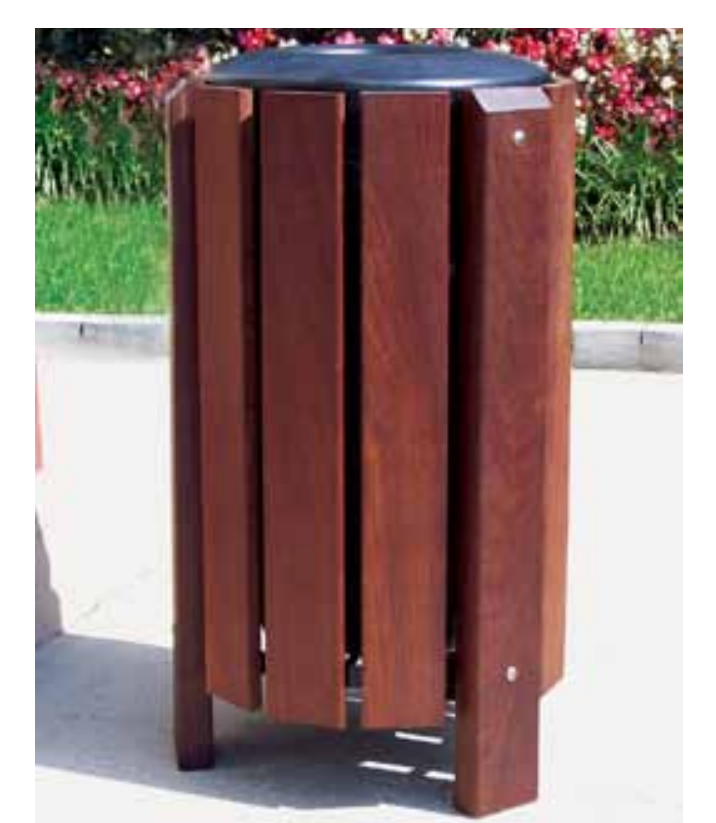

(www.siteessentialsc ompany.com)

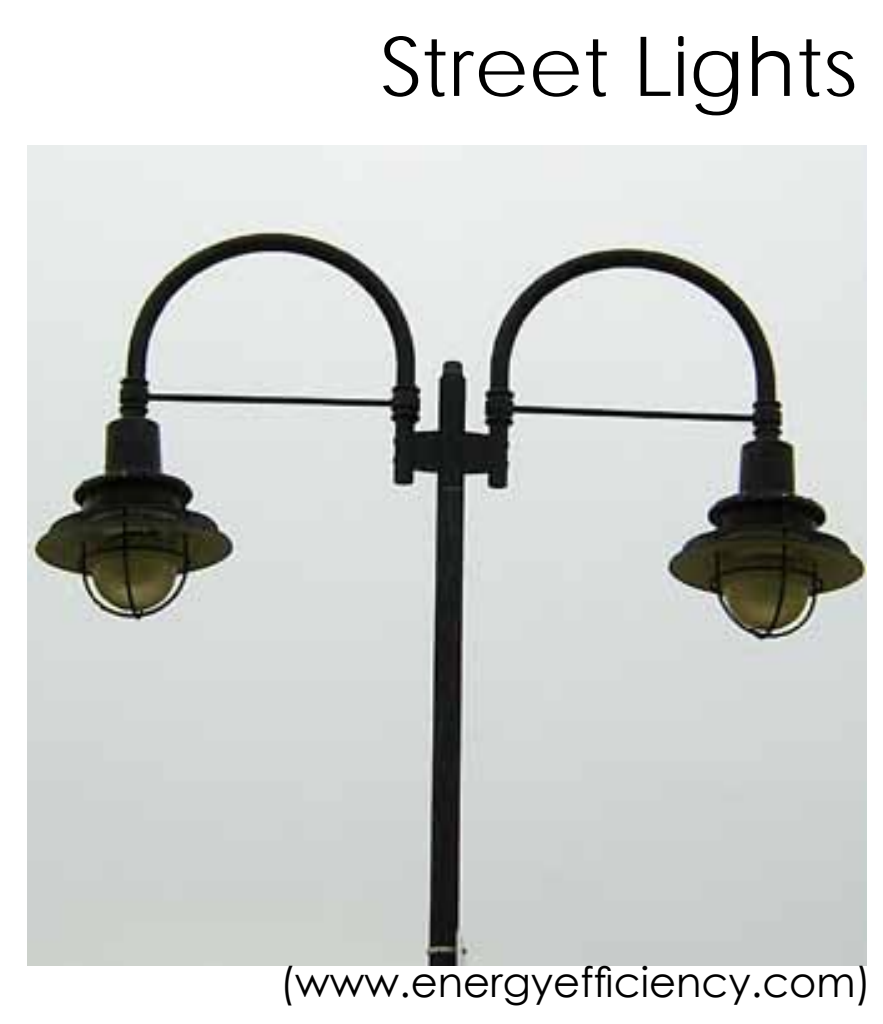

Bicycle Racks

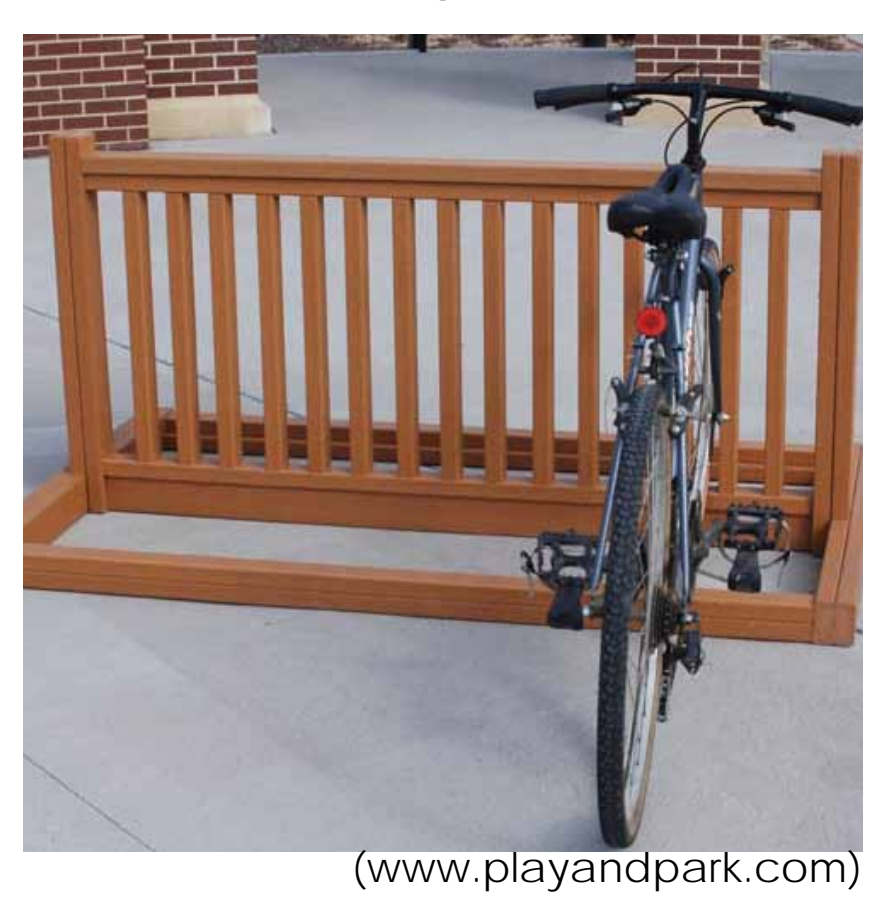




\section{Summary}

In esta blishing initial design pa ra meters for the Sincla ir Ranch design proposal, each element was

utilized throughout the design process and are identified throughout the community as follows:

1. Pedestrian-oriented community

\section{Maintenance-free living and downsized accommodations}

5 Community center hub with a variety of a menities/ services

6 Top-notch fitness facilities

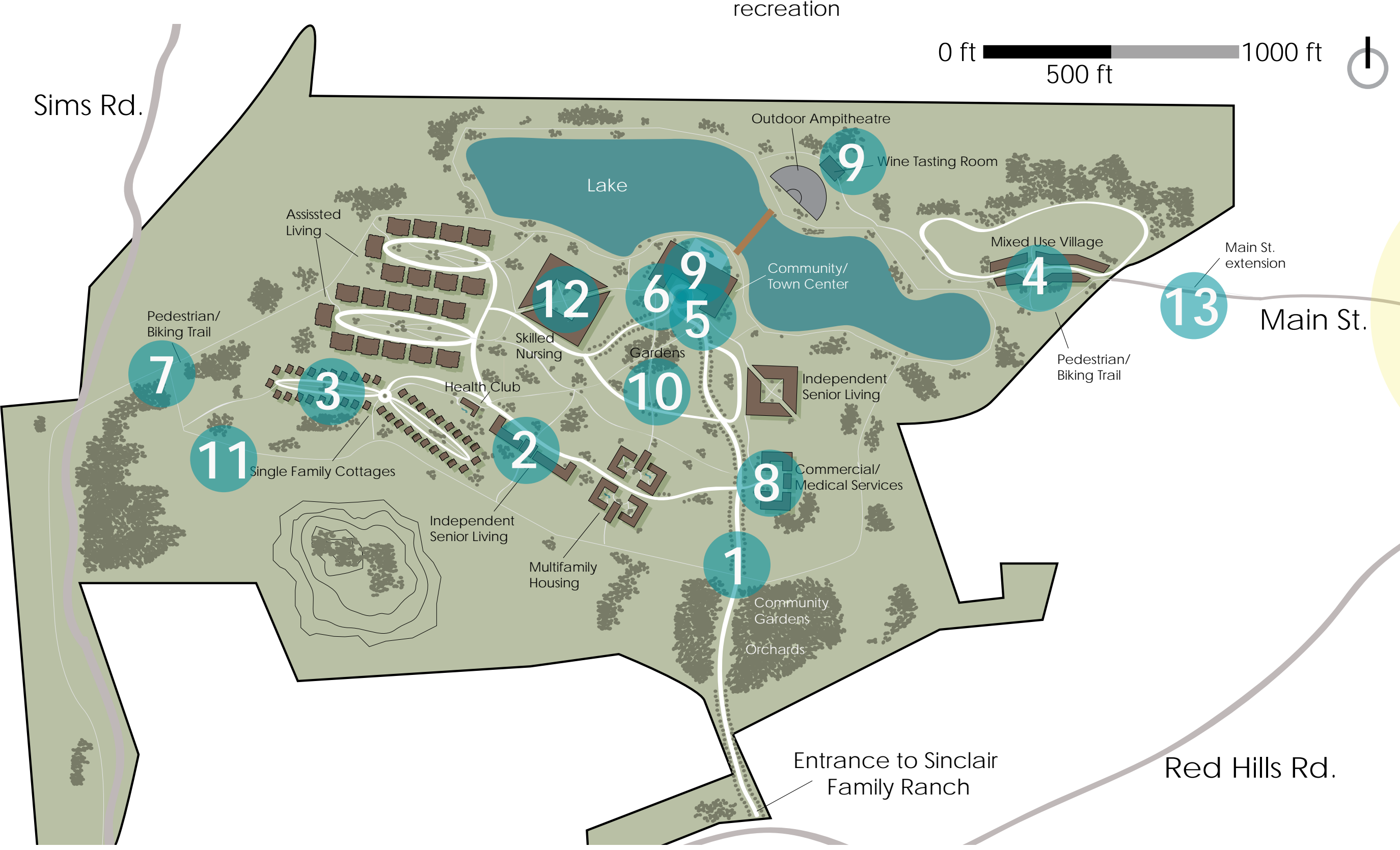

9 Variety of fine dining establishments, cockta il lounges, and wine tasting
3 Va riety of housing options (including single family units)

7 Wa lking trails and pathways to enhance connectivity and

4 Mixed use development

8 Onsite health facilities and care
10 Ample open space for parks, gardens, recreation, and natural landscaping
11 Bicycle pathways for recreation and short distance travel
13 Linkage to surrounding community/ town 


\section{References}

Abbott, P. S., Carman, N., Caman, J., \& Scarfo, B. (2009). Re-creating neighborhoods for successful again. Baltimore: Health Professions Press, Inc

Abrahms, S. (2012). Senior centers evolve to attract boomers. AARP Bulletin. Bamett, M. D. (2010). Future expectations a mong older adults in independent living retirement communities. University
of Houston. ProQuest Dissertations and Theses, 79 .

Bryant, T. (2011). As ba by boomers retire, senior housing ada pts. McClatchy - Tribune Business News.

Carstens, D. (1993). Site planning and design for the elderly: issues, guidelines, and altematives. New York: Van Nostrand Reinhold.

Golant, S., Hyde, J . (2008). The assisted living residenc e: A vision for the future. Baltimore: The J ohn Hopkins University Press.

Greene, K. (2010, Aug 07). Weekend Investor - the new basic s- fa mily value: Continuing-care retirement communities: weighing the risks. Wall street joumal, pp. B.8. Retrieved from http://search.proquest.com/doc view/740167969

Haas, W., \& Serow, W. (2002). The baby boom, amenity retirement migration, and retirement communities: Will the golden age of retirement continue? Research on aging. Retrieved from

http://roa.sage pub.com/content/24/1/150

Harigan, J. E. (1998). Senior residenc es: Designing retirement c ommunities for the future. New York: J ohn Wiley

Hunt, K. (2012). The new senior housing market. J oumal of property management, 77(3), 19-23.

Lynn, D., Wang, T. (2008). The U.S. senior housing opportunity: Investment strategies. Real Estate Issues, 33(2), 33-51.

Perkins, B. (2004). Build ing type basics for senior living. Hoboken: J ohn Wiley \& Sons, Inc.

The RiverWoods (n.d.). Retrieved from http://www.riverwoodsrc .org

Sbranti, J (2006, Oct 28). Active market: Senior communities cater to on-the-go boomers seeking low-maintenance retirement. McClatchy - Tribune Business News, pp. 1-1. Retrieved from

Spears, S. (1992). The continuing care residential community. New York: Springer Publishing Company.

Trilogy at Monarch Dunes. (n.d.). Retrieved from http://www.trilogylife.com/communities/califo mia/monarchdunes

Stroud, H. (1995). The promise of paradise: Rec reational and retirement communities in the united states since 1950. Baltimore: The J ohn Hopkins University Press.

U.S. Census Bureau. (2010). Decennial census of population 1990-2010. Retrieved from

htp/l:www.censusgov/prod/1/pop/p23-190/p23-190.pdf 


\section{Baby Boomer Living \\ Retirement Lifestyle Preferences Survey}

Baby Boomers, born between 1946 and 1964, are the largest generation in U.S. History with a population of over 82.8 million people. This vast group is currently in the midst of retirement, and thus it is the objective of this survey to better understand lifestyle preferences for those contemplating retirement communities and active adult communities. Information gathered from this survey will be analyzed to help guide and develop an ideal retirement community "prototype" that strives to meet the demands and needs of Baby Boomers. Thank you for taking this survey!

Sex: $\square$ Male $\square$ Female

Age: $\square 45-49 \square 50-54 \square 55-59 \square 60-64 \square 65+$

What type of accommodation do you currently reside in? (Please check one)

Single Family House

Multi-family House

Condominium

Apartment

Senior/ Retirement Community Other

Have you ever considered living in a retirement or active adult community?

Yes / No

Do you find retirement or active adult communities to be an attractive option to live in?

Yes / No

If you responded "No" to the above question, please mention why:

What type of housing would you find most appealing for a retirement community to offer?

Single-family housing

Condominiums

Apartments

Mixed Use (variety of the above)

Other
On a scale of $1-5$ ( 5 being the most favorable and 1 being least favorable), please rate the following activities and/or services that a retirement or active adult community should offer:

Fitness Facilities

Bicycle Trails

Community Gardening

Walking Trails

Horse Riding

Wine Tasting

Hiking

Amphitheater for live music

Bocce Ball

Tennis

Golf

Swimming

Kayaking

Retail/ Shops

Coffee Shop

Dining Options

Art Studio

Are there any additional activities or services that a community should offer?

On a scale of 1-5 (5 being the highest and 1 the lowest), please rate the following reasons why you would consider moving into a retirement community:

Downsizing

Sense of Place/ Community

Amenities

Elderly Care and Service

Maintenance-free living

Other

Other 
Are on site health services and personalized care important options for you to have when looking at retirement or active adult communities?

Yes / No

According to your preference, please prioritize and rank the following 10 features $1-10$ ( 1 being the highest ranking and 10 being the lowest):

Water Features

Plazas

Gardens

Public Art

Gated Entry

Landscaping

Lighting

Park/ Open Space

Paved Pathways

Agricultural Space

Are there any additional features that a community should offer?

Thank you for taking the time to complete this survey! If you have any additional comments regarding retiremen pr active adult communities, please feel free to use the below space. Your feedback is greatly appreciated.
Which of the following architectural styles would you prefer for a retirement or active adult community in the Sierra Nevada foothills of California? (Choose one)

Modern/ Contemporary Spanish/Mission Style Consistent with surrounding environment Other

When choosing a retirement or active adult community, is close proximity to a downtown or town center of high importance?

Yes / No

What is your preferred method of getting around within short distances ( $<$ than a mile)?

Walking

Bicycling

Driving

Public Transit/ Shuttle Service Other

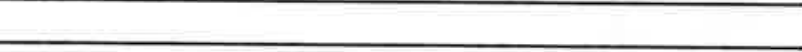




\section{Baby Boomer Living \\ Retirement Lifestyle Preferences Survey}

Baby Boomers, born between 1946 and 1964 , are the largest generation in U.S. History with a population of over 82.8 million people. This vast group is currently in the midst of retirement, and thus it is the objective of this survey to better understand lifestyle preferences for those contemplating retirement communities and active adult communities. Information gathered from this survey will be analyzed to help guide and develop an ideal retirement community "prototype" that strives to meet the demands and needs of Baby Boomers. Thank you for taking this survey!

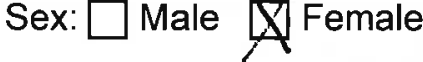

Age: $\square 45-49 \square 50-54 \not \mid 55-59 \square 60-64 \square 65+$

What type of accommodation do you currently reside in? (Please check one)

X' Single Family House

Multi-family House

Condominium

Apartment

Senior/ Retirement Community Other

Have you ever considered living in a retirement or active adult community?

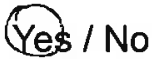

Do you find retirement or active adult communities to be an attractive option to live in?

$$
\text { Yes/No }
$$

If you responded "No" to the above question, please mention why:

What type of housing would you find most appealing for a retirement community to offer?

Single-family housing

X Condominiums Apartments

X Mixed Use (variety of the above) Other
On a scale of 1-5 ( 5 being the most favorable and 1 being least favorable), please rate the following activities and/or services that a retirement or active adult community should offer:

5 Fitness Facilities

5 Bicycle Trails

5 Community Gardening

$\frac{5}{5}$ Walking Trails

5 Horse Riding

4 Wine Tasting

5 Hiking

4 Amphitheater for live music

5 Bocce Ball

4 Tennis

5 Golf

S Swimming

5 Kayaking

4 Retail/ Shops

4 Coffee Shop

4 Dining Options

4 Art Studio

Are there any additional activities or services that a community should offer?

On a scale of $1-5$ ( 5 being the highest and 1 the lowest), please rate the following reasons why you would consider moving into a retirement community:

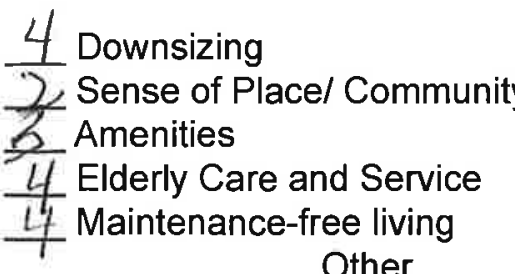
Other Other 
Are on site health services and personalized care important options for you to have when looking at retirement or active adult communities?

Yes / No

According to your preference, please prioritize and rank the following 10 features $1-10$ ( 1 being the highest ranking and 10 being the lowest):

\section{Water Features \\ 8 Plazas \\ 5 Gardens \\ 10 Public Art \\ 1 Gated Entry \\ 2 Landscaping \\ 3 Lighting \\ 4 Park/ Open Space \\ 6 Paved Pathways \\ $q$ Agricultural Space}

Are there any additional features that a community should offer?
Which of the following architectural styles would you prefer for a retirement or active adult community in the Sierra Nevada foothills of California?

(Choose one)

Modern/ Contemporary

Spanish/Mission Style

Consistent with surrounding environment Other

When choosing a retirement or active adult community, is close proximity to a downtown or town center of high importance?

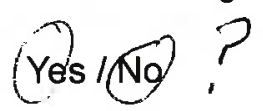

What is your preferred method of getting around within short distances ( $<$ than a mile)?

Walking

Bicycling

Driving

Public Transit/ Shuttle Service Other

Thank you for taking the time to complete this survey! If you have any additional comments regarding retirement or active adult communities, please feel free to use the below space. Your feedback is greatly appreciated. 


\section{Baby Boomer Living \\ Retirement Lifestyle Preferences Survey}

Baby Boomers, born between 1946 and 1964, are the largest generation in U.S. History with a population of over 82.8 million people. This vast group is currently in the midst of retirement, and thus it is the objective of this survey to better understand lifestyle preferences for those contemplating retirement communities and active adult communities. Information gathered from this survey will be analyzed to help guide and develop an ideal retirement community "prototype" that strives to meet the demands and needs of Baby Boomers. Thank you for taking this survey!

Sex: $\square$ Male $\square$ Female

Age: $\square$ 45-49 $\square 50-54 \square 55-59 \square 60-64 \square 65+\square$

What type of accommodation do you currently

reside in? (Please check one)

$\sqrt{ }$ Single Family House

Multi-family House

Condominium

Apartment

Senior/ Retirement Community

Other

Have you ever considered living in a retirement or active adult community?

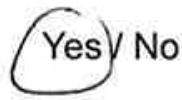

Do you find retirement or active adult communities to be an attractive option to live in?

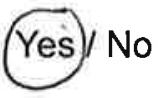

If you responded "No" to the above question, please mention why:

What type of housing would you find most appealing for a retirement community to offer?

Single-family housing

Condominiums

Apartments

Mixed Use (variety of the above)

Other
On a scale of 1-5 ( 5 being the most favorable and 1 being least favorable), please rate the following activities and/or services that a retirement or active adult community should offer:

5 Fitness Facilities

1 Bicycle Trails

5 Community Gardening

5 Walking Trails

$\frac{1}{5}$ Horse Riding

5 Wine Tasting

1 Hiking

(Amphitheater for live music

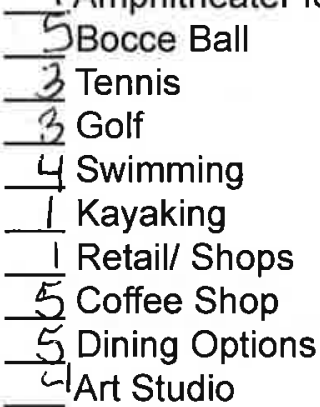

Are there any additional activities or services that a community should offer?

On a scale of $1-5$ ( 5 being the highest and 1 the lowest), please rate the following reasons why you would consider moving into a retirement community:

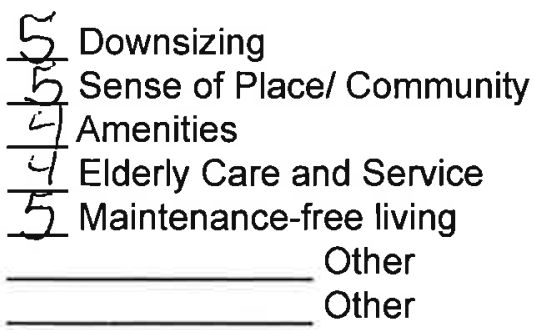


Are on site health services and personalized care important options for you to have when looking at retirement or active adult communities?

$$
\text { Yes No }
$$

According to your preference, please prioritize and rank the following 10 features $1-10$ ( 1 being the highest ranking and 10 being the lowest):

\footnotetext{
7 water Features

5 Plazas

10 Gardens

IPublic Art

9 Gated Entry

8 Landscaping

3 Lighting

4 Park/ Open Space

6 Paved Pathways

Agricultural Space
}

Are there any additional features that a community should offer?

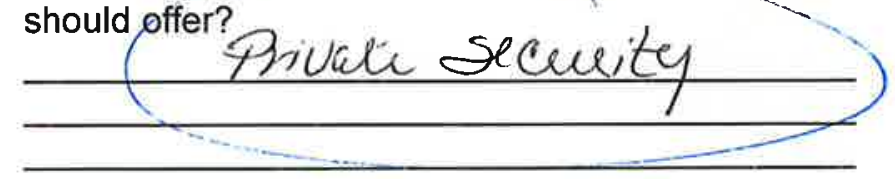

Which of the following architectural styles would you prefer for a retirement or active adult community in the Sierra Nevada foothills of California?

(Choose one)

Modern/ Contemporary

$\checkmark$ Spanish/Mission Style

Consistent with surrounding environment Other

When choosing a retirement or active adult community, is close proximity to a downtown or town center of high importance?

$$
\text { (Yes)! No }
$$

What is your preferred method of getting around within short distances (< than a mile)?

Walking

Bicycling

Driving

Public Transit/ Shuttle Service Other

Thank you for taking the time to complete this survey! If you have any additional comments regarding retirement or active adult communities, please feel free to use the below space. Your feedback is greatly appreciated. 


\section{Baby Boomer Living \\ Retirement Lifestyle Preferences Survey}

Baby Boomers, born between 1946 and 1964 , are the largest generation in U.S. History with a population of over 82.8 million people. This vast group is currently in the midst of retirement, and thus it is the objective of this survey to better understand lifestyle preferences for those contemplating retirement communities and active adult communities. Information gathered from this survey will be analyzed to help guide and develop an ideal retirement community "prototype" that strives to meet the demands and needs of Baby Boomers. Thank you for taking this survey!

Sex: $\not \mathbf{X}$ Male $\square$ Female

Age: $\square$ 45-49 $\square 50-54 \square 55-59 \square 60-64 \backslash 65+$

What type of accommodation do you currently reside in? (Please check one)

X Single Family House Multi-family House Condominium Apartment Senior/ Retirement Community Other

Have you ever considered living in a retirement or active adult community?<smiles>O=[N+]([O-])C1CC2CCC1C2</smiles>

Do you find retirement or active adult communities to be an attractive option to live in?

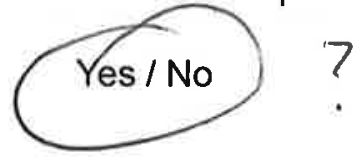

If you responded "No" to the above question, please mention why:

What type of housing would you find most appealing for a retirement community to offer?

Single-family housing Condominiums Apartments \Mixed Use (variety of the above) Other
On a scale of $1-5$ ( 5 being the most favorable and 1 being least favorable), please rate the following activities and/or services that a retirement or active adult community should offer:

4 Fitness Facilities

2 Bicycle Trails

2 Community Gardening

$\zeta$ Walking Trails

Horse Riding

12 Wine Tasting

2 Hiking

3Amphitheater for live music

S Bocce Ball

3 Tennis

3 Golf

4. Swimming

4 Kayaking

2Retail/ Shops

3 Coffee Shop

3 Dining Options

2ATt Studio

Are there any additional activities or services that a community should offer?

On a scale of $1-5$ ( 5 being the highest and 1 the lowest), please rate the following reasons why you would consider moving into a retirement community:

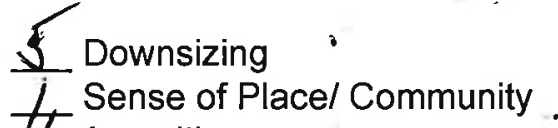

7 Amenities

3 Elderly Care and Service.

4 Maintenance-free living. Other Other 
Are on site health services and personalized care important options for you to hàve when looking at retirement or active adult commúnities?<smiles>[R5]S(=O)(=O)NCCCC</smiles>

According to your preference, please prioritize and rank the following 10 features $1-10$ (1 being the highest ranking and 10 being the lowest):

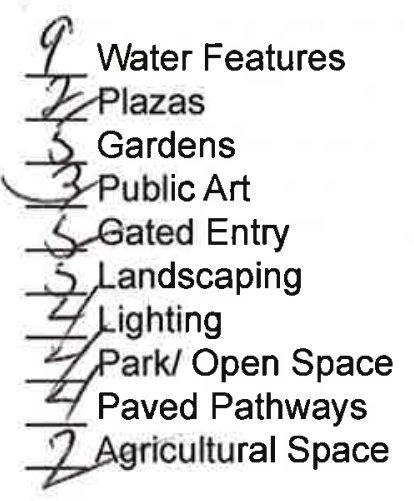

Are there any additional features that a community should offer?
Which of the following architectural styles would you prefer for a retirement or active adult community in the Sierra Nevada foothills of California? (Choose one)

Modern/ Contemporary Spanish/Mission Style

X Consistent with surrounding environment Other

When choosing a retirement or active adult community, is close proximity to a downtown or town center of high importance?

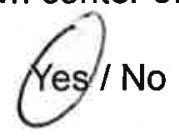

What is your preferred method of getting around within short distances $(<$ than a mile)?

Walking

Bicycling .

Driving

Public Transit/ Shuttle Service Other

Thank you for taking the time to complete this survey! If you have any additional comments regarding retirement or active adult communities, please feel free to use the below space. Your feedback is greatly appreciated. 


\section{Baby Boomer Living \\ Retirement Lifestyle Preferences Survey}

Baby Boomers, born between 1946 and 1964, are the largest generation in U.S. History with a population of over 82.8 million people. This vast group is currently in the midst of retirement, and thus it is the objective of this survey to better understand lifestyle preferences for those contemplating retirement communities and active adult communities. Information gathered from this survey will be analyzed to help guide and develop an ideal retirement community "prototype" that strives to meet the demands and needs of Baby Boomers. Thank you for taking this survey!

Sex: $\square$ Male $\triangle$ Female

Age: $\square$ 45-49 $\square 50-54 \square 55-59 \square 60-64 \otimes 65+$

What type of accommodation do you currently reside in? (Please check one)

Single Family House
Multi-family House
Condominium
Apartment Senior/ Retirement Community Other

Have you ever considered living in a retirement or active adult community?

Yes $/(10)$

Do you find retirement or active adult communities to be an attractive option to live in?

Yes / No

If you responded "No" to the above question, please mention why:

$\frac{\text { Like my ow }}{\text { Space }}$

What type of housing would you find most appealing for a retirement community to offer?

Single-family housing

Condominiums

Apartments

Mixed Use (variety of the above) Other
On a scale of 1-5 (5 being the most favorable and 1 being least favorable), please rate the following activities and/or services that a retirement or active adult community should offer:

5 Fitness Facilities

1 Bicycle Trails

$\overline{5}$ Community Gardening

5 Walking Trails

1 Horse Riding

1 Wine Tasting

$\perp$ Hiking

5 Amphitheater for live music

5 Bocce Ball

1 Tennis

1 Golf

5 Swimming

1 Kayaking

5 Retail/ Shops

5 Coffee Shop

5 Dining Options

5 Art Studio

Are there any additional activities or services that a community should offer?

On a scale of 1-5 (5 being the highest and 1 the lowest), please rate the following reasons why you would consider moving into a retirement community:

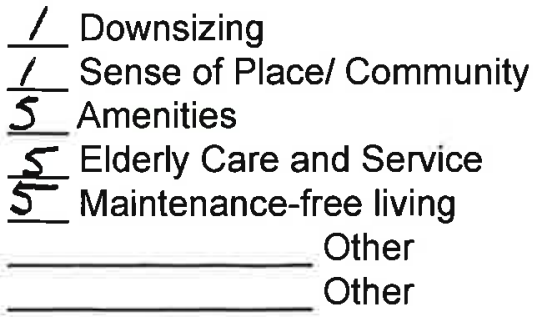


Are on site health services and personalized care important options for you to have when looking at retirement or active adult communities?

$$
\text { Yes' No }
$$

According to your preference, please prioritize and rank the following 10 features $1-10$ ( 1 being the highest ranking and 10 being the lowest):

\section{Water Features \\ 5 Plazas \\ 5 Gardens \\ 1 Public Art \\ 5 Gated Entry \\ 5 Landscaping \\ 5 Lighting \\ $\$$ Park/ Open Space \\ 5 Paved Pathways \\ $\perp$ Agricultural Space}

Are there any additional features that a community should offer?

Thank you for taking the time to complete this survey! If you have any additional comments regarding retirement or active adult communities, please feel free to use the below space. Your feedback is greatly appreciated.
Which of the following architectural styles would you prefer for a retirement or active adult community in the Sierra Nevada foothills of California? (Choose one)

Modern/ Contemporary Spanish/ Mission Style Consistent with surrounding environment Other

When choosing a retirement or active adult community, is close proximity to a downtown or town center of high importance?<smiles>[Nb][14c]1[14cH][14cH][14cH][14cH][14cH]1</smiles>

What is your preferred method of getting around within short distances (< than a mile)?

Walking

Bicycling

Driving

Public Transit/ Shuttle Service Other

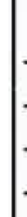




\section{Baby Boomer Living}

Retirement Lifestyle Preferences Survey

Baby Boomers, born between 1946 and 1964, are the largest generation in U.S. History with a population of over 82.8 million people. This vast group is currently in the midst of retirement, and thus it is the objective of this survey to better understand lifestyle preferences for those contemplating retirement communities and active adult communities. Information gathered from this survey will be analyzed to help guide and develop an ideal retirement community "prototype" that strives to meet the demands and needs of Baby Boomers. Thank you for taking this survey!

Sex: $\square$ Male $\square$ Female

Age: $\square$ 45-49 $\square 50-54 \square 55-59 \square 60-64 \square 65+$

What type of accommodation do you currently reside in? (Please check one)

X. Single Family House Multi-family House Condominium Apartment Senior/ Retirement Community Other

Have you ever considered living in a retirement or active adult community?

Yes 1 No

Do you find retirement or active adult communities to be an attractive option to live in?

Yes 1

If you responded "No" to the above question, please mention why:

$$
70 \text { Restrict20 - Raby }
$$

What type of housing would you find most appealing for a retirement community to offer?

- Single-family housing Condominiums Apartments Mixed Use (variety of the above) Other
On a scale of 1-5 (5 being the most favorable and 1 being least favorable), please rate the following activities and/or services that a retirement or active adult community should offer:

Fitness Facilities
5 Bicycle Trails
3 Community Gardening
5 Walking Trails
$\frac{1}{3}$ Horse Riding
$\frac{3}{3}$ Wine Tasting
Hiking
Amphitheater for live music
Bocce Ball
$\frac{2}{4}$ Gonnis
$\frac{3}{4}$ Swimming
$\frac{5}{5}$ Retail/ Shops
$\frac{4}{3}$ Coffee Shop
$\frac{1}{1}$ Aining Options Studio

Are there any additional activities or services that a community should offer?

aro

On a scale of 1-5 ( 5 being the highest and 1 the lowest), please rate the following reasons why you would consider moving into a retirement community:

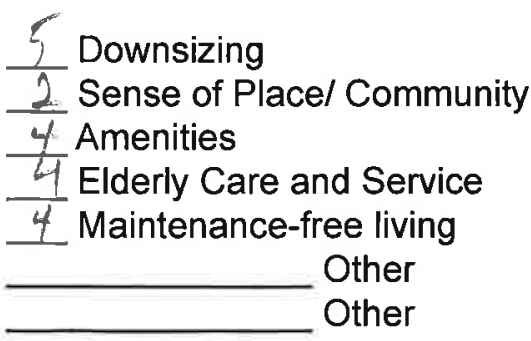


Are on site health services and personalized care important options for you to have when looking at retirement or active adult communities?<smiles>O=[Nb]1CCCC1</smiles>

According to your preference, please prioritize and rank the following 10 features $1-10$ (1 being the highest ranking and 10 being the lowest):

\section{Water Features \\ Plazas \\ 7 Gardens \\ 4 Public Art \\ 1 Gated Entry \\ 8 Landscaping \\ $\Rightarrow$ Lighting \\ $\angle 0$ Park/ Open Space \\ 2. Paved Pathways \\ Agricultural Space}

Are there any additional features that a community should offer?
Which of the following architectural styles would you prefer for a retirement or active adult community in the Sierra Nevada foothills of California?

(Choose one)

Modern/ Contemporary

Spanish/Mission Style

¿ Consistent with surrounding environment Other

When choosing a retirement or active adult community, is close proximity to a downtown or town center of high importance?

\section{Yes/I No}

What is your preferred method of getting around within short distances ( $<$ than a mile)?

Walking

Bicycling

Driving

Public Transit/ Shuttle Service Other

Thank you for taking the time to complete this survey! If you have any additional comments regarding retirement or active adult communities, please feel free to use the below space. Your feedback is greatly appreciated. 


\section{Baby Boomer Living \\ Retirement Lifestyle Preferences Survey}

Baby Boomers, born between 1946 and 1964 , are the largest generation in U.S. History with a population of over 82.8 million people. This vast group is currently in the midst of retirement, and thus it is the objective of this survey to better understand lifestyle preferences for those contemplating retirement communities and active adult communities. Information gathered from this survey will be analyzed to help guide and develop an ideal retirement community "prototype" that strives to meet the demands and needs of Baby Boomers. Thank you for taking this survey!

\section{Sex: $\square$ Male $\square$ Female}

Age: $\square$ 45-49 $\square$ 50-54

What type of accommodation do you currently reside in? (Please check one)

Single Family House

Multi-family House

Condominium

Apartment

Senior/ Retirement Community Other

Have you ever considered living in a retirement or active adult community?

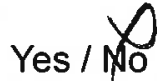

Do you find retirement or active adult communities to be an attractive option to live in?<smiles>CC(C)(C)N[N+]=O</smiles>

If you responded "No" to the above question, please mention why:

What type of housing would you find most appealing for a retirement community to offer?

Single-family housing

Condominiums

Apartments

Mixed Use (variety of the above) Other
On a scale of 1-5 (5 being the most favorable and 1 being least favorable), please rate the following activities and/or services that a retirement or active adult community should offer:

Fitness Facilities

Bicycle Trails

Community Gardening

W Walking Trails

Horse Riding

メWine Tasting

Hiking

Amphitheater for live music

Bocce Ball

Tennis

Golf

Swimming

_ Kayaking

_ Retail/ Shops

Coffee Shop

Dining Options

Art Studio

Are there any additional activities or services that a community should offer?

$$
\text { GARAGEJ }
$$

On a scale of 1-5 ( 5 being the highest and 1 the lowest), please rate the following reasons why you would consider moving into a retirement community:

4 Downsizing

2 Sense of Place/ Community

1 Amenities

3 Elderly Care and Service

5 Maintenance-free living Other

Other 
Are on site health services and personalized care important options for you to have when looking at retirement or active adult communities?

Yes / No

According to your preference, please prioritize and rank the following 10 features $1-10$ (1 being the highest ranking and 10 being the lowest):

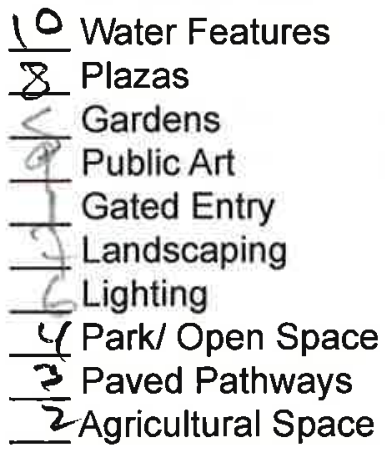

Are there any additional features that a community should offer?

$$
\text { GARACEd }
$$

Which of the following architectural styles would you prefer for a retirement or active adult community in the Sierra Nevada foothills of California? (Choose one)

Modern/ Contemporary

\. Spanish/Mission Style Consistent with surrounding environment Other

When choosing a retirement or active adult community, is close proximity to a downtown or town center of high importance?

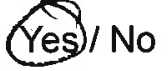

What is your preferred method of getting around within short distances ( $<$ than a mile)?

W Walking

Bicycling

Driving

Public Transit/ Shuttle Service Other

Thank you for taking the time to complete this survey! If you have any additional comments regarding retirement or active adult communities, please feel free to use the below space. Your feedback is greatly appreciated. 
Are on site health services and personalized care important options for you to have when looking at retirement or active adult communities?

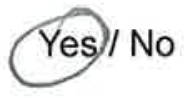

According to your preference, please prioritize and rank the following 10 features 1-10 (1 being the highest ranking and 10 being the lowest):

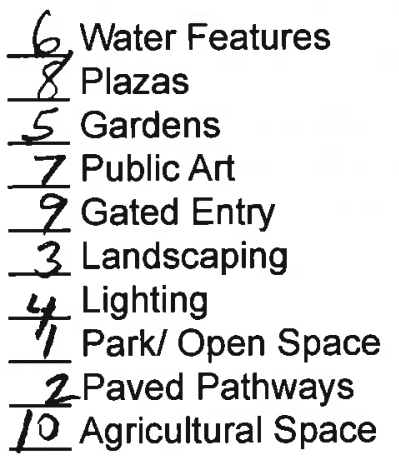

Are there any additional features that a community should offer?

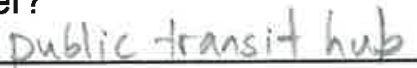

Which of the following architectural styles would you prefer for a retirement or active adult community in the Sierra Nevada foothills of California? (Choose one)

- Modern/ Contemporary Spanish/Mission Style 7 Consistent with surrounding environment Other

When choosing a retirement or active adult community, is close proximity to a downtown or town center of high importance?<smiles>[18O]=[Nb]</smiles>

What is your preferred method of getting around within short distances (< than a mile)?

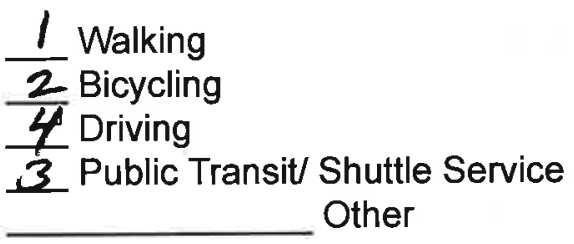

Thank you for taking the time to complete this survey! If you have any additional comments regarding retirement or active adult communities, please feel free to use the below space. Your feedback is greatly appreciated. 


\section{Baby Boomer Living}

\section{Retirement Lifestyle Preferences Survey}

Baby Boomers, born between 1946 and 1964 , are the largest generation in U.S. History with a population of over 82.8 million people. This vast group is currently in the midst of retirement, and thus it is the objective of this survey to better understand lifestyle preferences for those contemplating retirement communities and active adult communities. Information gathered from this survey will be analyzed to help guide and develop an ideal retirement community "prototype" that strives to meet the demands and needs of Baby Boomers. Thank you for taking this survey!

Sex: $\square$ Male $\$ Female

(Age: $\square$ 45-49 $\square 50-54 \square 55-59 \square 60-64 \square 65+$

What type of accommodation do you currently reside in? (Please check one)

A

Single Family House

Multi-family House

Condominium

Apartment

Senior/ Retirement Community Other

Have you ever considered living in a retirement or active adult community?

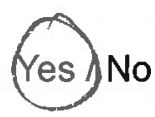

Do you find retirement or active adult communities to be an attractive option to live in?

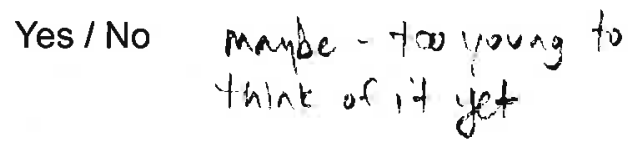

If you responded "No" to the above question, please mention why:

What type of housing would you find most appealing for a retirement community to offer?

Single-family housing

Condominiums

Apartments

$\chi_{\text {Mixed Use (variety of the above) }}$

Other
On a scale of $1-5$ ( 5 being the most favorable and 1 being least favorable), please rate the following activities and/or services that a retirement or active adult community should offer:

$\frac{4}{3}$ Fitness Facilities
$\frac{3}{5}$ Bicycle Trails
$\frac{5}{5}$ Walking Trails
$\frac{2}{3}$ Horse Riding
$\frac{3}{3}$ Hine Tasting
$\frac{3}{4}$ Amphing
$\frac{4}{4}$ Bocce Ball
$\frac{4}{5}$ Golf
$\frac{5}{2}$ Swimming
$\frac{5}{5}$ Retail/ Shops
$\frac{5}{5}$ Coffee Shop
$\frac{5}{5}$ Art Studio

Are there any additional activities or services that a community should offer?

$$
\text { Library }
$$

On a scale of $1-5$ ( 5 being the highest and 1 the lowest), please rate the following reasons why you would consider moving into a retirement community:

Downsizing

Sense of Place/ Community Amenities Elderly Care and Service

Maintenance-free living

Other

Other 


\section{Baby Boomer Living \\ Retirement Lifestyle Preferences Survey}

Baby Boomers, born between 1946 and 1964 , are the largest generation in U.S. History with a population of over 82.8 million people. This vast group is currently in the midst of retirement, and thus it is the objective of this survey to better understand lifestyle preferences for those contemplating retirement communities and active adult communities. Information gathered from this survey will be analyzed to help guide and develop an ideal retirement community "prototype" that strives to meet the demands and needs of Baby Boomers. Thank you for taking this survey!

Sex: $\square$ Male $\triangle$ Female

Age: $\square 45-49 \square 50-54 \square 55-59 \square 60-64 \square 65+$

What type of accommodation do you currently reside in? (Please check one)

Single Family House

Multi-family House

Condominium

Apartment

Senior/ Retirement Community Other

Have you ever considered living in a retirement or active adult community?

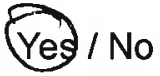

Do you find retirement or active adult communities to be an attractive option to live in?

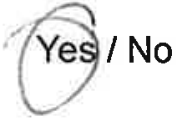

If you responded "No" to the above question, please mention why:

What type of housing would you find most appealing for a retirement community to offer?

Single-family housing

Condominiums

Apartments

Mixed Use (variety of the above)

Other
On a scale of 1-5 ( 5 being the most favorable and 1 being least favorable), please rate the following activities and/or services that a retirement or active adult community should offer:

$V$ Fitness Facilities
Bicycle Trails
Community Gardening 4
Walking Trails
Horse Riding
Wine Tasting
Hiking

ᄂ. Bocce Ball 4

LTennis 3 Golf 3

Swimming 5

Kayaking 2

$\sim$ Retail/ Shops 4

i. Coffee Shop 4

$\sim$ Dining Options 4

$\checkmark$ Art Studio 3

Are there any additional activities or services that a community should offer?

llikdical satteite services

On a scale of $1-5$ ( 5 being the highest and 1 the lowest), please rate the following reasons why you would consider moving into a retirement community:

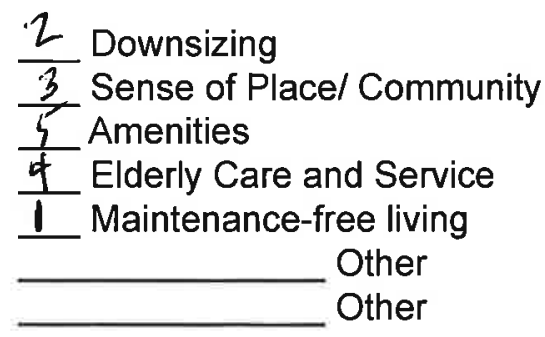


Are on site health services and personalized care important options for you to have when looking at retirement or active adult communities?

$$
\text { Yes) No }
$$

According to your preference, please prioritize and rank the following 10 features $1-10$ ( 1 being the highest ranking and 10 being the lowest):

\begin{tabular}{l}
$\frac{3}{1}$ Water Features \\
Plazas \\
2 Gardens \\
6 Public Art \\
$\frac{10}{3}$ Gated Entry \\
$\frac{3}{9}$ Landscaping \\
$\frac{8}{7}$ Park/ Open Space \\
$\frac{7}{5}$ Paved Pathways \\
\hline
\end{tabular}

Are there any additional features that a community should offer?

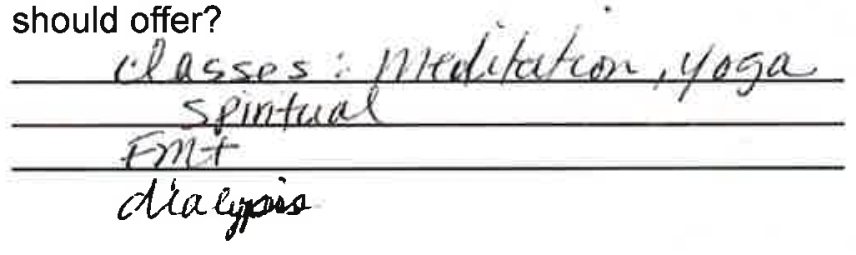

Which of the following architectural styles would you prefer for a retirement or active adult community in the Sierra Nevada foothills of California?

(Choose one) Modern/ Contemporary Spanish/Mission Style

$x$ Consistent with surrounding environment nature Other

When choosing a retirement or active adult community, is close proximity to a downtown or town center of high importance?

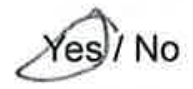

What is your preferred method of getting around within short distances (< than a mile)?

Walking

Bicycling

y Driving

Public Transit/ Shuttle Service Other

Thank you for taking the time to complete this survey! If you have any additional comments regarding retirement or active adult communities, please feel free to use the below space. Your feedback is greatly appreciated. 


\section{Baby Boomer Living}

\section{Retirement Lifestyle Preferences Survey}

Baby Boomers, born between 1946 and 1964 , are the largest generation in U.S. History with a population of over 82.8 million people. This vast group is currently in the midst of retirement, and thus it is the objective of this survey to better understand lifestyle preferences for those contemplating retirement communities and active adult communities. Information gathered from this survey will be analyzed to help guide and develop an ideal retirement community "prototype" that strives to meet the demands and needs of Baby Boomers. Thank you for taking this survey!

Sex: $\square$ Male $\square$ Female

Age: $\square 45-49 \square 50-54 \rrbracket 55-59 \square 60-64 \square 65+$

What type of accommodation do you currently reside in? (Please check one) Single Family House
Multi-family House
Condominium
Apartment
Senior/ Retirement Community
Other

Have you ever considered living in a retirement or active adult community?<smiles>[Mg][Mg]</smiles>

Do you find retirement, or active adult communities to be an attractive option to live in?

Yes / No

If you responded "No" to the above question, please mention why:

What type of housing would you find most appealing for a retirement community to offer?

Single-family housing

Condominiums

Apartments

Mixed Use (variety of the above) Other
On a scale of 1-5 ( 5 being the most favorable and 1 being least favorable), please rate the following activities and/or services that a retirement or active adult community should offer:

$5 \times$ Fitness Facilities
5 Bicycle Trails
4 Community Gardening
5 Walking Trails
3 Horse Riding
5 Wine Tasting
5 Hiking
5 Amphitheater for live music
5 Bocce Ball
$\frac{5}{5}$ Tennis
$\frac{4}{4}$ Golf
$\frac{5}{5}$ Kaymming
5 Retail/ Shops
5 Coffee Shop
5 Dining Options
4 Art Studio

Are there any additional activities or services that a community should offer?

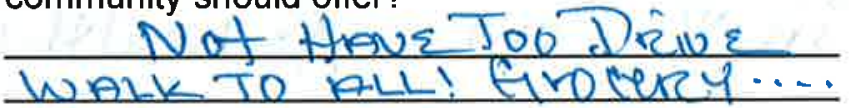

On a scale of 1-5 ( 5 being the highest and 1 the lowest), please rate the following reasons why you would consider moving into a retirement community:

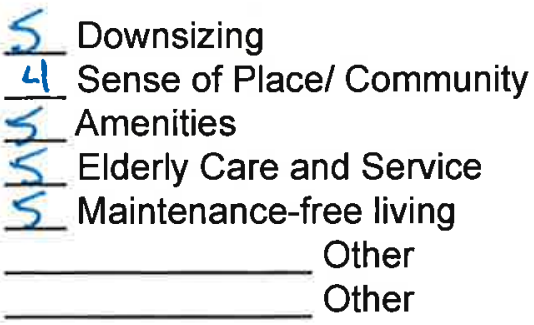


Are on site health services and personalized care important options for you to have when looking at retirement or active adult communities?

$$
\overrightarrow{\text { Yes }} \text { I No }
$$

According to your preference, please prioritize and rank the following 10 features $1-10$ ( 1 being the highest ranking and 10 being the lowest):
9 Water Features
4 4 Plazas
1 Gardens
104 Public Art
2 Gated Entry
8 ___ Landscaping
5 _ Lighting
3 _ Park/ Open Space
6 _ Paved Pathways
7 _ Agricultural Space

Are there any additional features that a community should offer?

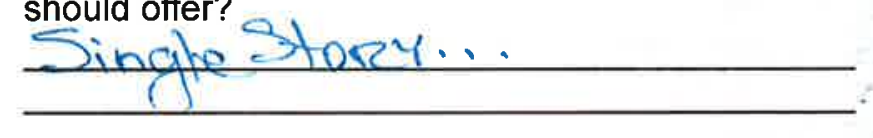

Which of the following architectural styles would you prefer for a retirement or active adult community in the Sierra Nevada foothills of California?

(Choose one)

Modern/ Contemporary

Sṕanish/Mission Style

Consistent with surrounding environment Other

When choosing a retirement or active adult community, is close proximity to a downtown or town center of high importance?

$$
\text { Yes! No }
$$

What is your preferred method of getting around within short distances ( $<$ than a mile)?

Walking

Bicycling

Driving

Public Transit/ Shuttle Service Other

Thank you for taking the time to complete this survey! If you have any additional comments regarding retirement or active adult communities, please feel free to use the below space. Your feedback is greatly appreciated.

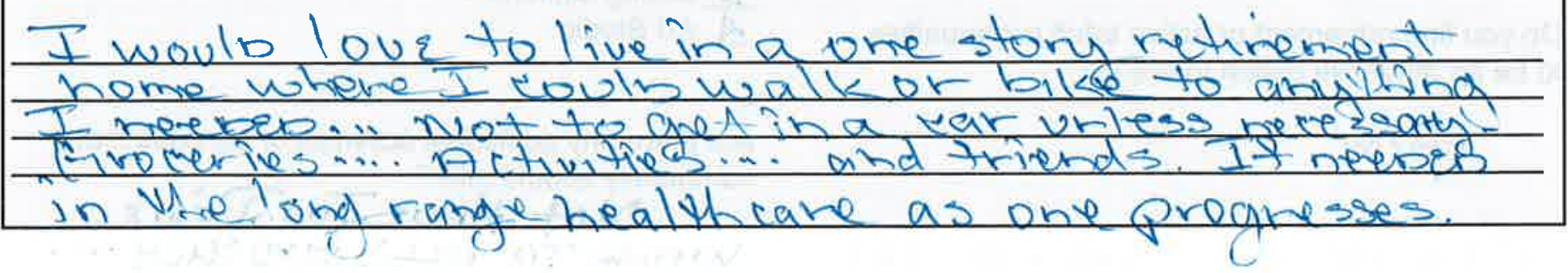




\section{Baby Boomer Living \\ Retirement Lifestyle Preferences Survey}

Baby Boomers, born between 1946 and 1964 , are the largest generation in U.S. History with a population of over 82.8 million people. This vast group is currently in the midst of retirement, and thus it is the objective of this survey to better understand lifestyle preferences for those contemplating retirement communities and active adult communities. Information gathered from this survey will be analyzed to help guide and develop an ideal retirement community "prototype" that strives to meet the demands and needs of Baby Boomers. Thank you for taking this survey!

Sex: $\square$ Male $\square$ Female

Age: $\square 45-49 \square 50-54 \square 55-59 \square 60-64 \rrbracket 65+$

What type of accommodation do you currently reside in? (Please check one)

Single Family House

Multi-family House

Condominium

Apartment

Senior/ Retirement Community Other

Have you ever considered living in a retirement or active adult community?

Yes $\widehat{N}$ o

Do you find retirement or active adult communities to be an attractive option to live in?

Yes/ No

If you responded "No" to the above question, please mention why:

What type of housing would you find most appealing for a retirement community to offer?

Single-family housing

Condominiums

Apartments

X Mixed Use (variety of the above) Other
On a scale of $1-5$ ( 5 being the most favorable and 1 being least favorable), please rate the following activities and/or services that a retirement or active adult community should offer:

Fitness Facilities
Bicycle Trails
Community Gardening
Walking Trails
Horse Riding
Wine Tasting
Hiking
Amphitheater for live music
Bocce Ball
Tennis
Golf
Swimming
Kayaking
Retail/ Shops
Coffee Shop
Dining Options
Art Studio

Are there any additional activities or services that a community should offer?

On a scale of $1-5$ ( 5 being the highest and 1 the lowest), please rate the following reasons why you would consider moving into a retirement community:

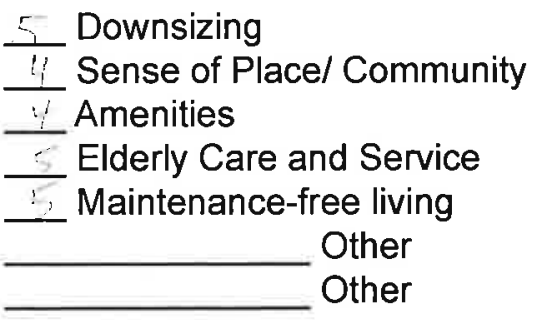


Are on site health services and personalized care important options for you to have when looking at retirement or active adult communities?

Yes / No

According to your preference, please prioritize and rank the following 10 features $1-10$ (1 being the highest ranking and 10 being the lowest):

\section{Water Features}

Plazas

Gardens

Public Art

Gated Entry

Landscaping

Lighting

9 Park/ Open Space

6 Paved Pathways

Agricultural Space

Are there any additional features that a community should offer?
Which of the following architectural styles would you prefer for a retirement or active adult community in the Sierra Nevada foothills of California?

(Choose one)

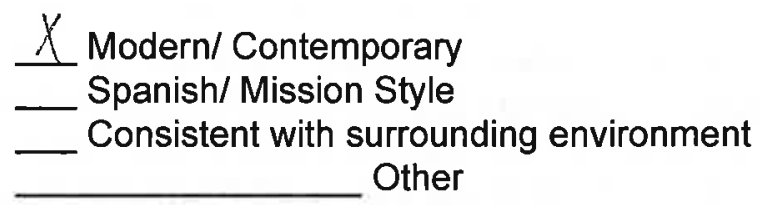

When choosing a retirement or active adult community, is close proximity to a downtown or town center of high importance?

$$
\text { Yes } \widehat{\mathrm{Ng}}
$$

What is your preferred method of getting around within short distances ( $<$ than a mile)?

Xalking
Bicycling
Driving
Public Transit/ Shuttle Service
Other

Thank you for taking the time to complete this survey! If you have any additional comments regarding retirement or active adult communities, please feel free to use the below space. Your feedback is greatly appreciated. 


\section{Baby Boomer Living \\ Retirement Lifestyle Preferences Survey}

Baby Boomers, born between 1946 and 1964 , are the largest generation in U.S. History with a population of over 82.8 million people. This vast group is currently in the midst of retirement, and thus it is the objective of this survey to better understand lifestyle preferences for those contemplating retirement communities and active adult communities. Information gathered from this survey will be analyzed to help guide and develop an ideal retirement community "prototype" that strives to meet the demands and needs of Baby Boomers. Thank you for taking this survey!

Sex: $\square$ Male $\bigotimes$ Female

Age: $\square 45-49 \square 50-54 \square 55-59 \square 60-64 \bigotimes 65+$

What type of accommodation do you currently reside in? (Please check one)

$\checkmark$ Single Family House

Multi-family House

Condominium

Apartment

Senior/ Retirement Community Other

Have you ever considered living in a retirement or active adult community?

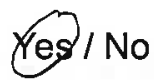

Do you find retirement or active adult communities to be an attractive option to live in?

Yes/ No

If you responded "No" to the above question, please mention why:

What type of housing would you find most appealing for a retirement community to offer?

$\checkmark$ Single-family housing

Condominiums

Apartments

Mixed Use (variety of the above)

Other
On a scale of 1-5 (5 being the most favorable and 1 being least favorable), please rate the following activities and/or services that a retirement or active adult community should offer:

$\frac{5}{5}$ Fitness Facilities

4 Community Gardening

5 Walking Trails

2 Horse Riding

5 Wine Tasting

5 Hiking

5 Amphitheater for live music

4 Bocce Ball

$\frac{4}{4}$ Tennis

3) Golf

5 Swimming

5 Kayaking

4 Retail/ Shops

5 Coffee Shop

$\frac{5}{4}$ Dining Options

4 Art Studio

Are there any additional activities or services that a community should offer?

Community es.ten for Social events,

On a scale of $1-5$ ( 5 being the highest and 1 the lowest), please rate the following reasons why you would consider moving into a retirement community:

$\frac{5}{5}$ Downsizing
$\frac{5}{5}$ Amenities
$\frac{5}{5}$ Elderly Care and Service
$\square$ Maintenance-free living
Other
Other


Are on site health services and personalized care important options for you to have when looking at retirement or active adult communities?

$$
\text { resl No }
$$

According to your preference, please prioritize and rank the following 10 features $1-10$ (1 being the highest ranking and 10 being the lowest):

3 Water Features

9 Plazas

6 Gardens

$\frac{6}{8}$ Public Art

$\frac{8}{10}$ Gated Entry

2 Landscaping

7 Lighting

$\perp$ Park/ Open Space

I Paved Pathways

5 Agricultural Space

Are there any additional features that a community should offer?
Which of the following architectural styles would you prefer for a retirement or active adult community in the Sierra Nevada foothills of California?

(Choose one)

Modern/ Contemporary Spanish/Mission Style

$\checkmark$ Consistent with surrounding environment Other

When choosing a retirement or active adult community, is close proximity to a downtown or town center of high importance?

Yes $/$ No

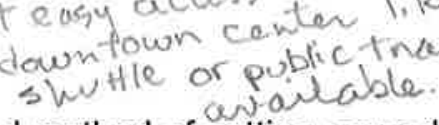

What is your preferred method of getting around within short distances ( $<$ than a mile)?

$\checkmark$ Walking

$\checkmark$ Bicycling

Driving

$\checkmark$ Public Transit/ Shuttle Service Other

Thank you for taking the time to complete this survey! If you have any additional comments regarding retirement or active adult communities, please feel free to use the below space. Your feedback is greatly appreciated. 


\section{Baby Boomer Living \\ Retirement Lifestyle Preferences Survey}

Baby Boomers, born between 1946 and 1964 , are the largest generation in U.S. History with a population of over 82.8 million people. This vast group is currently in the midst of retirement, and thus it is the objective of this survey to better understand lifestyle preferences for those contemplating retirement communities and active adult communities. Information gathered from this survey will be analyzed to help guide and develop an ideal retirement community "prototype" that strives to meet the demands and needs of Baby Boomers. Thank you for taking this survey!

Sex: $\square$ Male $\not$ Female

Age: $\triangle 45-49 \square 50-54 \square 55-59 \square 60-64 \square 65+$

What type of accommodation do you currently reside in? (Please check one)

Single Family House

Multi-family House

Condominium

Apartment

Senior/ Retirement Community Other

Have you ever considered living in a retirement or active adult community?

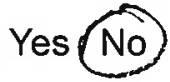

Do you find retirement or active adult communities to be an attractive option to live in?

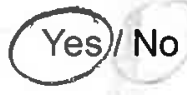

If you responded "No" to the above question, please mention why:

What type of housing would you find most appealing for a retirement community to offer?

Single-family housing

Condominiums

Apartments

Х Mixed Use (variety of the above) Other
On a scale of $1-5$ ( 5 being the most favorable and 1 being least favorable), please rate the following activities and/or services that a retirement or active adult community should offer:

5 Fitness Facilities
Bicycle Trails
5 Community Gardening
Walking Trails
5 Horse Riding
5 Wine Tasting
5 Hiking
$\frac{4}{5}$ Amphitheater for live music
$\frac{5}{5}$ Tecce Ball
$\frac{4}{4}$ Golf
$\frac{4}{3}$ Kayimming
$\frac{3}{4}$ Retail/ Shops
$\frac{4}{4}$ Dining Options
$\frac{3}{3}$ Art Studio

Are there any additional activities or services that a community should offer?

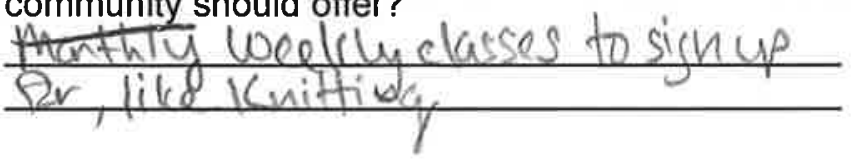

On a scale of 1-5 (5 being the highest and 1 the lowest), please rate the following reasons why you would consider moving into a retirement community:

Downsizing

Sense of Place/ Community

Amenities

5 Elderly Care and Service

5 Maintenance-free living

Other

Other 
Are on site health services and personalized care important options for you to have when looking at retirement or active adult communities?

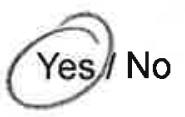

According to your preference, please prioritize and rank the following 10 features $1-10$ (1 being the highest ranking and 10 being the lowest):

10 Water Features

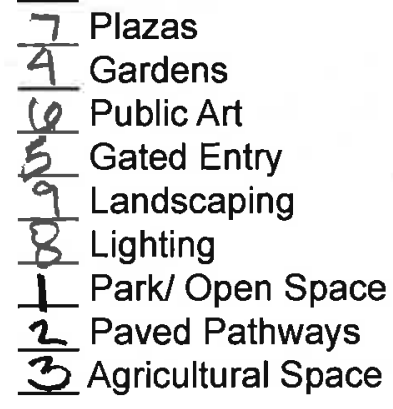

Are there any additional features that a community should offer?
Which of the following architectural styles would you prefer for a retirement or active adult community in the Sierra Nevada foothills of California? (Choose one)

Modern/ Contemporary Spanish/Mission Style Consistent with surrounding environment Other

When choosing a retirement or active adult community, is close proximity to a downtown or town center of high importance?

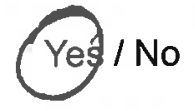

What is your preferred method of getting around within short distances ( $<$ than a mile)?

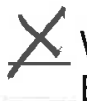

Walking Bicycling Driving Public Transit/ Shuttle Service Other

\footnotetext{
Thank you for taking the time to complete this survey! If you have any additional comments regarding retirement
or active adult communities, please feel free to use the below space. Your feedback is greatly appreciated.

Thank you for taking the time to complete this survey! If you have any additional comments regarding retirement
or active adult communities, please feel free to use the below space. Your feedback is greatly appreciated.
} 


\section{Baby Boomer Living \\ Retirement Lifestyle Preferences Survey}

Baby Boomers, born between 1946 and 1964, are the largest generation in U.S. History with a population of over 82.8 million people. This vast group is currently in the midst of retirement, and thus it is the objective of this survey to better understand lifestyle preferences for those contemplating retirement communities and active adult communities. Information gathered from this survey will be analyzed to help guide and develop an ideal retirement community "prototype" that strives to meet the demands and needs of Baby Boomers. Thank you for taking this survey!

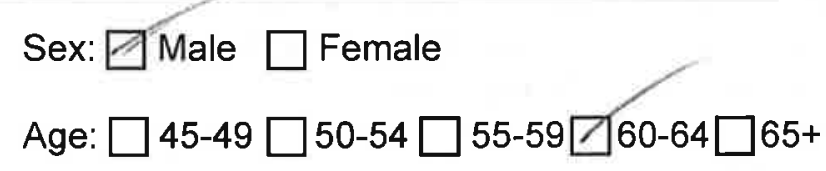

What type of accommodation do you currently reside in? (Please check one)

Single Family House

Multi-family House

Condominium

Apartment

Senior/ Retirement Community Other

Have you ever considered living in a retirement or active adult community?<smiles>[R][As](=O)([Na])c1ccccc1</smiles>

Do you find retirement or active adult communities to be an attractive option to live in?

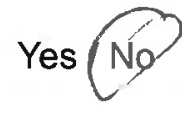

If you responded "No" to the above question, please mention why;

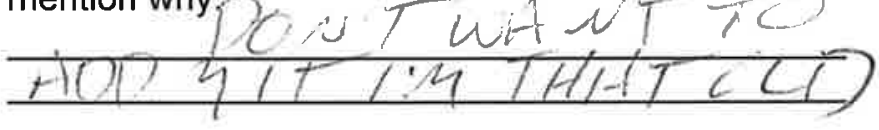

What type of housing would you find most appealing for a retirement community to offer?

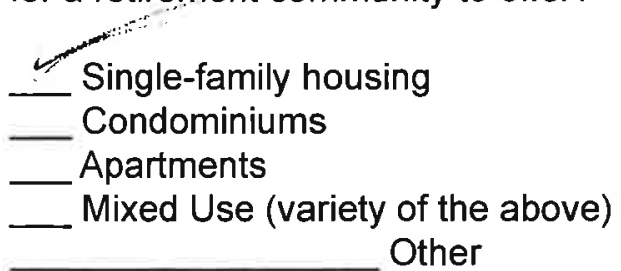

On a scale of 1-5 ( 5 being the most favorable and 1 being least favorable), please rate the following activities and/or services that a retirement or active adult community should offer:

Fitness Facilities
Bicycle Trails
Community Gardening
Walking Trails
Horse Riding
Hike Tasting
Amphitheater for live music
Bocce Ball
Tennis
Golf
Swimming
Kayaking
Retail/ Shops
Coffee Shop
Dining Options
Art Studio

Are there any additional activities or services that a community should offer?

On a scale of $1-5$ ( 5 being the highest and 1 the lowest), please rate the following reasons why you would consider moving into a retirement community:

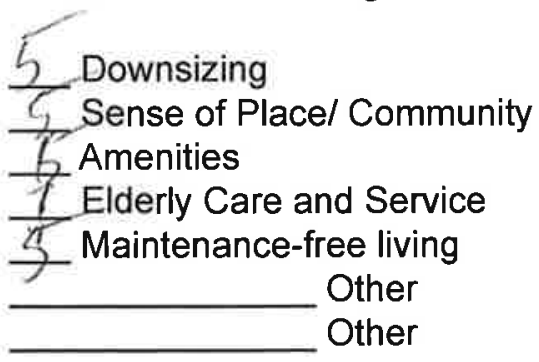


Are on site health services and personalized care important options for you to have when looking at retirement or active adult communities?

Yes / No

According to your preference, please prioritize and rank the following 10 features $1-10$ ( 1 being the highest ranking and 10 being the lowest):

Water Features

\section{Plazas}

Gardens

Public Art

Gated Entry

Landscaping

Lighting

Parkl Open Space

Paved Pathways

Agricultural Space

Are there any additional features that a community should offer?
Which of the following architectural styles would you prefer for a retirement or active adult community in the Sierra Nevada foothills of California?

(Choose one)

Modern/ Contemporary

Spanish/Mission Style

Consistent with surrounding environment Other

When choosing a retirement or active adult community, is close proximity to a downtown or town center of high importance?

Yes / No

What is your preferred method of getting around within short distances ( $<$ than a mile)?

Walking

Bicycling

Driving

Public Transit/ Shuttle Service Other

Thank you for taking the time to complete this survey! If you have any additional comments regarding retirement or active adult communities, please feel free to use the below space. Your feedback is greatly appreciated. 


\section{Baby Boomer Living \\ Retirement Lifestyle Preferences Survey}

Baby Boomers, born between 1946 and 1964 , are the largest generation in U.S. History with a population of over 82.8 million people. This vast group is currently in the midst of retirement, and thus it is the objective of this survey to better understand lifestyle preferences for those contemplating retirement communities and active adult communities. Information gathered from this survey will be analyzed to help guide and develop an ideal retirement community "prototype" that strives to meet the demands and needs of Baby Boomers. Thank you for taking this survey!

Sex: $\square$ Male $\square$ Female

Age: $\square 45-49 \square 50-54 \square 55-59 \square 60-64 \square 65+$

What type of accommodation do you currently reside in? (Please check one)

X Single Family House

Multi-family House

Condominium

Apartment

Senior/ Retirement Community Other

Have you ever considered living in a retirement or active adult community?<smiles>[AsH3][AsH3]</smiles>

Do you find retirement or active adult communities to be an attractive option to live in?

Yes No

If you responded "No" to the above question, please mention why:

What type of housing would you find most appealing for a retirement community to offer?

Single-family housing

$\underline{x}$ Condominiums

Apartments

Mixed Use (variety of the above)

Other
On a scale of 1-5 ( 5 being the most favorable and 1 being least favorable), please rate the following activities and/or services that a retirement or active adult community should offer:

$\frac{5}{5}$ Fitness Facilities
$\frac{5}{3}$ Bicycle Trails
$\frac{3}{5}$ Walking Trails
$\frac{3}{3}$ Horse Riding
$\frac{3}{4}$ Wine Tasting
$\frac{4}{4}$ Amphitheater for live music
$\frac{5}{4}$ Bocce Ball
$\frac{3}{4}$ Golf
$\frac{4}{4}$ Kayimming
$\frac{4}{4}$ Retail/ Shops
$\frac{4}{3}$ Dining Options
Art Studio

Are there any additional activities or services that a community should offer?

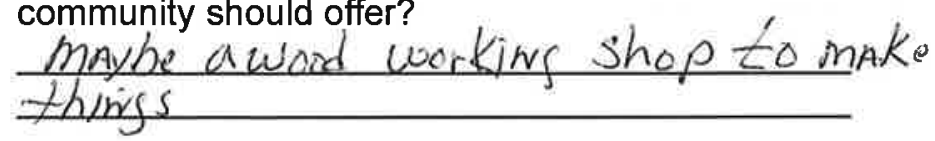

On a scale of 1-5 (5 being the highest and 1 the lowest), please rate the following reasons why you would consider moving into a retirement community:

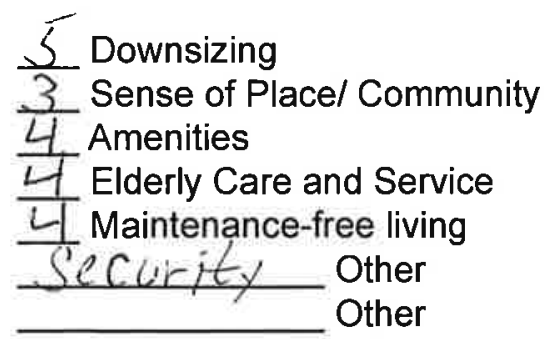


Are on site health services and personalized care important options for you to have when looking at retirement or active adult communities?

$$
\text { Yes No }
$$

According to your preference, please prioritize and rank the following 10 features $1-10$ ( 1 being the highest ranking and 10 being the lowest):

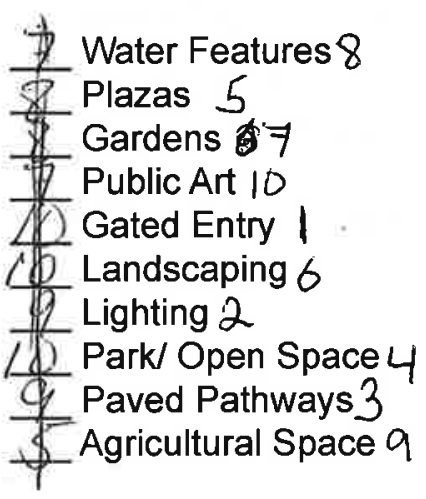

Are there any additional features that a community should offer?

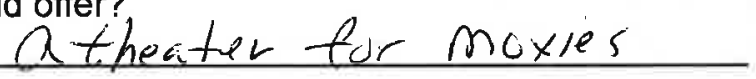

Which of the following architectural styles would you prefer for a retirement or active adult community in the Sierra Nevada foothills of California?

(Choose one)

Modern/ Contemporary

Spanish/Mission Style

$\not$ Consistent with surrounding environment Other

When choosing a retirement or active adult community, is close proximity to a downtown or town center of high importance?

$$
\text { Yes } / \mathrm{Ng})
$$

What is your preferred method of getting around within short distances ( $<$ than a mile)?

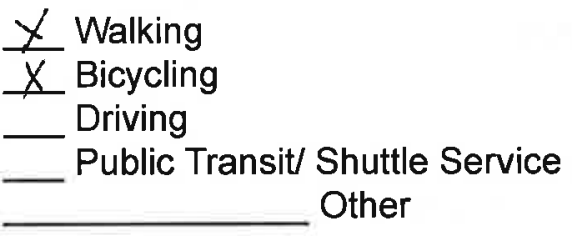

Thank you for taking the time to complete this survey! If you have any additional comments regarding retirement or active adult communities, please feel free to use the below space. Your feedback is greatly appreciated. 


\section{Baby Boomer Living \\ Retirement Lifestyle Preferences Survey}

Baby Boomers, born between 1946 and 1964 , are the largest generation in U.S. History with a population of over 82.8 million people. This vast group is currently in the midst of retirement, and thus it is the objective of this survey to better understand lifestyle preferences for those contemplating retirement communities and active adult communities. Information gathered from this survey will be analyzed to help guide and develop an ideal retirement community "prototype" that strives to meet the demands and needs of Baby Boomers. Thank you for taking this survey!

Sex: $\square$ Male $\square$ Female

Age: $\square 45-49 \square 50-54 \square 55-59 \square 60-64 \square 65+$

What type of accommodation do you currently reside in? (Please check one)

Single Family House

Multi-family House

Condominium

Apartment

Senior/ Retirement Community Other

Have you ever considered living in a retirement or active adult community?

\section{Yes/No}

Do you find retirement or active adult communities to be an attractive option to live in?

Yes / No

If you responded "No" to the above question, please mention why:

What type of housing would you find most appealing for a retirement community to offer?

Single-family housing

Condominiums

Apartments

Mixed Use (variety of the above) Other
On a scale of $1-5$ ( 5 being the most favorable and 1 being least favorable), please rate the following activities and/or services that a retirement or active adult community should offer:

Fitness Facilities
Bicycle Trails
Community Gardening
Walking Trails
Horse Riding
Wine Tasting
Aiking
Amphitheater for live music
Bocce Ball
Tennis
Golf
Kayimming
Retail/ Shops
Coffee Shop
Aining Options
Art Studio

Are there any additional activities or services that a community should offer?

On a scale of $1-5$ ( 5 being the highest and 1 the lowest), please rate the following reasons why you would consider moving into a retirement community:

Downsizing

Sense of Place/ Community

Amenities

1) Elderly Care and Service

Maintenance-free living Other Other 
Are on site health services and personalized care important options for you to have when looking at retirement or active adult communities?

Yes / No

According to your preference, please prioritize and rank the following 10 features $1-10$ ( 1 being the highest ranking and 10 being the lowest):

Water Features

Plazas
Gardens
Public Art
Lated Entry
Pandscaping
Park/ Open Space
Paricultural Space

Are there any additional features that a community should offer?
Which of the following architectural styles would you prefer for a retirement or active adult community in the Sierra Nevada foothills of California?

(Choose one)

Modern/ Contemporary

Spanish/Mission Style

Consistent with surrounding environment Other

When choosing a retirement or active adult community, is close proximity to a downtown or town center of high importance?

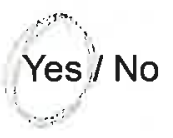

What is your preferred method of getting around within short distances (< than a mile)?

Walking

Bicycling

Driving

Public Transit/ Shuttle Service Other

Thank you for taking the time to complete this survey! If you have any additional comments regarding retirement or active adult communities, please feel free to use the below space. Your feedback is greatly appreciated. 


\section{Baby Boomer Living \\ Retirement Lifestyle Preferences Survey}

Baby Boomers, born between 1946 and 1964 , are the largest generation in U.S. History with a population of over 82.8 million people. This vast group is currently in the midst of retirement, and thus it is the objective of this survey to better understand lifestyle preferences for those contemplating retirement communities and active adult communities. Information gathered from this survey will be analyzed to help guide and develop an ideal retirement community "prototype" that strives to meet the demands and needs of Baby Boomers. Thank you for taking this survey!

Sex: $\square$ Male

Age: $\square$ 45-49 $\square 50-54 \square 55-59)(60-64 \square 65+$

What type of accommodation do you currently reside in? (Please check one)

thin

Single Family House

Multi-family House

Condominium

Apartment

Senior/ Retirement Community Other

Have you ever considered living in a retirement or active adult community?

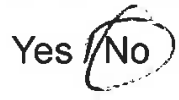

Do you find retirement or active adult communities to be an attractive option to live in?<smiles></smiles>

If you responded "No" to the above question, please mention why:

What type of housing would you find most appealing for a retirement community to offer?

Single-family housing

WCondominiums

Apartments

Mixed Use (variety of the above)

Other
On a scale of 1-5 ( 5 being the most favorable and 1 being least favorable), please rate the following activities and/or services that a retirement or active adult community should offer:

5 Fitness Facilities
5 Bicycle Trails
5 Community Gardening
Walking Trails
5 Horse Riding
5 Wine Tasting
Hiking
5 Amphitheater for live music
5 Tennis
5 Golf
5 Swimming
5 Kayaking
5 Retail/ Shops
5 Coffee Shop
5 Dining Options
5 Art Studio

Are there any additional activities or services that a community should offer?

On a scale of $1-5$ ( 5 being the highest and 1 the lowest), please rate the following reasons why you would consider moving into a retirement community:

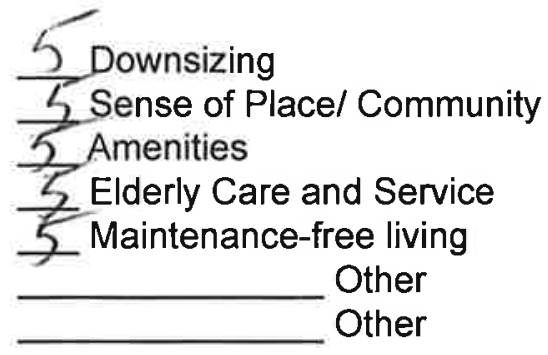


Are on site health services and personalized care important options for you to have when looking at retirement or active adult communities?<smiles>O=[N+]1CCC2CCC(C2)C1</smiles>

According to your preference, please prioritize and rank the following 10 features $1-10$ (1 being the highest ranking and 10 being the lowest):

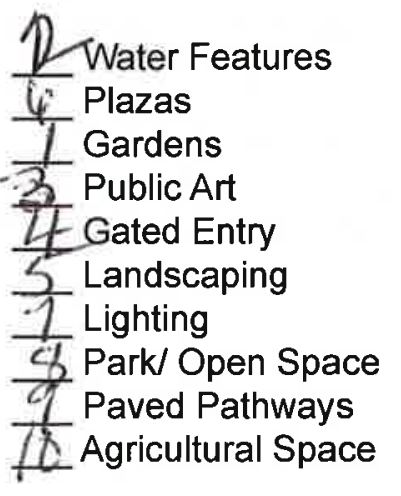

Are there any additional features that a community should offer?

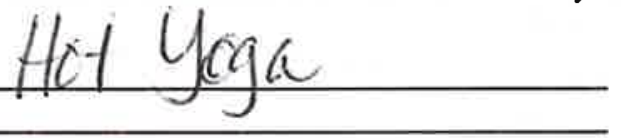

Which of the following architectural styles would you prefer for a retirement or active adult community in the Sierra Nevada foothills of California? (Choose one)

Modern/ Contemporary

Spanish/Mission Style

Consistent with surrounding environment Other

When choosing a retirement or active adult community, is close proximity to a downtown or town center of high importance?

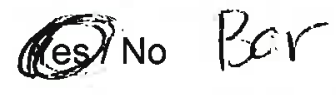

What is your preferred method of getting around within short distances ( $<$ than a mile)?

I Walking Bicycling Driving Public Transit/ Shuttle Service Other

Thank you for taking the time to complete this survey! If you have any additional comments regarding retirement or active adult communities, please feel free to use the below space. Your feedback is greatly appreciated. 


\section{Baby Boomer Living}

Retirement Lifestyle Preferences Survey

Baby Boomers, born between 1946 and 1964 , are the largest generation in U.S. History with a population of over 82.8 million people. This vast group is currently in the midst of retirement, and thus it is the objective of this survey to better understand lifestyle preferences for those contemplating retirement communities and active adult communities. Information gathered from this survey will be analyzed to help guide and develop an ideal retirement community "prototype" that strives to meet the demands and needs of Baby Boomers. Thank you for taking this survey!

Sex: $\square$ Male $\square$ Female

Age: $\square 45-49 \square 50-54 \square 55-59 \square 60-64 \square 65+$

What type of accommodation do you currently reside in? (Please check one)

Single Family House

Multi-family House

Condominium

Apartment

Senior/ Retirement Community Other

Have you ever considered living in a retirement or active adult community?

Yes/ $\hat{N a}$

Do you find retirement or active adult communities to be an attractive option to live in?

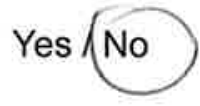

If you responded "No" to the above question, please mention why:

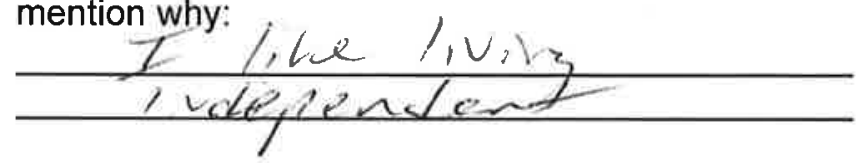

What type of housing would you find most appealing for a retirement community to offer?

Single-family housing

Condominiums

Apartments

Mixed Use (variety of the above)

Other
On a scale of 1-5 ( 5 being the most favorable and 1 being least favorable), please rate the following activities and/or services that a retirement or active adult community should offer:

3 Fitness Facilities
5 Bicycle Trails
5 Community Gardening
5 Walking Trails
2 Horse Riding
2 Wine Tasting
5 Hiking
1 Amphitheater for live music
1 Bocce Ball
1 Tennis
1 Golf
$\frac{1}{3}$ Swimming
2 Rayaking
4 Cotail/ Shops
3 Dining Options
5 Art Studio

Are there any additional activities or services that a community should offer?

On a scale of 1-5 (5 being the highest and 1 the lowest), please rate the following reasons why you would consider moving into a retirement community:

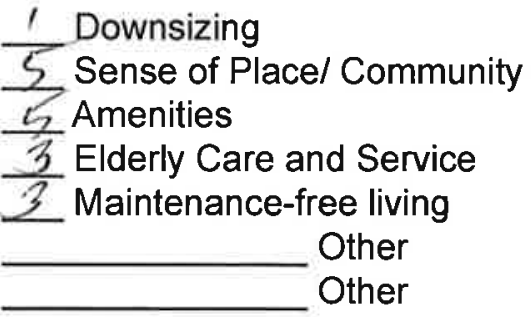


Are on site health services and personalized care important options for you to have when looking at retirement or active adult communities?<smiles>O=[N+]1CCCC2CCCCC21</smiles>

According to your preference, please prioritize and rank the following 10 features $1-10$ (1 being the highest ranking and 10 being the lowest):

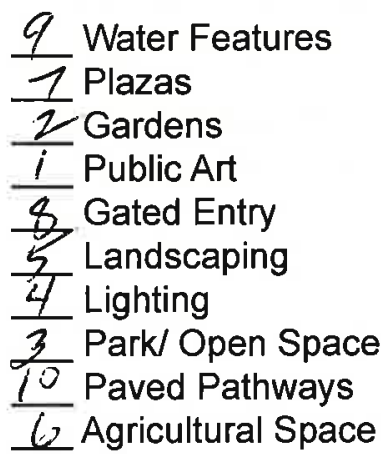

Are there any additional features that a community should offer?
Which of the following architectural styles would you prefer for a retirement or active adult community in the Sierra Nevada foothills of California? (Choose one)

Modern/ Contemporary Spanish/Mission Style Consistent with surrounding environment Other

When choosing a retirement or active adult community, is close proximity to a downtown or town center of high importance?

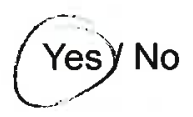

What is your preferred method of getting around within short distances ( $<$ than a mile)?

$\checkmark$ Walking
$\longleftarrow$ Bicycling
Driving
Public Transit/ Shuttle Service

Thank you for taking the time to complete this survey! If you have any additional comments regarding retirement or active adult communities, please feel free to use the below space. Your feedback is greatly appreciated. 


\section{Báby Boomer Living}

\section{Retirement Lifestyle Preferences Survey}

Baby Boomers, born between 1946 and 1964 , are the largest generation in U.S. History with a population of over 82.8 million people. This vast group is currently in the midst of retirement, and thus it is the objective of this survey to better understand lifestyle preferences for those contemplating retirement communities and active adult communities. Information gathered from this survey will be analyzed to help guide and develop an ideal retirement community "prototype" that strives to meet the demands and needs of Baby Boomers. Thank you for taking this survey!

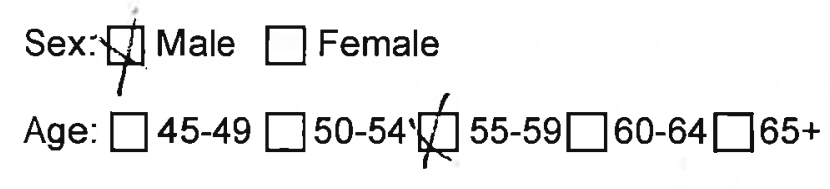

What type of accommodation do you currently reside in? (Please check one)

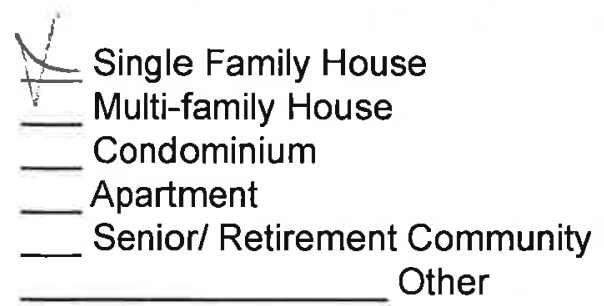

Have you ever considered living in a retirement or active adult community?<smiles>C[As](C)(=O)N1CCCC1</smiles>

Do you find retirement or active adult communities to be an attractive option to live in?<smiles>O=[Nb]1CCC2CCC1C2</smiles>

If you responded "No" to the above question, please mention why:

What type of housing would you find most appealing for a retirement community to offer?

Single-family housing

Condominiums
Apartments
Mixed Use (variety of the above)
Other
On a scale of 1-5 ( 5 being the most favorable and 1 being least favorable), please rate the following activities and/or services that a retirement or active adult community should offer:

$\{$ Fitness Facilities

, Bicycle Trails

$\frac{1}{6}$ Community Gardening

\% Walking Trails

1 Horse Riding

5 Wine Tasting

5 Hiking

$\zeta$ Amphitheater for live music

Bocce Ball

3 Tennis

5 Golf

5 Swimming

4 Kayaking

1 Retail/ Shops

2 Coffee Shop

$f$ Dining Options

3 Art Studio

Are there any additional activities or services that a community should offer?

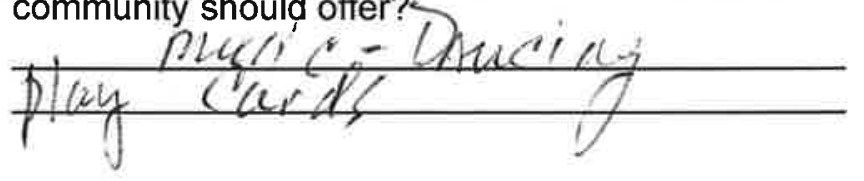

On a scale of 1-5 (5 being the highest and 1 the lowest), please rate the following reasons why you would consider moving into a retirement community:

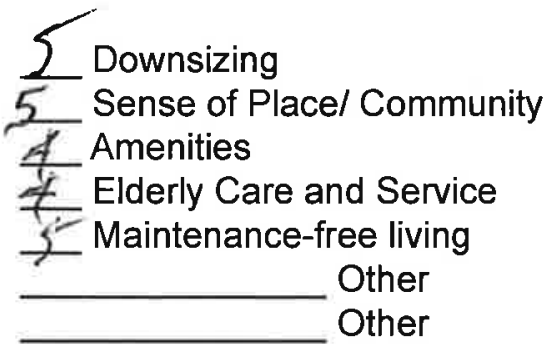


Are on site health services and personalized care important options for you to have when looking at retirement or active adult communities?

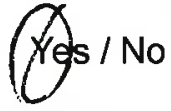

According to your preference, please prioritize and rank the following 10 features $1-10$ (1 being the highest ranking and 10 being the lowest):

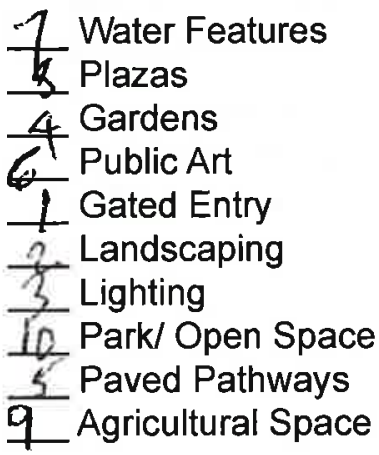

Are there any additional features that a community should offer?

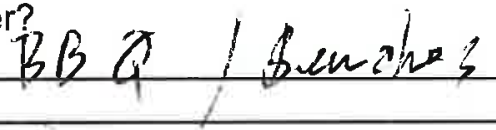

Which of the following architectural styles wou you prefer for a retirement or active adult commu iy in the Sierra Nevada foothills of California?

(Choose one)

Modern/ Contemporary

Spanish/Mission Style

Consistent with surrounding environment

Other

When choosing a retirement or active adult community, is close proximity to a downtown or town center of high importance?<smiles>[Nb][AsH]1CCC2CCC1C2</smiles>

What is your preferred method of getting around within short distances (< than a mile)?

T. Walking

Driving

Public Transit/ Shuttle Service Other

Thank you for taking the time to complete this survey! If you have any additional comments regarding retirement or active adult communities, please feel free to use the below space. Your feedback is greatly appreciated. 


\section{Baby Boomer Living}

\section{Retirement Lifestyle Preferences Survey}

Baby Boomers, born between 1946 and 1964 , are the largest generation in U.S. History with a population of over 82.8 million people. This vast group is currently in the midst of retirement, and thus it is the objective of this survey to better understand lifestyle preferences for those contemplating retirement communities and active adult communities. Information gathered from this survey will be analyzed to help guide and develop an ideal retirement community "prototype" that strives to meet the demands and needs of Baby Boomers. Thank you for taking this survey!

Sex: $\square$ Male $\square$ Female

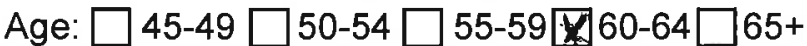

What type of accommodation do you currently reside in? (Please check one)

Single Family House

$X$ Multi-family House

Condominium

Apartment

Senior/ Retirement Community Other

Have you ever considered living in a retirement or active adult community?

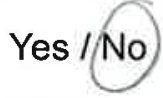

Do you find retirement or active adult communities to be an attractive option to live in?

$$
\text { Yes, No }
$$

If you responded "No" to the above question, please mention why:

$10.10: 0$

What type of housing would you find most appealing for a retirement community to offer?

Single-family housing

$X$ Condominiums

Apartments

Mixed Use (variety of the above)

Other
On a scale of 1-5 ( 5 being the most favorable and 1 being least favorable), please rate the following activities and/or services that a retirement or active adult community should offer:

\begin{tabular}{ll} 
& Fitness Facilities \\
Bicycle Trails \\
Community Gardening \\
Walking Trails \\
Horse Riding \\
Wine Tasting \\
Hiking \\
Amphitheater for live music \\
Bocce Ball \\
Tennis \\
Golf \\
Swimming \\
\hline 2 Kayaking \\
Retail/ Shops \\
\hline 2 Dining Options \\
Art Studio
\end{tabular}

Are there any additional activities or services that a community should offer?

On a scale of $1-5$ ( 5 being the highest and 1 the lowest), please rate the following reasons why you would consider moving into a retirement community:

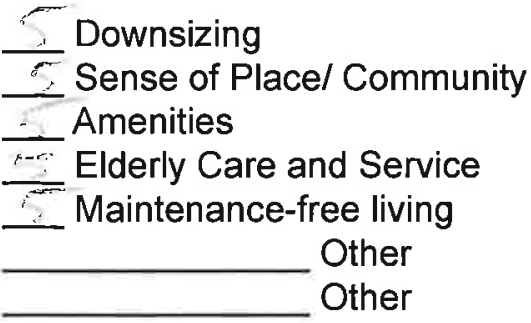


Are on site health services and personalized care important options for you to have when looking at retirement or active adult communities?

$$
\text { Yes) No }
$$

According to your preference, please prioritize and rank the following 10 features $1-10$ ( 1 being the highest ranking and 10 being the lowest):

Water Features

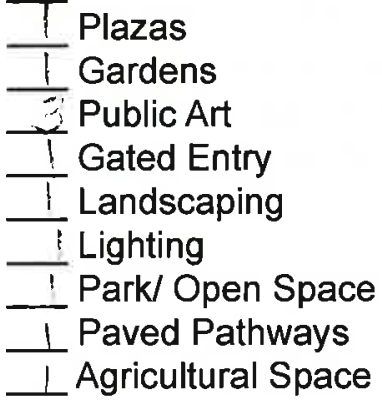

Are there any additional features that a community should offer?

Thank you for taking the time to complete this survey! If you have any additional comments regarding retirement or active adult communities, please feel free to use the below space. Your feedback is greatly appreciated.
Which of the following architectural styles would you in the Sierra Nevada foothills of California? (Choose one)

Modern/ Contemporary

X Spanish/Mission Style

Consistent with surrounding environment Other

When choosing a retirement or active adult community, is close proximity to a downtown or town center of high importance?<smiles>[AsH3][Nb]</smiles>

What is your preferred method of getting around within short distances ( $<$ than a mile)?

Walking

Bicycling

Driving

Public Transit/ Shuttle Service Other prefer for a retirement or active adult community 


\section{Baby Boomer Living \\ Retirement Lifestyle Preferences Survey}

Baby Boomers, born between 1946 and 1964 , are the largest generation in U.S. History with a population of over 82.8 million people. This vast group is currently in the midst of retirement, and thus it is the objective of this survey to better understand lifestyle preferences for those contemplating retirement communities and active adult communities. Information gathered from this survey will be analyzed to help guide and develop an ideal retirement community "prototype" that strives to meet the demands and needs of Baby Boomers. Thank you for taking this survey!

Sex: $\square$ Male $\square$ Female

Age: $\square$

$45-49 \square 50-54$

$55-59 \square 60-64 \square 65+$

What type of accommodation do you currently reside in? (Please check one)

Single Family House

Multi-family House

Condominium

Apartment

Senior/ Retirement Community Other

Have you ever considered living in a retirement or active adult community?

Yes / No

Do you find retirement or active adult communities to be an attractive option to live in?

Yes / No

If you responded "No" to the above question, please mention why:

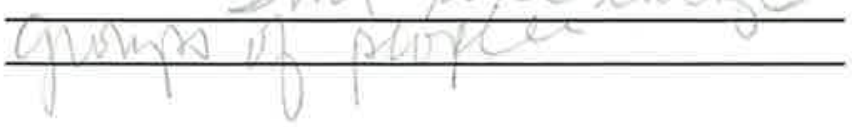

What type of housing would you find most appealing for a retirement community to offer?

Single-family housing

Condominiums

Apartments

Mixed Use (variety of the above)

Other
On a scale of 1-5 (5 being the most favorable and 1 being least favorable), please rate the following activities and/or services that a retirement or active adult community should offer:

Fitness Facilities

Bicycle Trails

Community Gardening

Walking Trails

Horse Riding

Wine Tasting

Hiking

Amphitheater for live music

Bocce Ball

Tennis

Golf

Swimming

Kayaking

Retail/ Shops

Coffee Shop

Dining Options

Art Studio

Are there any additional activities or services that a community should offer?

On a scale of $1-5$ ( 5 being the highest and 1 the lowest), please rate the following reasons why you would consider moving into a retirement community:

Downsizing

Sense of Place/ Community

Amenities

Elderly Care and Service

Maintenance-free living

Other

Other 
Are on site health services and personalized care important options for you to have when looking at retirement or active adult communities?

$$
\text { Yes / No }
$$

According to your preference, please prioritize and rank the following 10 features $1-10$ ( 1 being the highest ranking and 10 being the lowest):

\section{Water Features \\ Plazas \\ Gardens \\ Public Art \\ Gated Entry \\ Landscaping \\ Lighting \\ CPark/ Open Space \\ 10 Paved Pathways \\ Agricultural Space}

Are there any additional features that a community should offer?

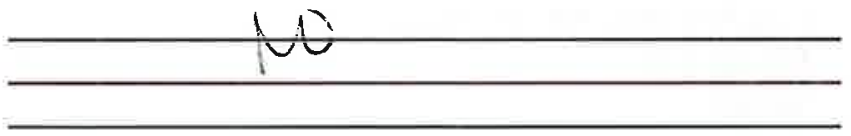

Which of the following architectural styles would you prefer for a retirement or active adult community in the Sierra Nevada foothills of California?

(Choose one)

Modern/ Contemporary

Spanish/Mission Style

Consistent with surrounding environment

Other

When choosing a retirement or active adult community, is close proximity to a downtown or town center of high importance?

$$
\text { (Yes I) No }
$$

What is your preferred method of getting around within short distances ( $<$ than a mile)?

$\checkmark$ Walking Bicycling Driving Public Transit/ Shuttle Service Other

Thank you for taking the time to complete this survey! If you have any additional comments regarding retirement or active adult communities, please feel free to use the below space. Your feedback is greatly appreciated. 


\section{Baby Boomer Living \\ Retirement Lifestyle Preferences Survey}

Baby Boomers, born between 1946 and 1964 , are the largest generation in U.S. History with a population of over 82.8 million people. This vast group is currently in the midst of retirement, and thus it is the objective of this survey to better understand lifestyle preferences for those contemplating retirement communities and active adult communities. Information gathered from this survey will be analyzed to help guide and develop an ideal retirement community "prototype" that strives to meet the demands and needs of Baby Boomers. Thank you for taking this survey!

Sex: $\square$ Male $\square$ Female

Age: $\square 45-49 \square 50-54 \square 55-59 \square 60-64 \square 65+$

What type of accommodation do you currently reside in? (Please check one)

$\checkmark$ Single Family House
Multi-family House
Condominium
Apartment
$\quad$ Senior/ Retirement Community Other

Have you ever considered living in a retirement or active adult community?

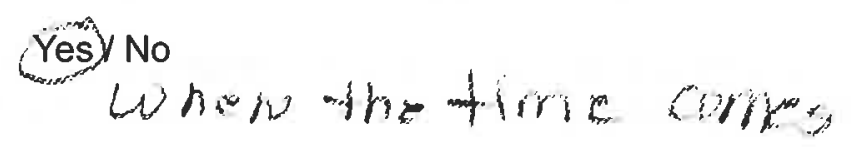

Do you find retirement or active adult communities to be an attractive option to live in?

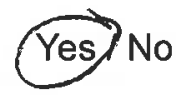

If you responded "No" to the above question, please mention why:

What type of housing would you find most appealing for a retirement community to offer?

Single-family housing

Condominiums

Apartments

Mixed Use (variety of the above) Other
On a scale of 1-5 (5 being the most favorable and 1 being least favorable), please rate the following activities and/or services that a retirement or active adult community should offer:

5 Fitness Facilities

Bicycle Trails

5 Community Gardening

5 Walking Trails Horse Riding.

5 Wine Tasting

Hiking

5 Amphitheater for live music

Bocce Ball

E⿱ $)$ Tennis

L. Golf

5 Swimming

4 Kayaking

5 Retail/ Shops

5 Coffee Shop

5 Dining Options

5 Art Studio

Are there any additional activities or services that a community should offer?

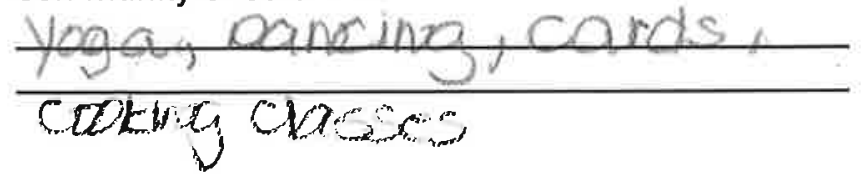

On a scale of $1-5$ ( 5 being the highest and 1 the lowest), please rate the following reasons why you would consider moving into a retirement community:

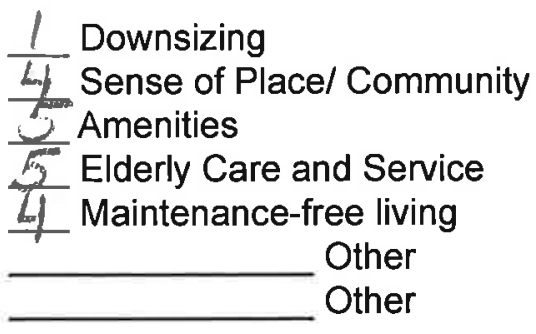


Are on site health services and personalized care important options for you to have when looking at retirement or active adult communities?

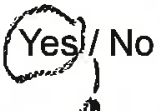

According to your preference, please prioritize and rank the following 10 features $1-10$ (1 being the highest ranking and 10 being the lowest):

$\perp$ Water Features

1 Plazas

LGardens

2. Public Art

I Gated Entry

j Landscaping

I Lighting

L Park/ Open Space

Paved Pathways

Agricultural Space

Are there any additional features that a community should offer?

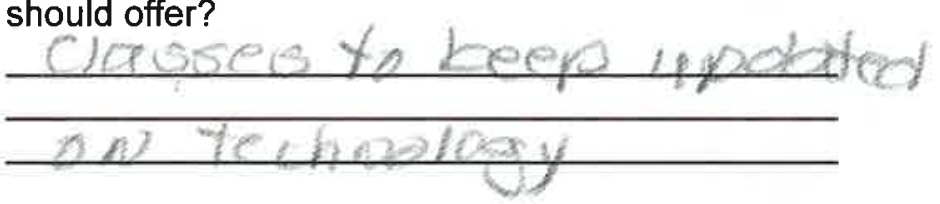

Which of the following architectural styles would you prefer for a retirement or active adult community in the Sierra Nevada foothills of California?

(Choose one)

Modern/ Contemporary

Spanish/ Mission Style

Consistent with surrounding environment

Simple Etfory Other

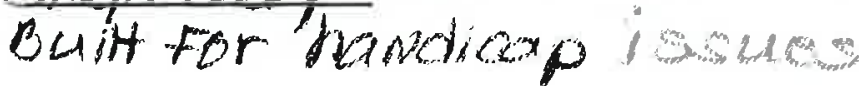

When choosing a retirement or active adult community, is close proximity to a downtown or town center of high importance?

$$
\text { (Yes)/ No }
$$

What is your preferred method of getting around within short distances ( $<$ than a mile)?

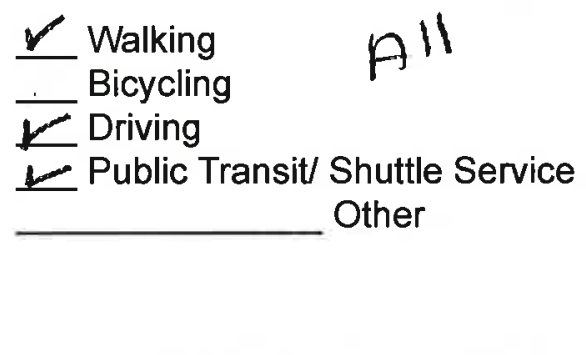

Thank you for taking the time to complete this survey! If you have any additional comments regarding retirement or active adult communities, please feel free to use the below space. Your feedback is greatly appreciated.

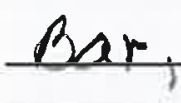




\section{Baby Boomer Living}

\section{Retirement Lifestyle Preferences Survey}

Baby Boomers, born between 1946 and 1964, are the largest generation in U.S. History with a population of over 82.8 million people. This vast group is currently in the midst of retirement, and thus it is the objective of this survey to better understand lifestyle preferences for those contemplating retirement communities and active adult communities. Information gathered from this survey will be analyzed to help guide and develop an ideal retirement community "prototype" that strives to meet the demands and needs of Baby Boomers. Thank you for taking this survey!

Sex: $\$ Male $\square$ Female

Age: $\square 45-49 \square 50-54 \square 55-59 \square 60-64 \square 65+$

What type of accommodation do you currently reside in? (Please check one)

$\checkmark$ Single Family House
Multi-family House
Condominium
Apartment
Senior/ Retirement Community
$\quad$ Other

Have you ever considered living in a retirement or active adult community?<smiles>[As][AsH3]</smiles>

Do you find retirement or active adult communities to be an attractive option to live in?<smiles></smiles>

If you responded "No" to the above question, please mention why:

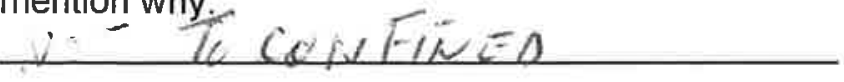

What type of housing would you find most appealing for a retirement community to offer?

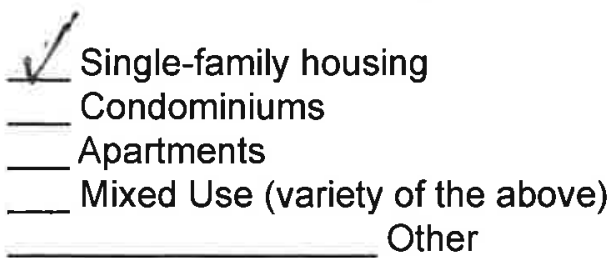

On a scale of 1-5 ( 5 being the most favorable and 1 being least favorable), please rate the following activities and/or services that a retirement or active adult community should offer:

3 Fitness Facilities
5 Bicycle Trails
5 Community Gardening
5 Walking Trails
1 Horse Riding
5 Wine Tasting
5 Hiking
$\frac{1}{5}$ Amphitheater for live music
$\frac{1}{1}$ Tennis
1 Golf
$\frac{1}{5}$ Swimming
$\frac{5}{1}$ Retail/ Shops
$\frac{1}{2}$ Coffee Shop
$\frac{1}{1}$ Dining Options
1 Art Studio

Are there any additional activities or services that a community should offer?

On a scale of $1-5$ ( 5 being the highest and 1 the lowest), please rate the following reasons why you would consider moving into a retirement community:

$\frac{3}{3}$ Downsizing
$\frac{4}{5}$ Sense of Place/ Community
$\frac{5}{3}$ Amenities
$\frac{3}{3}$ Maintenance-free living
Other
Other


Are on site health services and personalized care important options for you to have when looking at retirement or active adult communities?

$$
\text { Yes / No }
$$

According to your preference, please prioritize and rank the following 10 features $1-10$ ( 1 being the highest ranking and 10 being the lowest):

$$
\begin{aligned}
& 5 \text { Water Features } \\
& \text { Plazas } \\
& \text { Gardens } \\
& \text { ic Public Art } \\
& 2 \text { Gated Entry } \\
& 4 \text { Landscaping } \\
& 5 \text { Lighting } \\
& \text { (4) Park/ Open Space } \\
& \$ \text { Paved Pathways } \\
& \text { Agricultural Space }
\end{aligned}
$$

Are there any additional features that a community should offer?

Thank you for taking the time to complete this survey! If you have any additional comments regarding retirement or active adult communities, please feel free to use the below space. Your feedback is greatly appreciated.
Which of the following architectural styles would you prefer for a retirement or active adult community in the Sierra Nevada foothills of California?

(Choose one)

Modern/ Contemporary Spanish/Mission Style Consistent with surrounding environment Other

When choosing a retirement or active adult community, is close proximity to a downtown or town center of high importance?

$$
\text { Yes / No }
$$

What is your preferred method of getting around within short distances (< than a mile)?

$\stackrel{f}{\checkmark}$ Walking Bicycling Driving Public Transit/ Shuttle Service Other 


\section{Baby Boomer Living \\ Retirement Lifestyle Preferences Survey}

Baby Boomers, born between 1946 and 1964, are the largest generation in U.S. History with a population of over 82.8 million people. This vast group is currently in the midst of retirement, and thus it is the objective of this survey to better understand lifestyle preferences for those contemplating retirement communities and active adult communities. Information gathered from this survey will be analyzed to help guide and develop an ideal retirement community "prototype" that strives to meet the demands and needs of Baby Boomers. Thank you for taking this survey!

Sex: $\$$ Male $\square$ Female

Age: $\square$ 45-49 $\square 50-54 \square 55-59 \mathbb{X} 60-64 \square 65+$

What type of accommodation do you currently reside in? (Please check one)

\begin{tabular}{l} 
A Single Family House \\
Multi-family House \\
Condominium \\
Apartment \\
Senior/ Retirement Community \\
\hline Other
\end{tabular}

Have you ever considered living in a retirement or active adult community?

$$
\text { Yes / No? }
$$

Do you find retirement or active adult communities to be an attractive option to live in?

$$
\text { Yes / No? }
$$

If you responded "No" to the above question, please mention why:

What type of housing would you find most appealing for a retirement community to offer?

Single-family housing

X. Condominiums

Apartments

Mixed Use (variety of the above)

Other
On a scale of 1-5 (5 being the most favorable and 1 being least favorable), please rate the following activities and/or services that a retirement or active adult community should offer:

Fitness Facilities
Bicycle Trails
Community Gardening
Walking Trails
Horse Riding
Wine Tasting
Hiking
Amphitheater for live music
Bocce Ball
Tennis
Golf
Swimming
Kayaking
Retail/ Shops
Coffee Shop
Dining Options
Art Studio

Are there any additional activities or services that a community should offer?

On a scale of $1-5$ ( 5 being the highest and 1 the lowest), please rate the following reasons why you would consider moving into a retirement community:

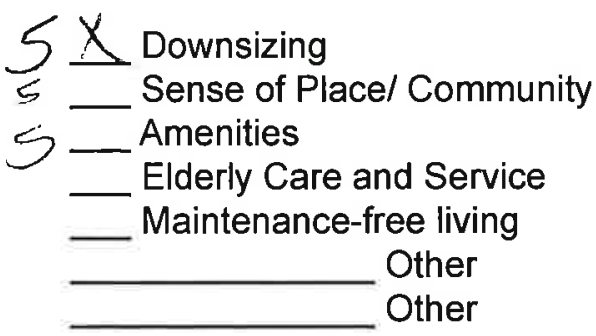


Are on site health services and personalized care important options for you to have when looking at retirement or active adult communities?

\section{Yes $/$ No}

According to your preference, please prioritize and rank the following 10 features $1-10$ ( 1 being the highest ranking and 10 being the lowest):
1 Water Features
Plazas
Gardens
Public Art
Gated Entry
Landscaping
Lighting
L Park/ Open Space
Paved Pathways
Agricultural Space

Are there any additional features that a community should offer?
Which of the following architectural styles would you prefer for a retirement or active adult community in the Sierra Nevada foothills of California?

(Choose one)

Modern/ Contemporary

Spanish/Mission Style

Consistent with surrounding environment Other

When choosing a retirement or active adult community, is close proximity to a downtown or town center of high importance?

$$
\text { (Ces / No }
$$

What is your preferred method of getting around within short distances ( $<$ than a mile)?

$\frac{X}{x}$ Walking
$X$ Bicycling

$X$ Driving
Public Transit/ Shuttle Service
Other

Thank you for taking the time to complete this survey! If you have any additional comments regarding retirement or active adult communities, please feel free to use the below space. Your feedback is greatly appreciated.

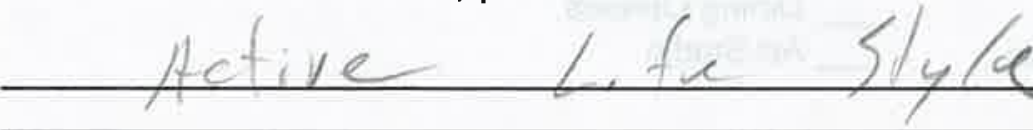


Baby Boomers, born between 1946 and 1964, are the largest generation in U.S. History with a population of over 82.8 million people. This vast group is currently in the midst of retirement, and thus it is the objective of this survey to better understand lifestyle preferences for those contemplating retirement communities and active adult communities. Information gathered from this survey will be analyzed to help guide and develop an ideal retirement community "prototype" that strives to meet the demands and needs of Baby Boomers. Thank you for taking this survey!

Sex: $\square$ Male $\square$ Female

Age: $\square 45-49 \square 50-54 \square 55-59 \square 60-64 \square 65+$

What type of accommodation do you currently reside in? (Please check one)

Single Family House

Multi-family House

Condominium

Apartment

Senior/ Retirement Community Other

Have you ever considered living in a retirement or active adult community?

Yes/ No

Do you find retirement or active adult communities to be an attractive option to live in?

Yes / No

If you responded "No" to the above question, please mention why:

What type of housing would you find most appealing for a retirement community to offer?

Single-family housing

Condominiums

Apartments

Mixed Use (variety of the above) Other
On a scale of 1-5 ( 5 being the most favorable and 1 being least favorable), please rate the following activities and/or services that a retirement or active adult community should offer:

$\frac{5}{3}$ Fitness Facilities
$\frac{3}{3}$ Cicycle Trails
$\frac{3}{3}$ Walking Trails
$\frac{1}{5}$ Horse Riding
$\frac{5}{4}$ Wine Tasting
$\frac{4}{3}$ Amphing
$\frac{4}{4}$ Bocce Ball
$\frac{4}{5}$ Gonnis
$\frac{3}{5}$ Swimming
$\frac{3}{5}$ Retail/ Shops
$\frac{5}{5}$ Coffee Shop
$\frac{5}{4}$ Aining Options
Art Studio

Are there any additional activities or services that a community should offer?

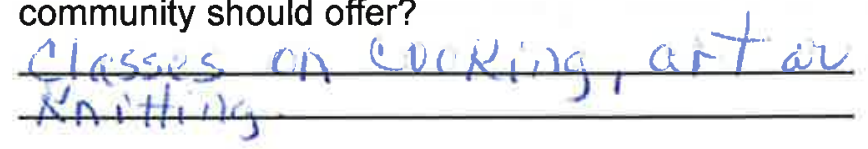

On a scale of $1-5$ ( 5 being the highest and 1 the lowest), please rate the following reasons why you would consider moving into a retirement community:

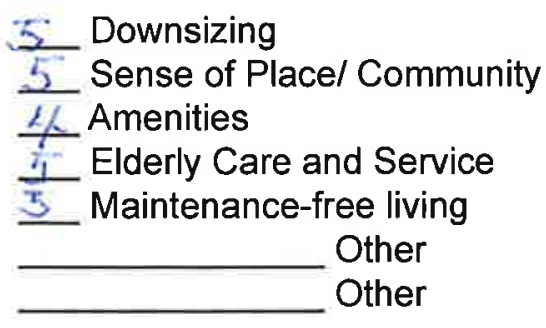


Are on site health services and personalized care important options for you to have when looking at retirement or active adult communities?

\section{Yes)/ No}

According to your preference, please prioritize and rank the following 10 features $1-10$ (1 being the highest ranking and 10 being the lowest):

$\frac{10}{5}$ Water Features
$\frac{3}{5}$ Plazas
Gardens
$\frac{1}{4}$ Public Art
$\frac{4}{3}$ Lated Entry
$\frac{1}{17}$ Lighting
$\frac{7}{8}$ Park/ Open Space
Paved Pathways
Agricultural Space

Are there any additional features that a community should offer? Entertriument
Which of the following architectural styles would you prefer for a retirement or active adult community in the Sierra Nevada foothills of California?

(Choose one)

Modern/ Contemporary

Spanish/Mission Style

Consistent with surrounding environment Other

When choosing a retirement or active adult community, is close proximity to a downtown or town center of high importance?

$$
\text { Yesy no }
$$

What is your preferred method of getting around within short distances (< than a mile)?

Walking

Bicycling

Driving

Public Transit/ Shuttle Service Other

Thank you for taking the time to complete this survey! If you have any additional comments regarding retirement or active adult communities, please feel free to use the below space. Your feedback is greatly appreciated. 


\section{Baby Boomer Living \\ Retirement Lifestyle Preferences Survey}

Baby Boomers, born between 1946 and 1964 , are the largest generation in U.S. History with a population of over 82.8 million people. This vast group is currently in the midst of retirement, and thus it is the objective of this survey to better understand lifestyle preferences for those contemplating retirement communities and active adult communities. Information gathered from this survey will be analyzed to help guide and develop an ideal retirement community "prototype" that strives to meet the demands and needs of Baby Boomers. Thank you for taking this survey!

Sex: $\square$ Male WFemale

Age: $\square 45-49 \square 50-54 \square 55-59 \bowtie 60-64 \square 65+$

What type of accommodation do you currently reside in? (Please check one)

$\chi$ Single Family House

Multi-family House

Condominium

Apartment

Senior/ Retirement Community Other

Have you ever considered living in a retirement or active adult community?

$$
\text { Yes/ No }
$$

Do you find retirement or active adult communities to be an attractive option to live in?

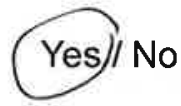

If you responded "No" to the above question, please mention why:

What type of housing would you find most appealing for a retirement community to offer?

$\Varangle$ Single-family housing

Condominiums

Apartments

Mixed Use (variety of the above)

Other
On a scale of 1-5 ( 5 being the most favorable and 1 being least favorable), please rate the following activities and/or services that a retirement or active adult community should offer:

$\frac{4}{4}$ Fitness Facilities
$\frac{3}{5}$ Bicycle Trails
Community Gardening
$\frac{5}{5}$ Walking Trails
$\frac{1}{1}$ Horse Riding
$\frac{1}{5}$ Hiking Tasting
$\frac{3}{3}$ Amphitheater for live music
$\frac{1}{1}$ Bocce Ball
$\frac{1}{3}$ Golf
3 Swimming
$\frac{1}{4}$ Kayaking
$\frac{4}{3}$ Cotail/ Shops
$\frac{3}{3}$ Dining Options
4 Art Studio

Are there any additional activities or services that a community should offer?

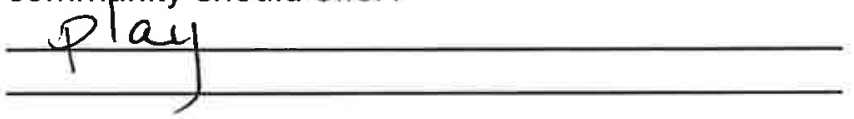

On a scale of $1-5$ ( 5 being the highest and 1 the lowest), please rate the following reasons why you would consider moving into a retirement community:

$\frac{4}{3}$ Downsizing
$\frac{3}{3}$ Sense of Place/ Community
$\frac{3}{3}$ Elderly Care and Service
5 Maintenance-free living
Other
Other


Are on site health services and personalized care important options for you to have when looking at retirement or active adult communities?<smiles></smiles>

According to your preference, please prioritize and rank the following 10 features $1-10$ ( 1 being the highest ranking and 10 being the lowest):

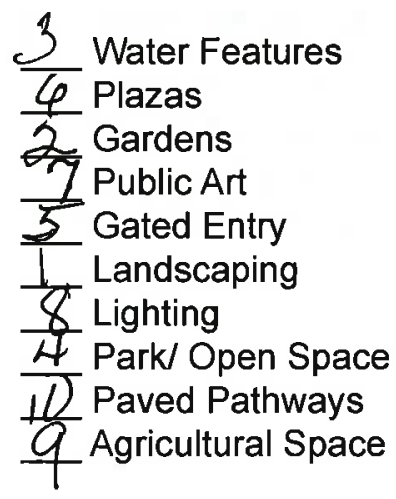

Are there any additional features that a community should offer?

Thank you for taking the time to complete this survey! If you have any additional comments regarding retirement or active adult communities, please feel free to use the below space. Your feedback is greatly appreciated.
Which of the following architectural styles would you prefer for a retirement or active adult community in the Sierra Nevada foothills of California? (Choose one)

Modern/ Contemporary Spanish/ Mission Style

$\underline{X}$ Consistent with surrounding environment Other

When choosing a retirement or active adult community, is close proximity to a downtown or town center of high importance?

$$
\text { YegtNo }
$$

What is your preferred method of getting around within short distances (< than a mile)?

Walking

Bicycling

Driving

Public Transit/ Shuttle Service Other

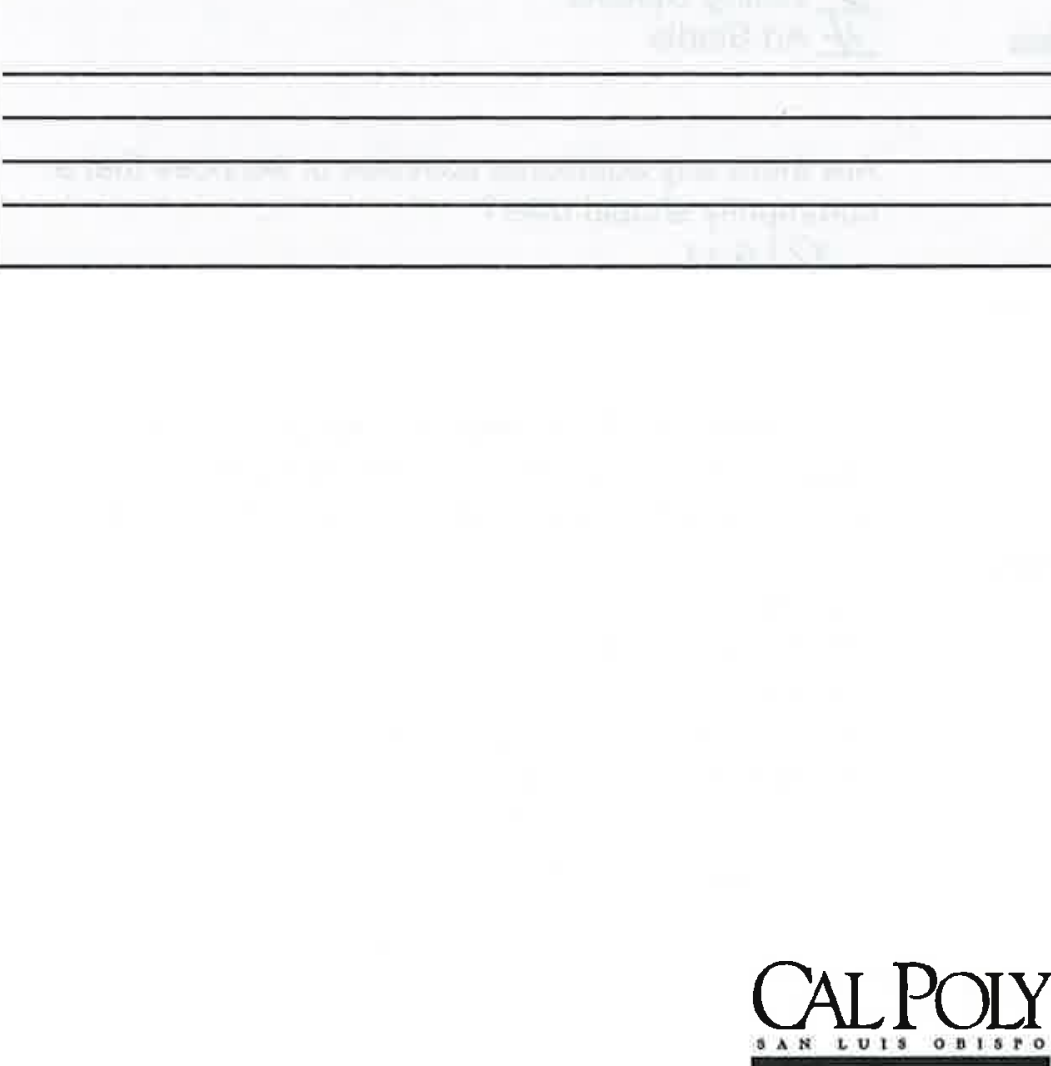




\section{Baby Boomer Living \\ Retirement Lifestyle Preferences Survey}

Baby Boomers, born between 1946 and 1964 , are the largest generation in U.S. History with a population of over 82.8 million people. This vast group is currently in the midst of retirement, and thus it is the objective of this survey to better understand lifestyle preferences for those contemplating retirement communities and active adult communities. Information gathered from this survey will be analyzed to help guide and develop an ideal retirement community "prototype" that strives to meet the demands and needs of Baby Boomers. Thank you for taking this survey!

Sex: $\square$ Male $\square$ Female

Age: $\square 45-49 \square 50-54 \square 55-59 \square 60-64 \square 65+$

What type of accommodation do you currently reside in? (Please check one)

Single Family House

Multi-family House

Condominium

Apartment

Senior/ Retirement Community Other

Have you ever considered living in a retirement or active adult community?

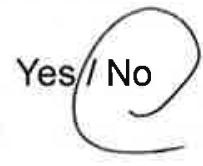

Do you find retirement or active adult communities to be an attractive option to live in?

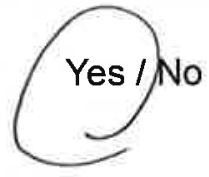

If you responded "No" to the above question, please mention why:

What type of housing would you find most appealing for a retirement community to offer?

Single-family housing

Condominiums

Apartments

Mixed Use (variety of the above)

Other
On a scale of 1-5 ( 5 being the most favorable and 1 being least favorable), please rate the following activities and/or services that a retirement or active adult community should offer:

1 Fitness Facilities

4 Bicycle Trails

C. Community Gardening

5 Walking Trails

1 Horse Riding

5 Wine Tasting

2 Hiking

3 Amphitheater for live music

3 Bocce Ball

3 Tennis

3 Golf

4 Swimming

2 Kayaking

4 Retail/ Shops

Coffee Shop

5 Dining Options

5 Art Studio

Are there any additional activities or services that a community should offer?

weekly opatherens

On a scale of 1-5 (5 being the highest and 1 the lowest), please rate the following reasons why you would consider moving into a retirement community:

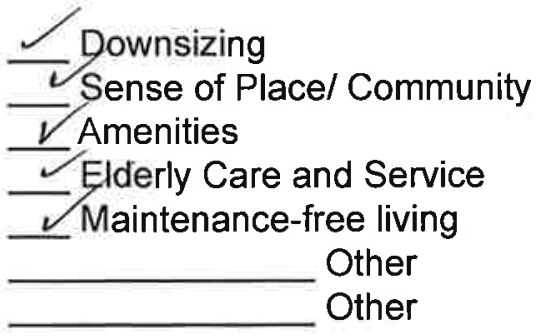


Are on site health services and personalized care important options for you to have when looking at retirement or active adult communities?

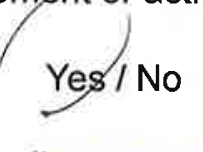

According to your preference, please prioritize and rank the following 10 features $1-10$ (1 being the highest ranking and 10 being the lowest):

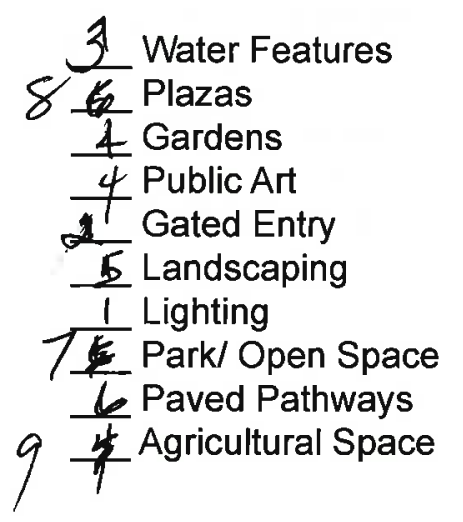

Are there any additional features that a community should offer?
Which of the following architectural styles would you prefer for a retirement or active adult community in the Sierra Nevada foothills of California?

(Choose one)

$\checkmark$ Modern/ Contemporary Spanish/Mission Style

Consistent with surrounding environment Other

When choosing a retirement or active aduilt community, is close proximity to a downtown or town center of high importance?

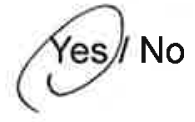

What is your preferred method of getting around within short distances (< than a mile)?

Walking
Bicycling
Driving
Public Transit/ Shuttle Service
Other

Thank you for taking the time to complete this survey! If you have any additional comments regarding retirement or active adult communities, please feel free to use the below space. Your feedback is greatly appreciated. 


\section{Baby Boomer Living}

\section{Retirement Lifestyle Preferences Survey}

Baby Boomers, born between 1946 and 1964, are the largest generation in U.S. History with a population of over 82.8 million people. This vast group is currently in the midst of retirement, and thus it is the objective of this survey to better understand lifestyle preferences for those contemplating retirement communities and active adult communities. Information gathered from this survey will be analyzed to help guide and develop an ideal retirement community "prototype" that strives to meet the demands and needs of Baby Boomers. Thank you for taking this survey!

Sex: $\square$ Male $\square$ Female

Age: $\square 45-49 \square 50-54 \square 55-59 \square 60-64 \square 65+$

What type of accommodation do you currently reside in? (Please check one)

Single Family House

Multi-family House

Condominium

Apartment

Senior/ Retirement Community Other

Have you ever considered living in a retirement or active adult community?

Yes $/(10)$

Do you find retirement or active adult communities to be an attractive option to live in?

Yes $/$ (No)

If you responded "No" to the above question, please mention why:

old peonle

What type of housing would you find most appealing for a retirement community to offer?

\footnotetext{
$\checkmark$ Single-family housing

Condominiums

Apartments

Mixed Use (variety of the above)

Other
}

On a scale of 1-5 (5 being the most favorable and 1 being least favorable), please rate the following activities and/or services that a retirement or active adult community should offer:

5 Fitness Facilities
5 Bicycle Trails
1 Community Gardening
5 Walking Trails
$\frac{1}{1}$ Horse Riding
$\frac{5}{5}$ Wine Tasting
$\frac{5}{2}$ Amphitheater for live music
$\frac{2}{2}$ Bocce Ball
$\frac{2}{5}$ Tennis
$\frac{5}{2}$ Solf
$\frac{1}{1}$ Kayimming
$\frac{5}{5}$ Retail/ Shops
$\frac{5}{5}$ Dining Options
5 Art Studio

Are there any additional activities or services that a community should offer?

$$
\text { Salon - Hair nails }
$$

On a scale of $1-5$ ( 5 being the highest and 1 the lowest), please rate the following reasons why you would consider moving into a retirement community:

Downsizing
Sense of Place/ Community
Amenities
Elderly Care and Service
Maintenance-free living
Other
Other


Are on site health services and personalized care important options for you to have when looking at retirement or active adult communities?

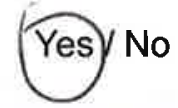

According to your preference, please prioritize and rank the following 10 features $1-10$ ( 1 being the highest ranking and 10 being the lowest):
5 Water Features
5 Plazas
7 Gardens
10 Public Art
1 Gated Entry
2 Landscaping
1 Lighting
L Park/ Open Space
I Paved Pathways
7 Agricultural Space

Are there any additional features that a community should offer?

$$
x
$$

Which of the following architectural styles would you prefer for a retirement or active adult community in the Sierra Nevada foothills of California?

(Choose one)

Modern/ Contemporary

Х Spanish/ Mission Style

Consistent with surrounding environment Other

When choosing a retirement or active adult community, is close proximity to a downtown or town center of high importance?

$$
\text { (res) No }
$$

What is your preferred method of getting around within short distances ( $<$ than a mile)?

Walking
Bicycling
Driving
Public Transit/ Shuttle Service
Other

Thank you for taking the time to complete this survey! If you have any additional comments regarding retirement or active adult communities, please feel free to use the below space. Your feedback is greatly appreciated. 


\section{Baby Boomer Living \\ Retirement Lifestyle Preferences Survey}

Baby Boomers, born between 1946 and 1964 , are the largest generation in U.S. History with a population of over 82.8 million people. This vast group is currently in the midst of retirement, and thus it is the objective of this survey to better understand lifestyle preferences for those contemplating retirement communities and active adult communities. Information gathered from this survey will be analyzed to help guide and develop an ideal retirement community "prototype" that strives to meet the demands and needs of Baby Boomers. Thank you for taking this survey!

Sex: $\square$ Male $\square$ Female

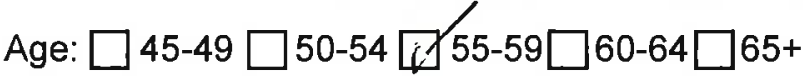

What type of accommodation do you currently reside in? (Please check one)

Single Family House

Multi-family House

Condominium

Apartment

Senior/ Retirement Community Other

Have you ever considered living in a retirement or active adult community?

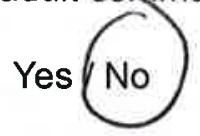

Do you find retirement or active adult communities to be an attractive option to live in?

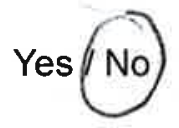

If you responded "No" to the above question, please mention why:

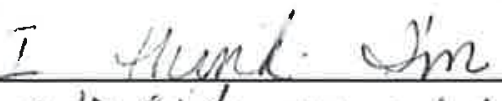

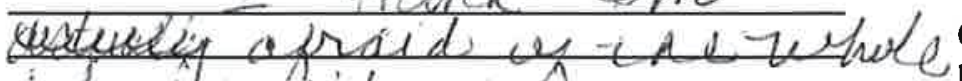
idea untid necbsaref.

What type of housing would you find most appealing for a retirement community to offer?

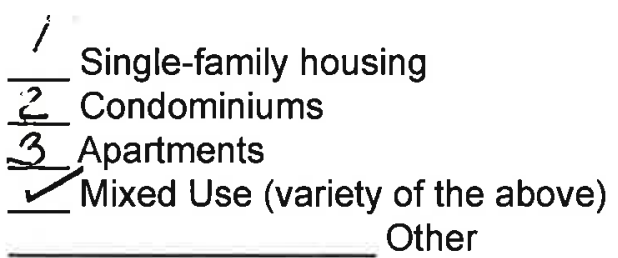

On a scale of $1-5$ ( 5 being the most favorable and 1 being least favorable), please rate the following activities and/or services that a retirement or active adult community should offer:

$\sum$ Fitness Facilities

$\frac{5}{5}$ Bicycle Trails

$\frac{5}{5}$ Community Gardening

5 Walking Trails

2 Horse Riding

4 Wine Tasting

4 Hiking

5 Amphitheater for live music

5 Bocce Ball

2 Tennis

3 Golf

4 Swimming

4 Kayaking

$\frac{7}{3}$ Retail/ Shops

4 Coffee Shop

4 Dining Options

F Art Studio

Are there any additional activities or services that a community should offer?

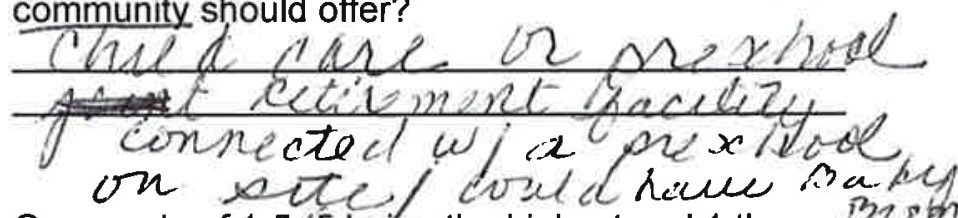

On a scale of $1-5$ ( 5 being the highest and 1 the lowest), please rate the following reasons why you would consider moving into a retirement community:

3209x-20 aveirder 
Are on site health services and personalized care important options for you to have when looking at retirement or active adult communities?

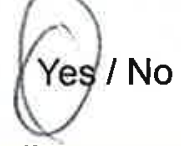

According to your preference, please prioritize and rank the following 10 features $1-10$ ( 1 being the highest ranking and 10 being the lowest):

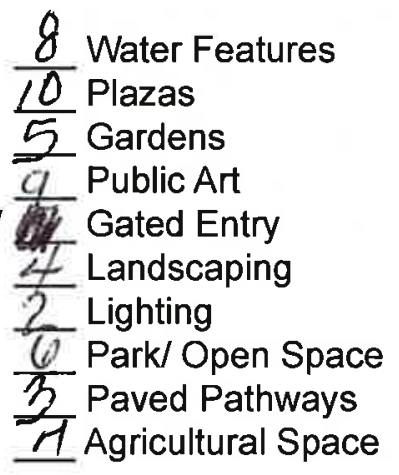

Are there any additional features that a community

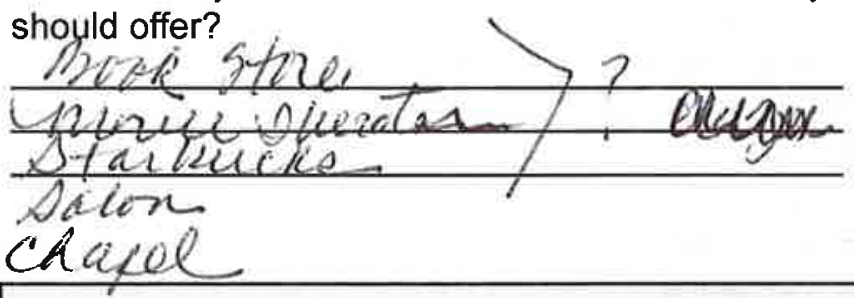

Thank you for taking the time to complete this survey! If you have any additional comments regarding retirement or active adult communities, please feel free to use the below space. Your feedback is greatly appreciated.
Which of the following architectural styles would you prefer for a retirement or active adult community in the Sierra Nevada foothills of California?

(Choose one)

Modern/ Contemporary Spanish/Mission Style

Consistent with surrounding environment Other

When choosing a retirement or active adult community, is close proximity to a downtown or town center of high importance?

$$
\text { Yes/No }
$$

What is your preferred method of getting around within short distances ( $<$ than a mile)?

Walking
Bicycling Driving

Public Transit/ Shuttle Service Other 


\section{Baby Boomer Living \\ Retirement Lifestyle Preferences Survey}

Baby Boomers, born between 1946 and 1964 , are the largest generation in U.S. History with a population of over 82.8 million people. This vast group is currently in the midst of retirement, and thus it is the objective of this survey to better understand lifestyle preferences for those contemplating retirement communities and active adult communities. Information gathered from this survey will be analyzed to help guide and develop an ideal retirement community "prototype" that strives to meet the demands and needs of Baby Boomers. Thank you for taking this survey!

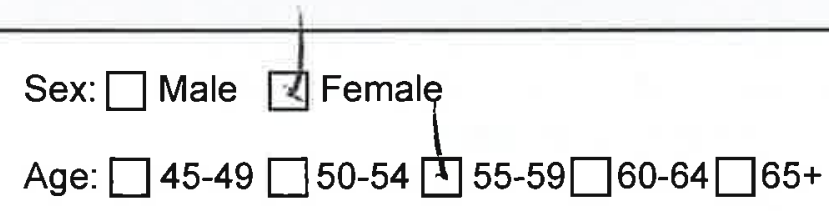

What type of accommodation do you currently reside in? (Please check one)

$\int$

Single Family House

Multi-family House

Condominium

Apartment

Senior/ Retirement Community Other

Have you ever considered living in a retirement or active adult community?<smiles>[Mg][As]1CCCC1</smiles>

Do you find retirement or active adult communities to be an attractive option to live in?

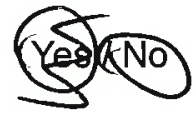

If you responded "No" to the above question, please mention why:

No

What type of housing would you find most appealing for a retirement community to offer?

Single-family housing

Condominiums

Apartments

Mixed Use (variety of the above)

Other
On a scale of 1-5 ( 5 being the most favorable and 1 being least favorable), please rate the following activities and/or services that a retirement or active adult community should offer:

5 Fitness Facilities
3 Bicycle Trails
Community Gardening
5 Walking Trails
1 Horse Riding
5 Wine Tasting
Hiking
2 Amphitheater for live music
2 Bocce Ball
1 Tennis
1 Golf
1 Swimming
Kayaking
5 Retail/ Shops
5 Coffee Shop
5 Dining Options
1 Art Studio

Are there any additional activities or services that a community should offer?

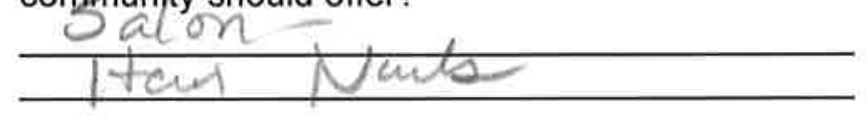

On a scale of $1-5$ ( 5 being the highest and 1 the lowest), please rate the following reasons why you would consider moving into a retirement community:

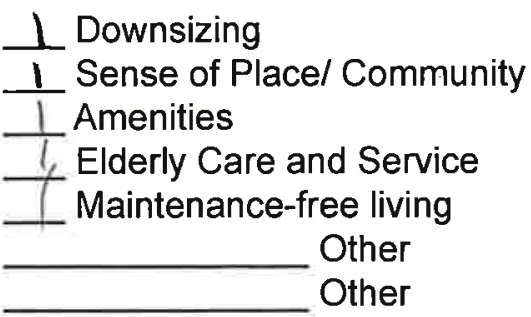


Are on site health services and personalized care important options for you to have when looking at retirement or active adult communities?<smiles>[Nb][N+]1CCCCC1</smiles>

According to your preference, please prioritize and rank the following 10 features $1-10$ ( 1 being the highest ranking and 10 being the lowest):

Water Features

Plazas

Gardens

Public Art

Gated Entry

Landscaping

Lighting

Dark/ Open Space

Paved Pathways

Agricultural Space

Are there any additional features that a community should offer?
Which of the following architectural styles would you prefer for a retirement or active adult community in the Sierra Nevada foothills of California?

(Choose one)

Modern/ Contemporary

Spanish/Mission Style

Consistent with surrounding environment Other

When choosing a retirement or active adult community, is close proximity to a downtown or town center of high importance?

\section{Yes No}

What is your preferred method of getting around within short distances ( $<$ than a mile)?

Walking

Bicycling

Driving

Public Transit/ Shuttle Service Other

Thank you for taking the time to complete this survey! If you have any additional comments regarding retirement or active adult communities, please feel free to use the below space. Your feedback is greatly appreciated. 


\section{Baby Boomer Living \\ Retirement Lifestyle Preferences Survey}

Baby Boomers, born between 1946 and 1964 , are the largest generation in U.S. History with a population of over 82.8 million people. This vast group is currently in the midst of retirement, and thus it is the objective of this survey to better understand lifestyle preferences for those contemplating retirement communities and active adult communities. Information gathered from this survey will be analyzed to help guide and develop an ideal retirement community "prototype" that strives to meet the demands and needs of Baby Boomers. Thank you for taking this survey!

Sex: $\square$ Male $\square$ Female

Age: $\square$ 45-49 $\square 50-54 \square 55-59 \square 60-64 \square 65+$

What type of accommodation do you currently reside in? (Please check one)

Single Family House
Multi-family House
Condominium
Apartment Senior/ Retirement Community Other

Have you ever considered living in a retirement or active adult community?<smiles>C1CC[AsH2]C1</smiles>

Do you find retirement or active adult communities to be an attractive option to live in?

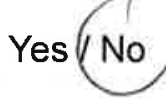

If you responded "No" to the above question, please

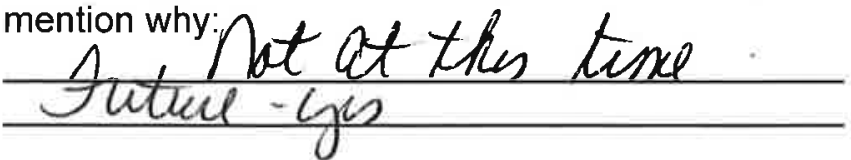

What type of housing would you find most appealing for a retirement community to offer?

Single-family housing

Condominiums

Apartments

Mixed Use (variety of the above)

Other
On a scale of 1-5 (5 being the most favorable and 1 being least favorable), please rate the following activities and/or services that a retirement or active adult community should offer:

Fitness Facilities
Bicycle Trails
Community Gardening
Walking Trails
Horse Riding
Wine Tasting
Hiking
Amphitheater for live music
Bocce Ball
Tennis
Golf
$\checkmark$ Swimming
Kayaking
Retail/ Shops
Coffee Shop
Dining Options
Art Studio

Are there any additional activities or services that a community should offer?

On a scale of 1-5 ( 5 being the highest and 1 the lowest), please rate the following reasons why you would consider moving into a retirement community:

Downsizing Sense of Place/ Community Amenities Elderly Care and Service Maintenance-free living Other Other 
Are on site health services and personalized care important options for you to have when looking at retirement or active adult communities?

\section{Yes / No}

According to your preference, please prioritize and rank the following 10 features $1-10$ ( 1 being the highest ranking and 10 being the lowest):

Water Features

Plazas

Gardens

Public Art

Gated Entry

Landscaping

Lighting

Park/ Open Space

Paved Pathways

Agricultural Space

Are there any additional features that a community should offer?
Which of the following architectural styles would you prefer for a retirement or active adult community in the Sierra Nevada foothills of California?

(Choose one)

Modern/ Contemporary

Spanish/Mission Style

Consistent with surrounding environment Other

When choosing a retirement or active adult community, is close proximity to a downtown or town center of high importance?

Yes / No

What is your preferred method of getting around within short distances ( $<$ than a mile)?

Walking

Bicycling

Driving

Public Transit/ Shuttle Service Other

Thank you for taking the time to complete this survey! If you have any additional comments regarding retirement or active adult communities, please feel free to use the below space. Your feedback is greatly appreciated. 


\section{Baby Boomer Living \\ Retirement Lifestyle Preferences Survey}

Baby Boomers, born between 1946 and 1964 , are the largest generation in U.S. History with a population of over 82.8 million people. This vast group is currently in the midst of retirement, and thus it is the objective of this survey to better understand lifestyle preferences for those contemplating retirement communities and active adult communities. Information gathered from this survey will be analyzed to help guide and develop an ideal retirement community "prototype" that strives to meet the demands and needs of Baby Boomers. Thank you for taking this survey!

Sex: Male [ب Fèmale

Age: $\square 45-49 \square 50-54 \square 55-59 \square 60-64 \square 665+$

What type of accommodation do you currently reside in? (Please check one)

X Single Family House

Multi-family House

Condominium

Apartment

Senior/ Retirement Community Other

Have you ever considered living in a retirement or active adult community?

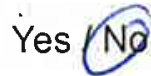

Do you find retirement or active adult communities to be an attractive option to live in?

Yes

If you responded "No" to the above question, please mention why:
Fin Not A JONAR

What type of housing would you find most appealing for a retirement community to offer?

Single-family housing

Condominiums

Apartments

X Mixed Use (variety of the above) Other
On a scale of $1-5$ ( 5 being the most favorable and 1 being least favorable), please rate the following activities and/or services that a retirement or active adult community should offer:

5 Fitness Facilities

5 Bicycle Trails

3 Community Gardening

5 Walking Trails

I Horse Riding

2 Wine Tasting

5 Hiking

2 Amphitheater for live music

2 Bocce Ball

1 Tennis

$\frac{1}{3}$ Golf

$\frac{3}{3}$ Swimming

3 Kayaking

$\frac{3}{3}$ Retail/ Shops

$\frac{3}{3}$ Coffee Shop

5 Dining Options

I Art Studio

Are there any additional activities or services that a community should offer?

On a scale of $1-5$ ( 5 being the highest and 1 the lowest), please rate the following reasons why you would consider moving into a retirement community:

$\frac{3}{1}$ Downsizing
$\frac{1}{3}$ Amense of Place/ Community
$\frac{3}{4}$ Elderly Care and Service
$\frac{\text { Maintenance-free living }}{4}$

Other

Other 
Are on site health services and personalized care important options for you to have when looking at retirement or active adult communities?<smiles>[Mg][14C]1C=CC=C1</smiles>

According to your preference, please prioritize and rank the following 10 features $1-10$ ( 1 being the highest ranking and 10 being the lowest):

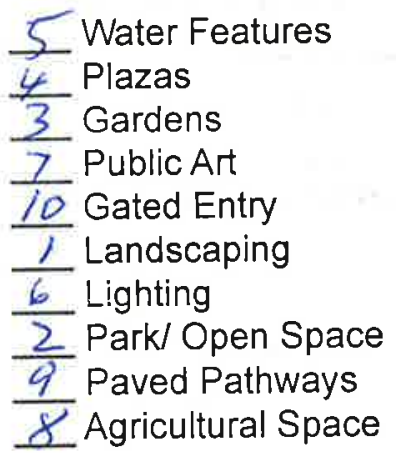

Are there any additional features that a community should offer?
Which of the following architectural styles would you prefer for a retirement or active adult community in the Sierra Nevada foothills of California? (Choose one)

Modern/ Contemporary

X Spanish/Mission Style Consistent with surrounding environment Other

When choosing a retirement or active adult community, is close proximity to a downtown or town center of high importance?<smiles>C1C[C@@H]2C[C@@H]12</smiles><smiles></smiles>

What is your preferred method of getting around within short distances (< than a mile)?

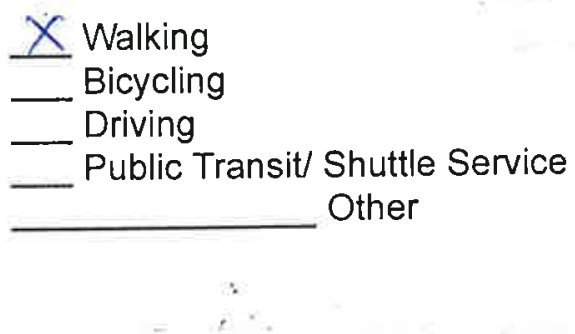

Thank you for taking the time to complete this survey! If you have any additional comments regarding retirement or active adult communities, please feel free to use the below space. Your feedback is greatly appreciated. 